FÁBIO JOSÉ MUNERATTI ORTEGA

\title{
MODELAGEM E ANÁLISE DE POLÍTICAS DE SEGURANÇA EM SISTEMAS COM REGRAS ASSOCIADAS AO NEGÓCIO
}

Dissertação apresentada à Escola

Politécnica da Universidade de São

Paulo para obtenção do Título de Mestre

em Ciências, Programa de Engenharia

Elétrica. 


\section{FÁBIO JOSÉ MUNERATTI ORTEGA}

\section{MODELAGEM E ANÁLISE DE POLÍTICAS DE SEGURANÇA EM SISTEMAS COM REGRAS ASSOCIADAS AO NEGÓCIO}

Dissertação apresentada à Escola

Politécnica da Universidade de São

Paulo para obtenção do Título de Mestre em Ciências, Programa de Engenharia Elétrica.

Área de Concentração:

Sistemas Digitais

Orientador:

Prof. Titular Wilson Vicente Ruggiero 
Este exemplar foi revisado e corrigido em relação à versão original, sob responsabilidade única do autor e com a anuência de seu orientador.

São Paulo, de novembro de 2013.

Assinatura do autor

Assinatura do orientador

\section{FICHA CATALOGRÁFICA}

Ortega, Fábio José Muneratti

Modelagem e análise de políticas de segurança em sistemas com regras associadas ao negócio/ F. J. M. Ortega. - versão corr. - São Paulo, 2013.

$120 \mathrm{p}$.

Dissertação (Mestrado) - Escola Politécnica da Universidade de São Paulo. Departamento de Engenharia de Computação e Sistemas Digitais.

1. Segurança de redes (Política) 2. Redes de Petri 3. Verificação de modelos I. Universidade de São Paulo. Escola Politécnica. Departamento de Engenharia de Computação e Sistemas Digitais. II. t. 
Aos meus pais, que por acreditarem e vibrarem com as minhas conquistas até mais do que eu mesmo, tornaram este trabalho possível. 


\section{AGRADECIMENTOS}

Agradeço ao Prof. Dr. Wilson Ruggiero, meu orientador, cujo espírito inovador tem me guiado e motivado desde que o conheço.

Aos caros Pedro e Flávio, bem como todos os amigos que depositaram atenção nos meus mais variados raciocínios, digressões, avanços e lamentações, minha profunda gratidão.

Em especial agradeço à Ligia, que com carinho, apoio e paciência me levou a superar em muito o que eu poderia ter esperado dessa jornada.

Finalmente, a todos que contribuíram para que meu crescimento transcendesse o escopo de um mestrado, muito obrigado. 


\section{RESUMO}

Propõe-se uma estratégia de modelagem e de análise formal de políticas de segurança para sistemas baseados em fluxos de trabalho (workflows) e contendo regras que envolvam aspectos de lógica de negócios. Verifica-se com 0 auxílio de uma política de exemplo que a estratégia proposta resulta em modelos amplamente capazes de expressar restrições lógicas em função de parâmetros de negócio sem comprometer a viabilidade de suas análises. A modelagem baseia-se no uso de um metamodelo definido a partir da identificação das entidades que caracterizam o estado de proteção de um sistema e representado na forma de uma rede de Petri colorida. Por meio da escrita de predicados para consulta sobre o espaço de estados da rede de Petri, verifica-se 0 atendimento às regras de segurança no modelo formal. A tratabilidade da análise é garantida pela adoção de um paradigma diferenciado principalmente pela busca de ramos inseguros em vez de nós inseguros no espaço de estados e por explorar a natureza independente entre serviços de negócio distintos, expressa por restrições ao fluxo de informaç̧ão no metamodelo. Tais restrições permitem que a análise seja fracionada evitando o problema da explosão de estados. 0 exemplo discutido de modelagem e análise de um sistema de serviços bancários online fornece evidências suficientes para atestar a aplicabilidade do método à validação de políticas de segurança para sistemas reais. 


\section{ABSTRACT}

A strategy is proposed for the formal modeling and analysis of workflow-based security policies having rules which involve aspects of business logic. Aided by an example of security policy, the proposed strategy is shown to lead to models widely capable of expressing logical restrictions as functions of business parameters without compromising the feasibility of its analyses. The modeling is based on the usage of a metamodel defined from the identification of the entities that characterize the protection state of a system, and represented as a colored Petri net. By writing predicates for querying the Petri net state-space, compliance with security rules at the formal model is verified. The feasibility of the analysis is ensured by the adoption of a paradigm distinguished mainly for the search for insecure branches rather than insecure nodes in the state-space, and for exploiting the independent nature among different business services, expressed by restrictions to the information flow within the metamodel. Such restrictions allow the analysis to be fractioned, avoiding the state explosion problem. The example provided of modeling and analysis of an online banking services system offers enough evidence to attest the applicability of the method to the validation of security policies for real-world systems. 


\section{SUMÁRIO}

\section{Lista de Ilustrações}

Lista de Tabelas

\section{Lista de Abreviaturas e Siglas}

1 Introdução

1.1 Objetivos . . . . . . . . . . . . . . . . . . . 14

1.2 Metodologia . . . . . . . . . . . . . . . . . . 15

1.3 Organização . . . . . . . . . . . . . . . 16

2 Revisão de conceitos $\quad 17$

2.1 Workflows e sistemas . . . . . . . . . . . . . . . . 17

2.1 .1 Workflows ................... 17

2.1 .2 Sistemas de workflow . . . . . . . . . . . . . . . 18

2.1 .3 Sistemas de serviços online . . . . . . . . . . . . 19

2.2 Verificação de modelos . . . . . . . . . . . . . . . . 20

2.3 Redes de Petri . . . . . . . . . . . . . . . . . . . . 22

2.3 .1 Definições . . . . . . . . . . . . . . . . . . 22

2.3.2 Redes de Petri coloridas . . . . . . . . . . . . . . 24

2.3.2.1 Definição formal . . . . . . . . . . . . . . 25 
2.3.2.2 Exemplo da representatividade das CPN . . . 28

2.3.3 Análise de espaço de estados . . . . . . . . . . . . 29

2.3 .4 CPN Tools . . . . . . . . . . . . . . . . . 30

2.3.4.1 Exemplo da modelagem em CPN Tools . . . . . 31

2.4 Segurança de sistemas . . . . . . . . . . . . . . . 35

2.4.1 Políticas de segurança . . . . . . . . . . . . . 35

2.4 .2 Controle de acesso $\ldots \ldots 37$

2.5 Trabalhos Relacionados . . . . . . . . . . . . . . . . . . . . . . . 39

3 Um metamodelo para representação e validação de políticas de $\begin{array}{ll}\text { segurança } & 43\end{array}$

3.1 Modelando workflows . . . . . . . . . . . . . . . . 43

3.1 .1 o cenário de interesse . . . . . . . . . . . 44

3.2 Definição formal do metamodelo . . . . . . . . . . . . . . . . 47

3.2.1 Implementação do metamodelo . . . . . . . . . . . 56

3.3 Exemplo de utilização do metamodelo . . . . . . . . . . . . . . 57

3.3 .1 Login . . . . . . . . . . . . . . . . . . . . . 58

3.3.1.1 Troca de chaves . . . . . . . . . . . . 59

3.3.1.2 Início de sessão / identificação do cliente . . . . 59

3.3.1.3 Autenticação do cliente . . . . . . . . . . . . 60

3.3 .2 Serviço de saldo . . . . . . . . . . . . . . . . . 61

3.3.3 Serviço de transferência entre contas . . . . . . . . . . . 61 
3.3.3.1 Seleção do serviço . . . . . . . . . . . . . . 62

3.3.3.2 Especificação de parâmetros . . . . . . . . . . 62

3.3.3.3 Confirmação . . . . . . . . . . . . 63

3.3 .4 Política . . . . . . . . . . . . . . . . . 64

3.3 .5 Modelagem ................... 66

4 Análise de políticas de segurança para sistemas de grande porte 70

4.1 Objetivos da análise . . . . . . . . . . . . . . . 70

4.2 Metodologia da análise . . . . . . . . . . . . . . 72

4.3 Formulação precisa de regras de segurança . . . . . . . . . 76

4.4 Consultas sobre o espaço de estados da CPN . . . . . . . . 81

4.5 Partição da análise . . . . . . . . . . . . . . . . . . . . 86

4.6 Validação da análise . . . . . . . . . . . . . . . . . 88

4.7 Resultados obtidos e avaliação do processo . . . . . . . . . . 93

5 Considerações Finais $\quad 96$

5.1 Revisão de trabalhos relacionados . . . . . . . . . . . . . . . 97

5.2 Contribuições . . . . . . . . . . . . . . . . . . 100

5.3 Trabalhos Futuros . . . . . . . . . . . . . . . 101

$\begin{array}{ll}\text { Referências } & 103\end{array}$

Apêndice A - Código-fonte da modelagem do exemplo 107

A.1 Funções de autorização $\left(f_{A}\right) \ldots 107$ 
A.2 Funções de atualização de contas $\left(f_{B}\right) \ldots \ldots \ldots \ldots$

A.3 Funções de atualização de usuários $\left(f_{C}\right) \ldots \ldots \ldots \ldots \ldots$

A.4 Funções de atualização de sessões $\left(f_{D}\right) \ldots \ldots \ldots \ldots \ldots$

A.5 Definições de estados iniciais . . . . . . . . . . . . . . . 112

Apêndice B - Detalhamento dos casos de análise do exemplo

114

Apêndice C - Evidências da coleta de dados para os casos de análise117 


\section{LISTA DE ILUSTRAÇÕES}

1 Os elementos constituintes de um fluxo de trabalho . . . . . 18

2 Exemplo de rede de Petri convencional . . . . . . . . 23

3 Exemplo de rede de Petri colorida . . . . . . . . . . . . 29

4 Exemplo de rede de Petri colorida modelada com CPN Tools . . 30

5 Espaço de estados do exemplo em CPN Tools . . . . . . . . . . . 31

6 CPN para o sistema de operações "A" e "B" . . . . . . . . . . . 33

7 Modelo de comunicação com o WfS . . . . . . . . . . . . 44 43

8 Diagrama entidade-relacionamento para o metamodelo . . . . . 47

9 Estágios do processamento de uma requisição . . . . . . . . . . . 51

10 A CPN que implementa o metamodelo . . . . . . . . . . . . 58

11 Espaço de estados do modelo do cap. 2 (fig. 6) otimizado . . . . 74

12 CPN representando o modelo de comunicação com o WfS . . . 82

13 S eção do espaço de estados evidenciando estado inseguro . . . 92

14 Dados caso $1 \ldots 117$

15 Dados caso $2 \ldots \ldots 118$

16 Dados caso $3 \ldots \ldots$. . . . . . . . . . . . . . . . . . . . . . . . . .

17 Dados caso $4 \ldots \ldots$. . . . . . . . . . . . . . . . . . . . . . .

18 Dados caso $5 \ldots \ldots 119$

19 Dados caso $6 \ldots 119$ 
20 Dados caso $7 \ldots \ldots \ldots \ldots$

21 Dados caso $8 \ldots \ldots \ldots$. . . . . . . . . . . . . . . 120

22 Dados da união de todos os casos . . . . . . . . . . . . . 120 


\section{LISTA DE TABELAS}

1 Resumo da política modelada . . . . . . . . . . . . . . . 66

2 Estados do exemplo do cap. 2 e suas classificações, para $(A, q=1)$ em $n \ldots \ldots \ldots 73$

3 Casos do exemplo do cap. 2 após inserção de vulnerabilidade, para $(A, q=1)$ em $n \ldots \ldots \ldots$. . . . . . . . . . . . . 74

4 Detalhes das divisões da análise do exemplo . . . . . . . . . . . . 90

5 Comparação entre trabalhos relacionados . . . . . . . . . . . . . 99 


\title{
LISTA DE ABREVIATURAS E SIGLAS
}

\author{
AJ AX Asynchronous J avaScript and XML \\ API Application Programming Interface \\ CPN Coloured Petri Nets \\ DAC Discretionary Access Control \\ HTTP Hypertext Transfer Protocol \\ MAC Mandatory Access Control \\ OLTP Online Transaction P rocessing \\ OSI Open Systems Interconnection \\ RBAC Role-based Access Control \\ SaaS Software as a Service \\ TLS Transport Layer Security \\ UML Universal Modeling Language \\ USP Universidade de São Paulo \\ XML Extensible Markup Language \\ WfMC Workflow Management Coalition \\ WFMS Workflow Management System \\ WfS Workflow System
}




\section{INTRODUÇÃO}

0 projeto de qualquer sistema que possua requisitos de segurança passa, obrigatoriamente, pela definição da sua política de segurança, isto é, a declaração que divide os estados que o sistema pode assumir entre autorizados e não autorizados (BISHOP, 2003).

A definição de políticas de segurança é uma tarefa tipicamente complexa, que dá margem à inclusão de erros de difícil detecção capazes de gerar sérias consequências ao negócio. Por conta dessa característica, o emprego de modelos formais na sua concepção fornece uma alternativa promissora para mitigar tais riscos do projeto, ao fornecer evidências do nível de segurança atingido pelas definições modeladas.

Porém, para uma ampla gama de sistemas, notavelmente aqueles voltados ao gerenciamento de processos de negócio - os sistemas dirigidos por fluxo de trabalho (ou WfS, workflow systems) - as definições de estados seguros estão fortemente ligadas ao próprio processo implementado.

Apesar de diversos avanços na descrição, modelagem e validação de políticas de segurança, projetar sistemas sob restrições dessa natureza que envolvam parâmetros de negócio utilizando os paradigmas existentes pode levar a modelos grandes que são inadequados para análise. Além disso, descrições de políticas de segurança baseadas em entidades com um alto nível de abstração resultam em modelos pouco relacionados à arquitetura da implementação 
do sistema, potencialmente causando a inclusão de vulnerabilidades no ato da conversão desses modelos em código para implantação ou, caso sejam metódica ou automaticamente traduzidos, podem ainda resultar em elementos de software com desempenho insatisfatório.

\subsection{Objetivos}

Deseja-se definir uma estratégia de modelagem e análise para a validação de políticas de segurança, em especial, políticas para sistemas de serviços online, que possibilite tratar adequadamente regras fortemente dependentes dos estados do seu fluxo de trabalho (workflow) e de parâmetros ligados ao negócio.

Como maneira de orientar a modelagem desses sistemas segundo uma estrutura que atenda aos requisitos desejados, define-se um arcabouço lógico que atue como gabarito para construção de modelos ao qual denomina-se "metamodelo". Ele deve especificar a estrutura da modelagem ao ponto que se possa verificar, a partir das definições previstas nele próprio, a aplicabilidade de métodos formais de análise adequados para a validação das políticas de segurança modeladas.

Portanto, o foco do trabalho está em: (a) especificar um metamodelo que oriente a definição de políticas de segurança, (b) evidenciar que o metamodelo concebido é capaz de representar as políticas de segurança do cenário de interesse, e (c) garantir que os modelos resultantes sejam passíveis de análise formal para validação das políticas que eles representam. 


\subsection{Metodologia}

O objetivo definido envolve uma série de etapas que formarão, em conjunto, o processo de modelagem e análise proposto. A conclusão de cada etapa permite o desenvolvimento da subsequente. São elas:

1. A identificação do cenário de interesse e suas características determinantes, delimitação do seu escopo e representação do mesmo de maneira adequada à modelagem;

2. A definição de uma representação de políticas de segurança aplicável a esses sistemas, que seja enunciável dentro da visão do sistema estabelecida no item 1 e livre de ambiguidades;

3. A construção de um metamodelo abrangente, que dê suporte à modelagem de políticas de segurança dentro do cenário de interesse e minimize as restrições impostas sobre a lógica das regras de segurança e sobre os estados possíveis dos modelos construídos sobre sua estrutura.

4. A verificação da aplicabilidade do metamodelo para análise formal de políticas por meio do uso de técnicas que permitam a validação de representações como definidas no item 2 frente a modelos construídos segundo as diretrizes do item 3.

O desenvolvimento de todas as etapas é guiado pela modelagem de um cenário específico que a constitui num caso exemplo de serviços bancários online, cuja política de segurança está fortemente ligada ao negócio, realçando as propriedades desejadas do processo de análise em definição. 


\subsection{Organização}

O capítulo seguinte apresenta os principais conceitos que fundamentam este trabalho e os avanços obtidos por pesquisas anteriores. 0 capítulo 3 inicia-se com uma visão do cenário de interesse a fim de identificar as principais propriedades que motivam as decisões de projeto, evoluindo, a partir delas, à especificação do metamodelo para validação de políticas de segurança. 0 capítulo 4 discute as intenções por trás de uma análise de políticas de segurança e, com o auxílio do exemplo de serviços bancários online, demonstra como o metamodelo definido pode ser utilizado para validação de uma descrição de política aplicável a sistemas com alta complexidade lógica, avaliando, com isso, o processo proposto como um todo. Finalmente, o capítulo 5 compara os resultados obtidos à literatura, relacionando as contribuições originais, as oportunidades para trabalhos futuros e as conclusões gerais obtidas. 


\section{REVISÃO DE CONCEITOS}

\subsection{Workflows e sistemas}

O objetivo desta seção é estabelecer uma terminologia consistente para eliminar compreensões divergentes sobre os conceitos da área. Como o foco maior do trabalho será dado aos aspectos de segurança, algumas simplificações da visão arquitetural proposta pela Workflow Management Coalition (WORKFLOW MANAGEMENT COALITION, 1999) são adotadas.

\subsubsection{Workflows}

Um fluxo de trabalho, mais usualmente tratado pelo termo em inglês workflow, consiste da automação de um processo de negócio, em todo ou em parte (WORKFLOW MANAGEMENT COALITION, 1999). No contexto de interesse, ambos os termos representam a sequência de etapas que se pretende que aconteça. Essa sequência de etapas é definida por uma definição de processo, que será chamada ao longo do trabalho de tarefa. A cada unidade de trabalho atômica executada pelo sistema no cumprimento de uma tarefa, dá-se o nome de atividade ou ação. A fim de aproximar o conceito da nomenclatura própria aos problemas de controle de acesso em segurança da informação, adotaremos este segundo ${ }^{1}$.

\footnotetext{
${ }^{1}$ Aqui, a nomenclatura adotada difere da definição da WfMC, que utiliza o termo task (tarefa) para as operações atômicas de um WfS e refere-se ao conjunto destas para uma finalidade específica sempre como process definition (definição de processo). Para priorizar
} 

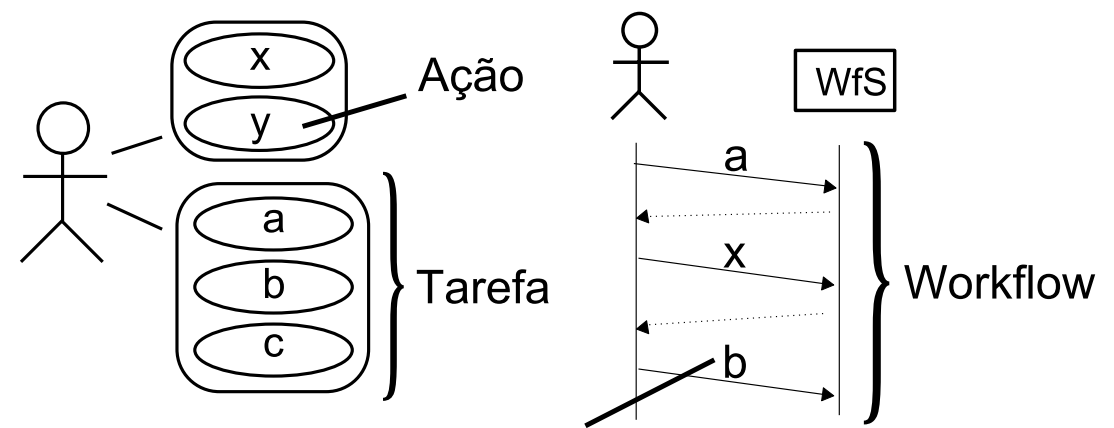

Requisição

Figura 1: Os elementos constituintes de um fluxo de trabalho

A figura 1 mostra na forma de diagramas a relação entre os elementos de um workflow. Cada processo de negócio é chamado de tarefa e dividido em ações atômicas. A sequência dessas ações define o workflow. Na ilustração vê-se duas tarefas sendo que o workflow previsto para a primeira consiste da sequência de ações $x$ e $y$ e pra a segunda, $a, b$ e $c$. Num paralelo com um sistema de comércio eletrônico, pode-se imaginar que $a$ seja o pedido de fechamento de uma encomenda, $b$, a seleção da modalidade de entrega e $c, 0$ envio dos dados para pagamento. A combinação das três ações completa 0 processo de compra. Além disso, a ação $x$ poderia representar a visualização de um produto e y sua inclusão no pedido. É válido ressaltar a distinção entre o workflow previsto na definição de um processo de negócio e o que é executado na operação do sistema. 0 workflow realizado segundo o diagrama de sequência visível na figura vale-se da possibilidade de execução paralela de ambas as tarefas, executando a sequência $a, x$ e $b$.

\subsubsection{Sistemas de workflow}

Entende-se por sistemas de gerenciamento de fluxo de trabalho (ou WFMS, do original workflow management systems), pacotes de software getermos curtos nas definições matemáticas e gerar associação aos termos de segurança, preferiu-se seu uso como expresso no texto. 
néricos voltados ao gerenciamento de processos de negócio do ponto de vista logístico, ou seja, garantindo que a informação correta atinja a pessoa ou aplicação correta no momento adequado, sem processar efetivamente as atividades do negócio. Traçando um paralelo com outra área da engenharia de software, da mesma maneira que os sistemas de gerenciamento de bancos de dados buscam concentrar o esforço de gerenciamento de dados, eliminando-o do software que dele necessita, os sistemas de gerenciamento de fluxo de trabalho concentram o gerenciamento dos fluxos de negócio, removendo-o do software que os utiliza (AALST; HEE, 2004). Por esse motivo adota-se o termo sistemas dirigidos por fluxo de trabalho, ou ainda, sistemas de workflow (abreviado WfS, do original workflow systems) como diferenciação para denotar os sistemas que processam as regras de negócio, utilizem eles ou não 0 auxílio de um WFMS. Como este trabalho emprega uma modelagem lógica, ligada aos conceitos do negócio e independente da arquitetura do sistema que o automatiza, frequentemente o termo sistema de workflow será empregado para referir-se ao sistema-alvo da modelagem.

\subsubsection{Sistemas de serviços online}

Uma classe específica de sistemas que lidam com processos de negócio é a de sistemas de serviços online. Entende-se como tais, serviços compatíveis com o paradigma de software como serviço (SaaS)(MELL; GRANCE, 2011), no sentido amplo de que informações e infra-estrutura para provimento do serviço encontram-se centralizadas e acessíveis somente ao sistema, e usuários requisitam uma tarefa no domínio de uma conta, comunicando-se com o sistema por meio de uma sessão.

É válido ressaltar que o trabalho desenvolvido não objetiva evoluir a modelagem de processos de negócio de maneira geral, e sim a modelagem de 
políticas de segurança dos sistemas que lidam com esses processos, aumentadas pela inclusão de parâmetros de negócio. Dessa forma, mesmo que as técnicas de modelagem se apliquem para esse fim alternativo, os objetivos de análise e da própria construção de modelos serão outros no caso da modelagem de processos de negócio.

\subsection{Verificação de modelos}

Qualquer que seja o sistema cujo comportamento se queira ganhar entendimento, a menos que a experimentação se aplique diretamente sobre o próprio sistema, alguma representação se faz necessária. Chamamos modelo qualquer representação de uma entidade ou fenômeno que permita abstrair uma propriedade ou comportamento da entidade ou fenômeno representado.

Sistemas de interesse também podem possuir memória, isto é, fornecer saídas distintas para uma mesma entrada em função de entradas anteriores. A informação agregada que um sistema tem após assimilar cada nova entrada é chamada de estado do sistema. Analogamente, modelos que representam sistemas dessa natureza também terão um conjunto de possíveis estados.

Verificação de modelos é uma técnica para verificação de propriedades de algum sistema baseada na exploração exaustiva dos estados de um modelo matematicamente preciso e inambíguo do mesmo (BAIER; KATOEN, 2008).

Baier e Katoen (2008) apresentam uma série de pontos fortes e fraquezas da aplicação desse tipo de técnica.

Entre os pontos fortes, ressalta-se a generalidade da abordagem, aplicável a diversas áreas; suporte a aplicação parcial, permitindo a verificação individual de propriedades ou sua priorização; invulnerabilidade a erros ocultos em eventos improváveis como ocorre com testes e simulações; disponibilidade 
de dados diagnósticos quando uma propriedade é invalidada; fundamentação matemática sólida entre outros.

Mais uma característica citada é que antes mesmo que a verificação seja realizada, a especificação de um modelo adequado ao seu emprego frequentemente leva à descoberta de aspectos incompletos, ambíguos ou inconsistentes na especificação informal do sistema, o que faz com que o próprio exercício da técnica colabore para a melhoria da especificação.

Notáveis fraquezas da estratégia incluem dificuldade de aplicação a cenários ricos em dados; sujeição a problemas de decidibilidade em determinadas aplicações; obtenção exclusiva de resultados dependentes da representatividade do modelo utilizado; sujeição a defeitos de software e, algo que será determinante para a estruturação da análise proposta neste trabalho, limitada à verificação de requisitos declarados, sem garantia de completeza ou julgamentos sobre a validade de propriedades não verificadas.

Finalmente, um forte obstáculo (GROOTE; KOUTERS; OSAIWERAN, 2012) ao emprego de verificação de modelos é o problema da explosão de estados, isto é, o número de estados necessários para modelar o sistema com acurácia pode facilmente exceder a quantidade de memória disponível, pois o mesmo cresce exponencialmente com respeito a múltiplos parâmetros das definições de modelos (BAIER; KATOEN, 2008).

Em geral, melhor explorando essa definição, o que frequentemente ocorre é que a fim de verificar propriedades de um sistema representadas por um modelo, torna-se necessário explorar todos os seus estados. Embora o modelo em si possa ser pequeno, a quantidade de estados que ele assume pode tomar proporções tão grandes que os recursos computacionais disponíveis não mais podem tratá-los individualmente, seja por escassez de memória ou pelo tempo de computação esperado exceder os limites factíveis. 
Um exemplo claro desse problema é a aplicação dessa técnica para decidir a melhor jogada em uma dada configuração de um tabuleiro de xadrez, como notado por Shannon (1950). É possível representar cada estado do jogo por um conjunto de informações: a posição de cada peça no tabuleiro, qual jogador tem a próxima jogada, se cada um dos reis já foi movido (condição que impede o "roque") e o número de movimentos desde a última movimentação de um peão (que se chegar a cinquenta implica o empate). A partir disso é simples determinar se o jogo encontra-se em uma situação final (de cheque-mate ou empate) e também é simples derivar o conjunto de jogadas válidas. Contudo, estabelecer a jogada que apresenta a maior probabilidade de cheque-mate envolve computar todas as sucessões de jogadas válidas a partir de cada jogada possível naquele estado. Na estimativa apresentada por Shannon, embora o número de jogadas válidas por configuração de tabuleiro seja da ordem de 30, a exploração de todos os estados alcançáveis a partir de uma configuração chega, num cálculo conservador, à ordem de $10^{120}$.

\subsection{Redes de Petri}

\subsubsection{Definições}

Redes de Petri são ferramentas para a modelagem de concorrência, não determinismos e controle de fluxo, com uma representação gráfica bem definida que facilita a compreensão dos modelos, propostas por Carl Adam Petri (1962).

A rede de Petri clássica é um grafo direcionado, ponderado e bipartido com dois tipos de nós chamados lugares e transições. Na sua forma gráfica, lugares são representados por círculos e transições, por retângulos. Arcos direcionados ligam lugares a transições ou transições a lugares e são mar- 


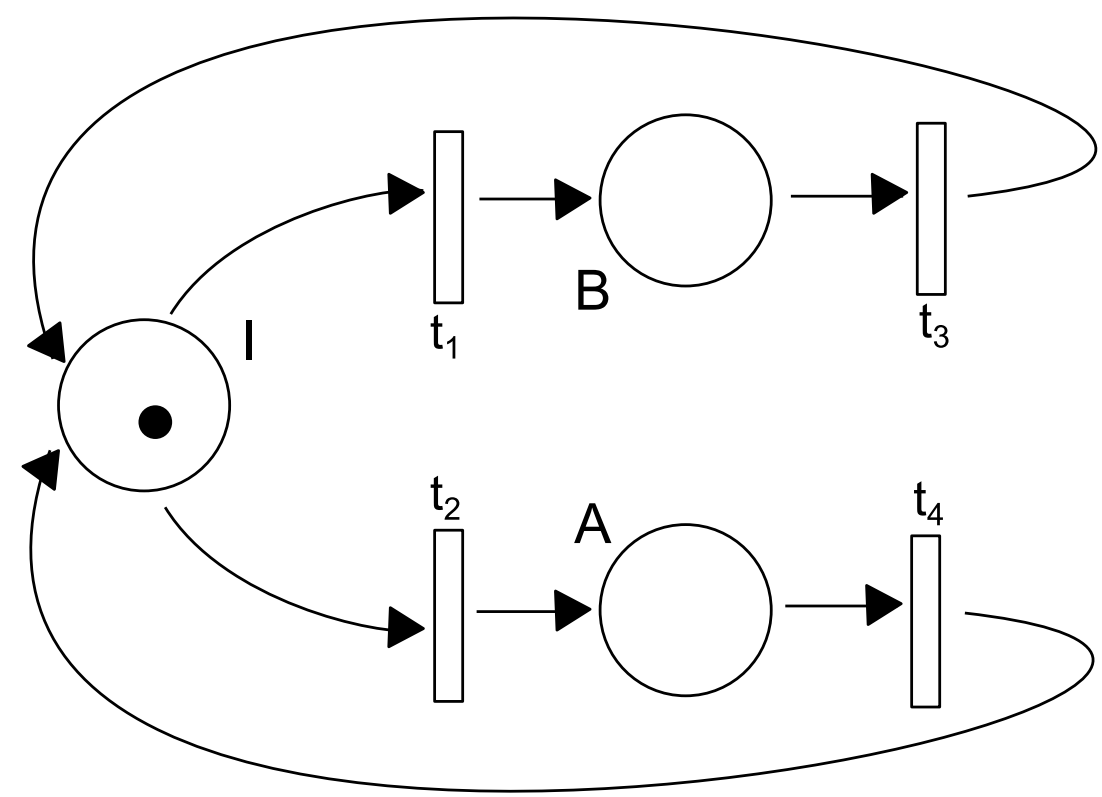

Figura 2: Exemplo de rede de Petri convencional

cados com seus pesos. Tipicamente, os lugares representam recursos do sistema modelado enquanto as transições representam atividades do sistema (RAKKAY; BOUCHENEB, 2009).

Os lugares da rede de Petri podem conter marcas, que são representadas por pontos. Chama-se marcação ou estado da rede cada configuração que atribui uma quantidade não negativa de marcas a cada lugar da rede. Um lugar $p$ é chamado lugar de entrada de uma transição $t$ se, e somente se, existe um arco de $p$ para t. O lugar $p$ é chamado lugar de saída da transição $t$ se, e somente se, existe um arco de $t$ para $p$. A dinâmica da rede de Petri é dada pelos disparos das transições. Diz-se que uma transição $t$ está habilitada para disparar quando há, no mínimo, tantas marcas em seus lugares de entrada quantos são os valores dos pesos dos seus respectivos arcos até $t$. Uma transição habilitada pode ou não disparar. 0 disparo de uma transição $t$ remove tantas marcas dos seus lugares de entrada quantos são os valores dos pesos dos seus respectivos arcos até $t$ e adiciona tantas marcas aos seus lugares de saída quantos forem os pesos dos seus respectivos arcos partindo de $t$. 
Um exemplo da representação gráfica da rede de Petri clássica é dado na figura 2. $I, A$ e $B$ são lugares da rede, $T, U, V$ e $W$, transições e os pontos pretos, as marcas. As setas ligando lugares e transições são os arcos da rede. Os pesos são tipicamente inscritos junto aos arcos. Na sua ausência, como no caso, subentende-se que o arco tem peso unitário.

Formalmente, representa-se o comportamento descrito da seguinte maneira (MURATA, 1989):

Definição 2.1. Uma rede de Petri é uma 5-upla, $P N=\left(P, T, \mathcal{A}, W, M_{0}\right)$, onde:

- $P=\left\{p_{1}, p_{2}, \ldots, p_{n}\right\}$ é um conjunto finito de lugares,

- $T=\left\{t_{1}, t_{2}, \ldots, t_{n}\right\}$ é um conjunto finito de transições,

- $\mathcal{A} \subseteq(P \times T) \cup(T \times P)$ é um conjunto de arcos,

- $W: F \rightarrow\{1,2,3, \ldots\}$ é uma função peso,

- $M_{0}: P \rightarrow\{0,1,2,3, \ldots\}$ é a marcação inicial

com $P \cap T=\emptyset$ e $P \cup T \neq \emptyset$

\subsubsection{Redes de Petri coloridas}

Redes de Petri coloridas ou CPN (coloured Petri nets) são uma linguagem para a construção de modelos e análise de suas propriedades, combinando as capacidades de redes de Petri com as de uma linguagem de programação de alto-nível (J ENSEN; KRISTENSEN, 2009).

Diz-se que uma rede de Petri é colorida quando a cada marca presente está associada uma cor, permitindo a distinção entre marcas e, consequentemente, caracterização de novos estados sem mudança topológica do modelo. 
As tais "cores" são abstrações para valores assumidos por marcas que comportam-se como variáveis de programação, com tipos bem definidos. Assim, o disparo das transições passa a estar condicionado não só à existência de marcas em determinados lugares, mas à existências de marcas de cores específicas, enquanto o resultado de um disparo leva à criação de marcas cujas cores também são determinadas.

Apesar de computacionalmente equivalentes às redes de Petri convencionais, as redes coloridas facilitam a reprodução de comportamentos de interesse dos sistemas sem aumentar significativamente a complexidade do modelo gráfico, oferecendo flexibilidade e facilidade de compreensão à modelagem.

\subsubsection{Definição formal}

Primeiramente é preciso definir o conceito de multiconjuntos (JENSEN, 1994):

Definição 2.2. Um multiconjunto $m$ sobre um conjunto não vazio $S$ é uma função $m: S \rightarrow \mathbb{N}$, onde $\mathbb{N}$ é o conjunto dos inteiros não negativos, que mapeia cada elemento $s \in S$ em um número $m(s) \in \mathbb{N}$ chamado número de ocorrências, ou coeficiente, do elemento s no multiconjunto $m$. Diz-se que o elemento $s \in S$ pertence ao multiconjunto $m$ se, e somente se, $m(s)>0$. Denota-se $S_{\mathrm{MS}}$ o conjunto de todos os multiconjuntos sobre $S$.

Intuitivamente, um multiconjunto nada mais é que a expressão de uma coleção de elementos de um conjunto, cada qual com uma determinada multiplicidade. Como exemplo, tomemos o conjunto $K=\{A, B, C\}$. Um multiconjunto 
que possua duas vezes o elemento $A$ e uma vez o elemento $B$ define-se:

$$
m \in K_{\mathrm{MS}} \mid m(k)=\left\{\begin{array}{l}
2 \text { se } k=A \\
1 \quad \text { se } k=B \\
0 \quad \text { se } k=C .
\end{array}\right.
$$

Para multiconjuntos também estão definidas as operações de soma, multiplicação escalar, comparação e cardinalidade. Como suas definições não são essenciais à compreensão dos demais conceitos, aconselha-se ao leitor interessado a consulta às referências (J ENSEN, 1994; J ENSEN; KRISTENSEN, 2009).

Nas redes de Petri tradicionais, todas as marcas são iguais entre si, portanto a marcação inicial de cada lugar é expressa simplesmente por uma quantidade e a produção e consumo de marcas no ato de uma transição é totalmente descrita pela quantidade de arcos ou os pesos dos arcos ligados à transição que dispara. Redes de Petri coloridas fornecem a facilidade de uma linguagem de inscrição, ou seja, uma linguagem de programação para definição de expressões que determinam as características das marcas, tanto em suas configurações iniciais quanto no disparo das transições. Esta linguagem de inscrição permite a existência de variáveis $v \in V$. As variáveis livres de uma expressão $e$ serão denotadas por $\operatorname{Var}[e]$ e o tipo de uma dada variável $v$, por Tipo[v]. Denotaremos por $\operatorname{EXPR}_{X}$ o conjunto de expressões na linguagem de inscrição tais que para $e \in \operatorname{EXPR}_{X}, \operatorname{Var}[\mathrm{e}] \in X$.

Neste ponto, pode-se definir as CPN formalmente.

Definição 2.3. Uma rede de Petri colorida é uma 9-upla $C P N=$ ( $\Sigma, P, T, \mathcal{A}, V, C, G, E, \mathcal{I})$ tal que (JENSEN; KRISTENSEN, 2009):

- $\Sigma$ é um conjunto finito de conjuntos de cores não vazios, também chamados de tipos; 
- $P$ é um conjunto finito de lugares;

- $T$ é um conjunto finito de transições, com $P \cap T=\emptyset$;

- $\mathcal{A}$ é um conjunto finito de arcos, com $\mathcal{A} \subseteq P \times T \cup T \times P$;

- $V$ é um conjunto finito de variáveis tipadas, tais que $\forall v \in V$, Tipo[v] $\in \Sigma$;

- $C$ é uma função de coloração, tal que $C: P \rightarrow \Sigma$;

- $G$ é uma função de guarda, tal que $G: T \rightarrow \operatorname{EXPR}_{V}, \operatorname{com} \operatorname{Tipo}[G(t)]=$ booleano, $t \in T$;

- E é uma função de anotações de arcos, tal que $E$ : $\mathcal{A} \rightarrow$ $\operatorname{EXPR}_{V}, \operatorname{com} \operatorname{Tipo}[E(a)]=C(p)_{M S}$, onde $p$ é o lugar associado ao arco $a ; \mathrm{e}$

- I e uma função de inicialização, tal que $\mathcal{I}: P \rightarrow \mathrm{EXPR}_{\emptyset}, \operatorname{com}$ Tipo[ $[\mathcal{I}(p)]=$ $C(p)_{M S}$.

$P, T$ e $\mathcal{A}$ definem-se analogamente à rede de Petri clássica. $E$ substitui a função peso existente na rede de Petri clássica por expressões na linguagem de inscrição que determinam um multiconjunto de marcas do tipo associado ao lugar de origem ou destino do arco, que the é atribuído pela função $C$. $G$ especifica uma condição para habilitação de cada transição, em função das variáveis $v \in V$ que assumem valores dados pelas marcas disponíveis. Uma transição $t$ somente dispara se sua função de guarda $G(t)$ tem resolução para a constante booleana "verdadeiro" para algum conjunto de marcas disponível que satisfaça as variáveis livres da expressão $G(t)$. Finalmente, $I$ cumpre 0 papel da marcação inicial definindo um multiconjunto de marcas para cada lugar da rede, ou seja, as quantidades de marcas com cada valor, sendo as quantidades dadas pelos coeficientes do multiconjunto e os valores perten- 
centes ao tipo do lugar. Note-se que as expressões iniciais não podem conter variáveis livres (indicado na definição por $\mathrm{EXPR}_{\emptyset}$ ).

\subsubsection{Exemplo da representatividade das CPN}

Para melhor compreender a modelagem com CPN e suas vantagens, voltemos ao exemplo de rede de Petri clássica como dado na figura 2. Suponha que uma marca em $A$ indica que uma ação $A$ foi realizada e uma marca em $B$, que realizou-se uma ação $B$.

Caso se desejasse representar mais ações, seria necessário incluir novas transições e lugares ao modelo, dificultando incrementalmente sua compreensão e análise.

Com o recurso dos conjuntos de cores existente em CPN, pode-se remodelar o exemplo anterior com uma interpretação distinta. A figura 3 representa o mesmo comportamento visto anteriormente se interpretarmos que, agora, o valor da marca em $O$ representa a ação executada. A variável $k$ é do mesmo tipo de $A$ e $B$ e a marca incolor no lugar $H$ garante que haverá sempre, no máximo, uma marca em $O$. Com relação à definição formal, neste exemplo temos:

- $\Sigma=\{\{A, B\},\{\epsilon\}\}$

- $P=\{H, I, O\}$

- $T=\left\{t_{1}, t_{2}\right\}$

- $\mathcal{A}=\left\{\left(H, t_{1}\right),\left(I, t_{1}\right),\left(t_{1}, I\right),\left(t_{1}, O\right),\left(O, t_{2}\right),\left(t_{2}, H\right)\right\}$

- $V=\{k\}, \operatorname{Tipo}[k]=\{A, B\}$

- $C(H)=\{\epsilon\} ; C(I)=C(O)=\{A, B\}$ 


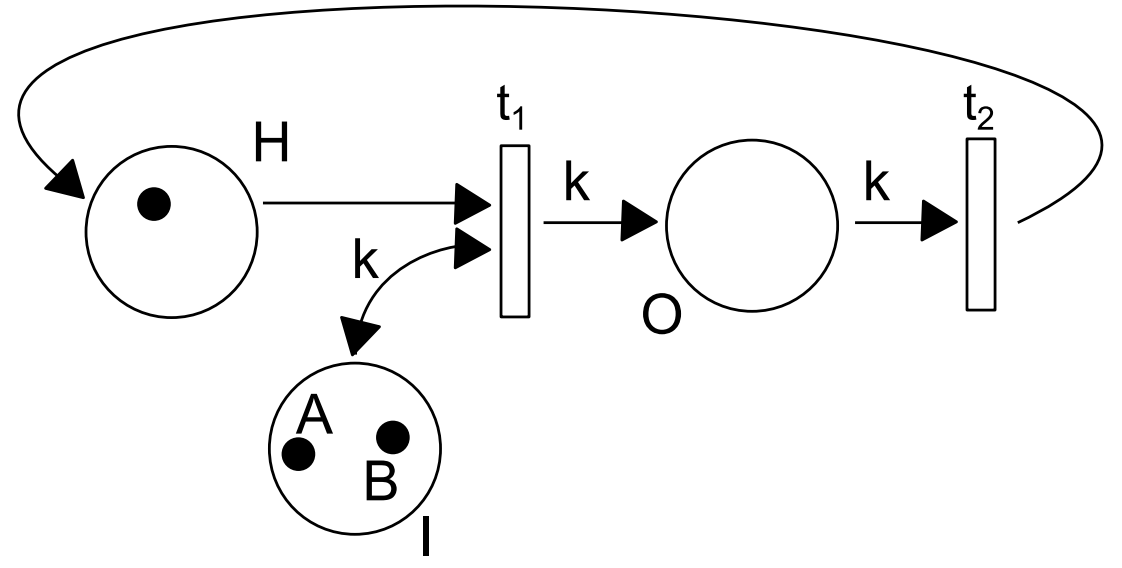

Figura 3: Exemplo de rede de Petri colorida

- $G\left(t_{1}\right)=G\left(t_{2}\right)=$ verdadeiro

- $E\left(H, t_{1}\right)=E\left(t_{2}, H\right)=1^{`}(\epsilon) ; E\left(I, t_{1}\right)=E\left(t_{1}, O\right)=E\left(O, t_{2}\right)=1^{`}(k)$

- $\mathcal{I}(H)=1^{`}(\epsilon) ; \mathcal{I}(I)=1^{`}(A)++1^{`}(B) ; \mathcal{I}(O)=\emptyset$

O valor $\epsilon$ foi utilizado para representar o valor da marca incolor. A notação $k^{*}(i)$ representa o multiconjunto no qual há $k$ ocorrências de $i$. $\emptyset$ representa o multiconjunto vazio. O operador ++ indica adição de multiconjuntos. Adotando os nomes Acoes para o conjunto $\{A, B\}$, UNIT para o conjunto $\{\epsilon\}$ e as convenções de omitir o valor $\epsilon$ das inscrições e omitir $G(\cdot)$ quando a mesma resolve incondicionalmente para o valor "verdadeiro", a notação utilizada na ferramenta CPN Tools e vista para esse modelo na figura 4 deve ser totalmente compreendida.

\subsubsection{Análise de espaço de estados}

Dada uma marcação de uma rede de Petri, diz-se que outra marcação da mesma rede é alcançável a partir da primeira, se existe uma sequência finita de disparos de transições que leva da primeira à segunda marcação.

Compreendido isto, essencialmente, a análise do espaço de estados é o 


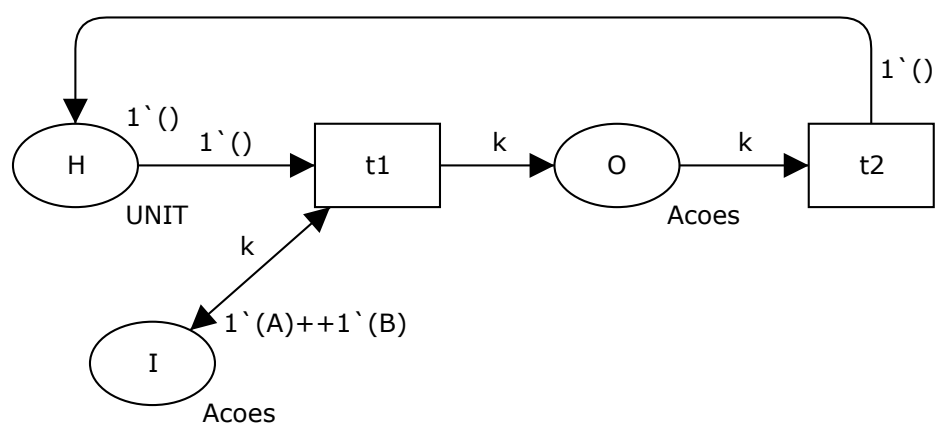

Figura 4: Exemplo de rede de Petri colorida modelada com CPN Tools

estudo do grafo de ocorrência de uma rede de Petri. Entende-se o grafo de ocorrência como sendo um grafo contendo um nó para cada marcação alcançável da rede e um arco ligando cada nó $m$ a cada outro nó $n$ tais que $n$ é alcançável a partir de m pelo disparo de uma única transição (J ENSEN, 1994). Portanto, cada arco representa um elemento de ligação distinto da rede, que corresponde ao par $(t, b)$, onde $t$ é uma transição habilitada na marcação de origem e $b$ é uma função que associa cada variável livre das definições de arcos da rede a uma marca de mesmo tipo que satisfaça as condições eventualmente presentes nas expressões de arco e funções de guarda. Note-se que para redes de Petri simples (sem cores), existe apenas um elemento de ligação para cada transição habilitada, uma vez que as marcas selecionadas nos lugares de entrada são indiferentes.

No exemplo em CPN discutido, só existem três marcações alcançáveis: a inicial, aquela onde a marca $A$ encontra-se no lugar $O$ e aquela onde a marca $B$ encontra-se no lugar $O$.

\subsubsection{CPN Tools}

O software CPN Tools (RATZER et al., 2003) permite a modelagem de redes de Petri coloridas com o uso da linguagem funcional Standard ML (MILNER, 1997; ULLMAN, 1998), aumentada para permitir as definições de cores, va- 


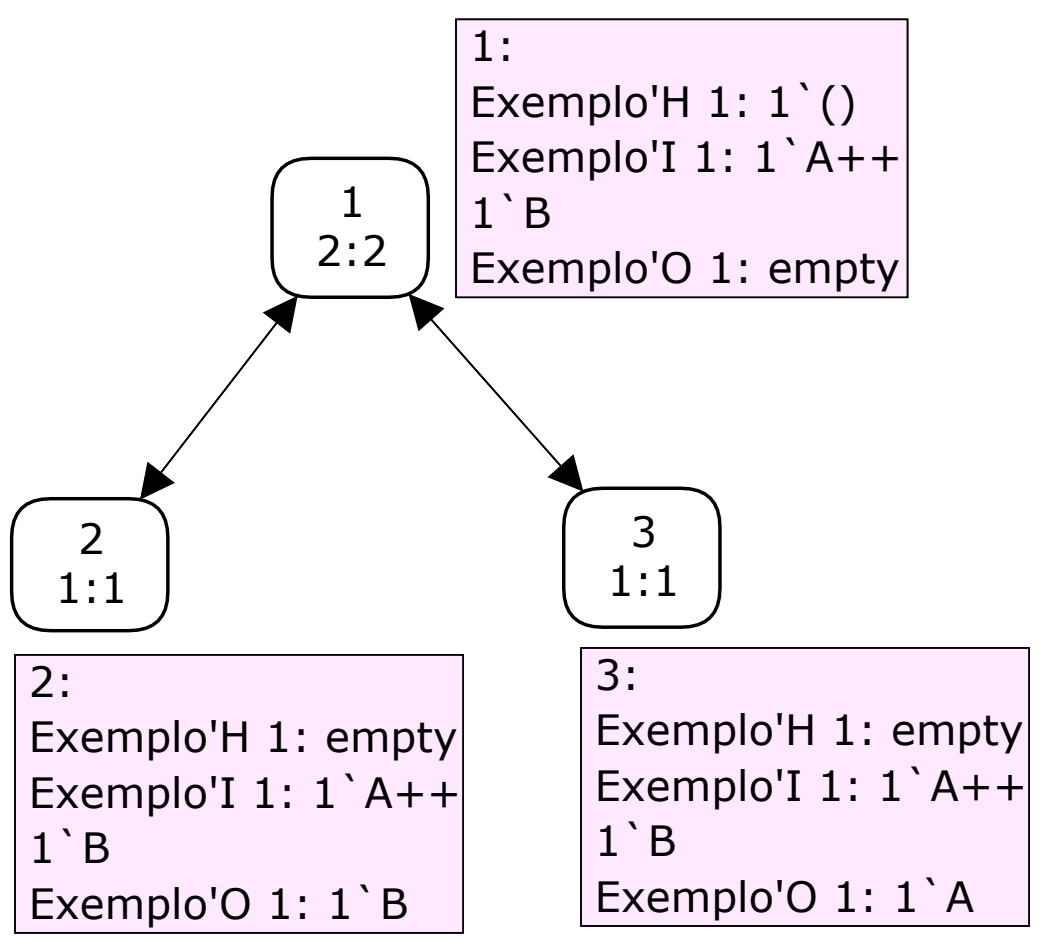

Figura 5: Espaço de estados do exemplo em CPN Tools

riáveis para uso nos arcos, multiconjuntos e funções sobre multiconjuntos. As definições de cores das marcas, de domínios de cores válidos para cada lugar ("tipos" dos lugares), as funções de entrada e saída das transições e alguns recursos adicionais como expressões booleanas que condicionam a habilitação de transições são escritos nessa linguagem.

A ferramenta também permite que a análise de espaço de estados seja realizada automaticamente para modelos definidos no seu ambiente. As figuras 4 e 5 mostram o modelo de exemplo da figura 3 modelado na ferramenta e a representação do espaço de estados calculado para ele, respectivamente.

\subsubsection{Exemplo da modelagem em CPN Tools}

Apresenta-se um exemplo adicional a fim de demonstrar mais a fundo as características das redes de Petri coloridas e a aplicabilidade do ferramental a um contexto mais próximo do que será discutido ao longo do trabalho. 
Suponhamos um sistema no qual dois tipos de operação, $A$ e $B$, são possíveis. A execução destas, contudo, está condicionada às relações de ordem e cardinalidade com que se apresentam, segundo a seguinte regra: $B$ só pode ser executada uma vez para cada duas vezes que se executa $A$. $A$, em contrapartida, pode ser executada até duas vezes antes que ocorra uma execução de $B$. Portanto, a única sequência de execuções permitida nesse sistema tem a forma " $A-A-B-A-A-B-\ldots$ ".

Embora expostas no exemplo de maneira arbitrária, tais relações de ordem e cardinalidade são comuns nas definições de sistemas. Num contexto financeiro, como o que motivará o modelo mais complexo definido adiante, a operação $A$ poderia ser vista como o resgate de fundos de uma aplicação, enquanto $B$ seria o evento de término de um período de carência. A restrição, nesse caso, representaria um limite de dois saques por período. Outra possibilidade de interpretação compreenderia $A$ como uma autorização de pagamento e $B$ como a efetivação da transação numa conta conjunta. A restrição seria equivalente ao requisito de anuência de ambos os titulares da conta para a efetivação de um pagamento (desde que verificado que cada operação $A$ tivesse sido realizada por um dos titulares).

Façamos ainda uma alteração no sistema proposto: a operação $A$ receberá um parâmetro $q$, que indica a quantidade de vezes que $A$ deve ser execeutada. Assim, para que a restrição continue válida, as sequências de operações terão de ser da forma "( $A, q=1)$ - $(A, q=1)$ - $B$ " ou " $(A, q=2)$ - $B$ ".

A figura 6 mostra uma CPN que modela a lógica subjacente à restrição à execução do sistema proposto. Dentro do ambiente CPN Tools, as declarações de tipos de marcas, declarações de variáveis, funções e valores auxiliares são definidas em uma área de programação, enquanto a rede de Petri, definida por seu diagrama, faz uso dessas declarações. 


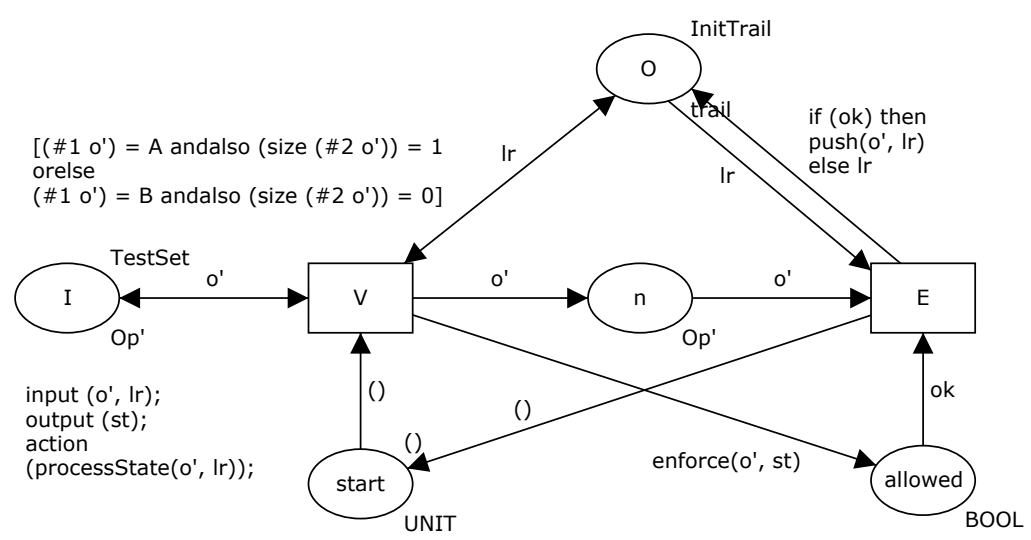

Figura 6: CPN para o sistema de operações "A" e "B"

De maneira geral, o lugar $I$ armazena as possíveis entradas do sistema enquanto o lugar $O$ armazena as últimas operações autorizadas, que caracterizam seu estado. A transição $V$ verifica a validade das operações segundo a restrição do sistema e a transição $E$ atualiza o estado do modelo registrando a operação, caso tenha sido autorizada, no lugar $O$. $V$ e $E$ disparam alternadamente, cada vez operando sobre uma nova entrada selecionada aleatoriamente.

Analisemos como cada elemento da rede de Petri é utilizado na modelagem.

O lugar I contém marcas coloridas que representam o universo de operações possíveis nesse sistema. O tipo (ou "conjunto de cores") deste lugar é "Op'", como lê-se junto ao lugar no diagrama. Este tipo consiste de um par ordenado, no qual o primeiro valor é a operação representada ( $A$ ou $B$ ) e 0 segundo, uma lista de parâmetros. As marcas iniciais de cada lugar são definidas por uma expressão tipicamente localizada acima e à direita do mesmo. A expressão para o lugar $I$, definida na área de programação da ferramenta, representa todas as combinações possíveis entre as operações existentes A e B - e uma lista de parâmetros contendo o parâmetro $q$ com o valor 1 , ou contendo o parâmetro $q$ com o valor 2 , ou sem conter quaisquer parâmetros. 
Por conta dessa e outras definições de expressões na área de programação da ferramenta, o parâmetro $q$ não é visível na figura, apesar de implicitamente representado.

Um arco liga o lugar $I$ à transição $V$. Note-se que o arco é bidirecional, indicando que a marca selecionada será devolvida ao lugar de origem após o disparo da transição. Uma variável $o^{\prime}$ representa a marca selecionada de $I$ para o disparo de $V$. Por meio da referência a essa variável, pode-se estabelecer as expressões lógicas que regem o comportamento da rede. Acima da transição $V$ tem-se uma expressão entre colchetes. Esta expressão é a função de guarda de $V$, ou seja, uma expressão booleana que deve ser satisfeita para que $V$ esteja habilitada a disparar. A expressão em questão obriga a variável $o^{\prime}$ a receber uma marca tal que, se a operação for do tipo $A$, a mesma contenha um único parâmetro e, se a operação for do tipo $B$, não haja qualquer parâmetro na marca. Portanto, aqui a função de guarda cumpre a validação da entrada do sistema. Fica pressuposto que não é interesse do modelador avaliar os casos rejeitados pela validação, já que tais marcas nunca circularão pela rede.

O trecho de código abaixo de $V$ corresponde a uma expressão que processa as variáveis presentes nos arcos de entrada gerando outros valores que podem ser referenciados nos arcos de saída para formar as marcas geradas pelo disparo da transição. Nesse modelo, a função calcula, a partir das marcas presentes em $O$, quantas operações do tipo $A$ ocorreram desde a última ocorrência de $B$.

No arco que liga $V$ ao lugar allowed, uma expressão verifica se a restrição à execução de $A$ ou $B$ foi respeitada. O valor da marca gerada, de tipo booleano, segue o resultado dessa verificação, de maneira que quando $E$ dispara, a modificação da marca em $O$ é função desse valor, como vê-se na chamada da 
função update, no arco que vai de $E$ a $O$.

Finalmente, o lugar start armazena marcas incolores e garante que $V$ e $E$ se alternem nos disparos, processando uma entrada por iteração da rede.

Assim, cada sequência de marcações da CPN nas quais exista uma marca descritora de operação no lugar $n$ e uma marca com valor booleano "verdadeiro" no lugar allowed corresponderá a uma sequência de operações do sistema proposto, e tais sequências serão alcançáveis a partir da marcação inicial da rede se, e somente se, a sequência de operações correspondente for válida segundo a restrição do sistema.

Ainda que simples, este exemplo permite uma melhor compreensão sobre cada elemento da definição formal das CPN e seus empregos num modelo prático.

\subsection{Segurança de sistemas}

\subsubsection{Políticas de segurança}

Da forma como Garfinkel, Spafford e Schwart definem o conceito de segurança de computadores, um computador é seguro se "pode-se depender de que ele e seus softwares se comportem como se espera". (GARFINKEL; SPAFFORD; SCHWARTZ, 2003, tradução nossa). Para corresponder a essa expectativa, deve-se atender a uma série de requisitos de domínios mais restritos, que podem ser agrupados em três principais serviços de segurança: confidencialidade, integridade e disponibilidade (BISHOP, 2003).

A confidencialidade caracteriza-se pela prevenção da divulgação de informações ou recursos. Integridade refere-se à confiança que se tem em dados ou recursos e é tipicamente tratada em termos de prevenção de modificações 
impróprias ou não autorizadas. O conceito abrange, além da integridade dos dados, a integridade da origem dos mesmos, chamado de autenticação. Por fim, disponibilidade refere-se à habilidade de utilizar a informação ou recurso desejado, e é relevante ao estudo de segurança na hipótese de que alguém possa maliciosamente restringir o acesso autorizado a informações ou recursos.

De maneira mais concreta, a forma de especificar os serviços de segurança desejados sobre um determinado sistema é estabelecer a sua política de segurança.

Considerando o espaço de estados que um sistema computacional pode assumir, uma política de segurança é uma declaração que particiona esses estados entre autorizados, ou seguros, e não autorizados, ou inseguros. Portanto, um sistema seguro é aquele que inicia sua operação em um estado autorizado e não pode entrar em um estado não autorizado. (BISHOP, 2003).

O estado de um sistema é a coleção dos valores correntes de todas as regiões de memória, armazenamento, registradores e demais componentes do mesmo. 0 subconjunto dessa coleção que lida com a proteção é chamado estado de proteção (BISHOP, 2003).

Com relação à confidencialidade, políticas de segurança identificam os estados nos quais ocorre vazamento de informação para entidades não autorizadas. Com respeito a integridade, ela identifica as maneiras autorizadas pelas quais as informações podem ser modificadas e as entidades autorizadas a tanto. Com respeito a disponibilidade, uma política de segurança descreve quais serviços devem ser fornecidos e os parâmetros e níveis de serviço para 0 fornecimento.

Contudo, com relação à forma, Garfinkel, Spafford e Schwartz (2003) ar- 
gumentam que políticas de segurança devem ser independentes das entidades concretas existentes nos sistemas, e fundada em princípios ligados diretamente aos requisitos de serviços de segurança e imutáveis para o propósito dos sistemas.

Para que a política possa ser implementada, tal especificação genérica e abstrata deve ser posta em contexto, gerando diretrizes que a interpretem para cada ação possível realizada por cada entidade existente no sistema, a fim de encontrar a decisão que melhor corresponde aos princípios estabelecidos.

Ao versar sobre políticas de segurança, este trabalho toma por base esse conjunto de diretrizes, pois dessa maneira torna-se possível especificar um comportamento preciso que diferencie os estados autorizados dos não autorizados no sistema e, consequentemente, estabelecer modelos formais com tal finalidade.

\subsubsection{Controle de acesso}

Por "controle de acesso" entende-se a restrição do acesso a recursos a entidades privilegiadas (MENEZES; OORSCHOT; VANSTONE, 1997). No contexto de interesse, pode-se dizer que políticas de segurança de sistemas de serviços online buscam restringir o acesso aos recursos provenientes dos serviços oferecidos, portanto consistem em diretrizes de controle de acesso.

$\mathrm{Na}$ especificação de modelos para regulação do controle de acesso, diz-se que determinadas permissões ou direitos são necessários à realização de certas ações. Dá-se o nome de objetos aos recursos ou informações cujo acesso é regulado. Chamam-se sujeitos às entidades capazes de realizar ações sobre objetos. 
Com respeito ao critério utilizado para determinação do controle de acesso, distinguem-se as estratégias de controle de acesso discricionário (discretionary access control, DAC), também chamado de "controle de acesso baseado em identidade", no qual as permissões para acesso a cada objeto são determinadas pelo sujeito que é compreendido como seu dono, individualmente; controle de acesso mandatório (mandatory access control, MAC), no qual, ao contrário do anterior, o sistema arbitra de maneira centralizada sobre as permissões de cada usuário sobre cada objeto e controle de acesso baseado em papeis (role-based access control, RBAC), no qual as permissões são atribuídas a papeis, e não a usuários. Estes obtém os privilégios de acesso necessários em virtude das suas associações a papeis apropriados (SANDHU; SAMARATI, 1996; BISHOP, 2003).

Existem diversos modelos para o tratamento do controle de acesso, com características diferentes para diferentes propósitos de sistemas. Ressalta-se o modelo de Bell-LaPadula (BELL; LAPADULA, 1973), direcionado à modelagem de políticas de confidencialidade caracterizadas pela existência de múltiplos níveis de classificação da informação.

Intuitivamente, define-se um conjunto ordenado de níveis de classificação sendo que cada objeto é classificado em um dos níveis definidos. De maneira similar, define-se um conjunto ordenado de níveis de autorização e atribui-se um desses níveis a cada um dos sujeitos. O escopo do modelo é o fluxo de informação por meio dos objetos e, portanto, duas ações são compreendidas: a leitura e a escrita sobre os mesmos. O objetivo do modelo é garantir que os sujeitos só obtenham acesso a informações compatíveis com seus níveis de autorização. Para tanto, os autores combinam uma estrutura estática de permissões característica de DAC e restrições globais características de MAC. Duas regras são necessárias. A primeira determina que: 
Definição 2.4. (BELL; LAPADULA, 1973) Seja uma função $L: O \rightarrow \mathbb{N}$, onde $O$ é o conjunto de objetos de um sistema. Dado um sujeito $s$ com nível de autorização L $(s)$ e um objeto o com nível de classificação L(o), s poderá ler $o$ se, e somente se, $\mathrm{L}(o) \leq \mathrm{L}(s)$ e s possuir acesso de leitura discricionário sobre $o$.

A segunda regra previne o vazamento de informação por usuários de níveis de autorização elevados e lê-se:

Definição 2.5. (BELL; LAPADULA, 1973) Dado um sujeito s com nível de autorização L $(s)$ e um objeto o com nível de classificação $\mathrm{L}(o)$, s poderá escrever sobre o se, e somente se, $\mathrm{L}(o) \geq \mathrm{L}(s)$ e s possuir acesso de escrita discricionário sobre $o$.

Assim, se preservadas as condições de ambas as regras, a confidencialidade mantém-se sobre qualquer sequência de ações executada. Um modelo equivalente para fornecimento de integridade proposto por Biba (1977) pode ser obtido interpretando-se os níveis de autorização como níveis de confiança e invertendo as desigualdades das regras, ou seja, usuários sobre os quais deposita-se menor confiança podem ler documentos mais confiáveis mas não escrever sobre os mesmos, enquanto informações sobre as quais há menos garantias de integridade são impedidas de chegar a usuários de maior nível de confiança, assim mantendo íntegros seus corpos de conhecimento. Genericamente, dá-se o nome de segurança multinível à aplicação desse paradigma de múltiplos níveis de classificação às entidades de um sistema de segurança.

\subsection{Trabalhos Relacionados}

O uso de redes de Petri para a modelagem de workflows de negócio tem sido amplamente aceito, principalmente graças às suas naturezas matema- 
ticamente bem estabelecidas combinadas com seus grandes poderes de representação de cenários baseados em estados (AALST, 1998). Atluri e Huang (1996b) exploraram essas características ao observarem a possibilidade de combinar workflows a ambientes de segurança multinível, consequentemente tratando problemas de autorização em tais workflows como problemas de alcançabilidade em suas redes de Petri correspondentes (ATLURI; HUANG, 1996a; ADAM; ATLURI; HUANG, 1998).

Os autores identificam os tipos de restrição que podem existir em regras de segurança como dependências às quais estão sujeitas as ações do sistema, e as dividem em três tipos:

- Dependências de controle de fluxo, quando a condição para que uma ação ocorra está ligada à ocorrência de outra;

- Dependências de valor, quando a condição para que uma ação ocorra é expressa em função de um valor gerado pela execução de outras;

- Dependências externas, quando a condição para que uma ação ocorra é função de um fator externo (sendo o tempo o principal exemplo).

Explorando ainda mais o conceito, Knorr (2000) emprega redes de Petri para modelar matrizes de controle de acesso aprimoradas pela adição de uma dimensão de estado de workflow, permitindo uma abordagem dinâmica ao controle de acesso. Posteriormente (KNORR et al., 2001), ele estende esse trabalho apresentando um modelo para a descrição de políticas de controle de acesso mandatório tais como o modelo de Bell-LaPadula dentro de sistemas de workflow. Nos anos seguintes, outros pesquisadores também exploraram a aplicação de redes de Petri e redes de Petri coloridas à representação e análise dos principais modelos teóricos de políticas de segurança (JIANG et 
al., 2004; ZHANG; HONG; XIAO, 2006; ZHANG; HONG; LIAO, 2006). Todas as propostas, contudo, afastam-se do problema da representação prática de regras envolvendo lógica de negócio.

Uma abordagem distinta tomada para o SecureUML (BASIN; DOSER; LODDERSTEDT, 2003) busca tratar o planejamento de segurança de sistemas complexos, em especial com requisitos de $\mathrm{RBAC}$, orientando seus projetos e traduzindo especificações segundo um modelo formal de política de segurança. No artigo, uma arquitetura de software é construída com o auxílio de linguagem UML (RUMBAUGH; JACOBSON; BOOCH, 2004) para cumprir o papel de metamodelo das especificações de sistemas seguros, permitindo, com sua aplicação, a geração automática de uma infraestrutura de segurança.

Apesar de ser aplicada diretamente ao projeto dos sistemas, essa metodologia pode ser aplicada ao projeto de modelos, permitindo que se capture comportamentos ligados ao negócio como deseja-se para os objetivos deste trabalho, com a vantagem da existência de uma rede de Petri correspondente para validação de resultados.

Recentemente, avanços significativos foram alcançados nas aplicações de verificação de modelos, em especial na análise de redes de Petri coloridas. Utilizando a ferramenta CPN Tools, Rakkay e Boucheneb (2009) mostram métodos eficazes para a análise de modelagens de requisitos de RBAC. Os autores relacionam um workflow limitado por regras de segurança a predicados que descrevem as características dos estados inseguros da CPN que deveriam ser inalcançáveis. Ao determinar e localizar pela ferramenta os estados inseguros indiretamente com o auxílio de tais predicados, torna-se possível analisar modelos com grandes quantidades de estados, limitados apenas pela capacidade de processamento da ferramenta.

Além disso, como é notável das discussões sobre CPN, os estados alcan- 
çáveis são dependentes da marcação inicial da rede, portanto é importante que a configuração inicial reflita a variedade de situações encontradas no ambiente real. Xu et al. (2012) exploram esse problema na definição de testes para verificação de consistência das políticas que modelam.

A partir da exploração destes trabalhos, pode-se resumir os requisitos para a abordagem desenvolvida por este trabalho em cinco aspectos: versatilidade na modelagem de políticas de segurança - com especial atenção aos sistemas de serviços online, suporte a regras de segurança contendo lógica de negócio, possibilidade de análise formal por verificação de modelos, suporte a modelos sujeitos a workflows e aplicabilidade a modelos de maior escala. 0 capítulo 5 revisita esses tópicos frente aos resultados apresentados ao longo do trabalho de maneira a evidenciar as contribuições obtidas. 


\section{UM METAMODELO PARA REPRESENTAÇÃO E VALIDAÇÃO DE POLÍTICAS DE SEGURANÇA}

\subsection{Modelando workflows}

Independentemente de sua estrutura, todo sistema de workflow pode ser compreendido, do ponto de vista de suas entradas e saídas, como uma entidade recebendo sequências de mensagens, ou requisições, dos atores que podem alterar o seu estado interno. Para a modelagem de uma política de segurança para tais sistemas, o objetivo é determinar se os mesmos devem autorizar ou negar cada requisição recebida. Por conta disso, simplifica-se a modelagem omitindo ações e dados com os quais os sistemas respondem e que não têm influência sobre o subconjunto dos seus estados internos que rege as decisões a respeito da autorização de requisições recebidas, ou seja, o estado de proteção dos sistemas.

A figura 7 indica a estrutura de uma requisição. A parte que emite requsições será denominada usuário. Cada requisição especifica uma ação desejada, que está sujeita a restrições de segurança. O conjunto de ações rela-

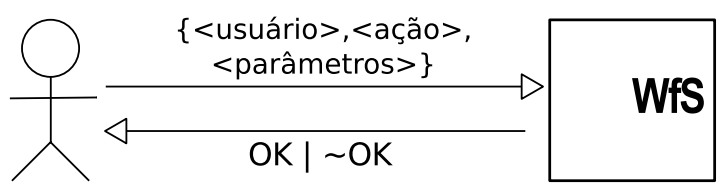

Figura 7: Modelo de comunicação com o WfS 
cionadas ao mesmo processo de negócio constitui uma tarefa, preservando assim a nomenclatura de sistemas de workflow adotada. Os parâmetros especificam o escopo da ação, e podem ser vistos como pares chave-valor, como elementos de vetores associativos.

Restringindo os domínios matemáticos para cada um desses elementos, pode-se definir as possíveis sequências de requisições necessárias para executar tarefas. Portanto, interpretando o conjunto de todas as requisições sintaticamente corretas como um alfabeto, a união das concatenações das mesmas que constituem um workflow válido pode ser vista como uma linguagem formal. Assim, no nível de abstração desejado, uma política de segurança poderá ser modelada a exemplo de uma máquina de Mealy (MEALY, 1955). Adaptando diretamente o conceito para o problema em questão, uma definição abrangente de um modelo de política de segurança é como segue:

Definição 3.1. Um modelo de política de segurança para sistema de workflow é uma 6-upla $\left(S, s_{0}, \Sigma, \Gamma, \delta, \omega\right)$, onde $S$ é o conjunto de estados internos do sistema, $s_{0}$ é o estado inicial do sistema, $\Sigma$ é o conjunto de todas as requisições sintaticamente válidas, $\omega: S \times \Sigma \rightarrow \Gamma$ é a função de autorização, que determina se uma dada ação requisitada pode ou não ser executada, sendo $\Gamma=\{$ autorizada, negada $\}$ as decisões de tal função, e $\delta: S \times \Sigma \rightarrow S$ é a função característica do sistema, que determina o próximo estado frente ao processamento de uma requisição.

A definição apresentada permite que se construa um modelo de política por associação ao seu enunciado, de maneira que qualquer propriedade que se verifique sobre a estrutura definida se aplique também ao modelo. Ela atua, portanto, como metamodelo do cenário de interesse.

Se obtivermos uma visão mais profunda e detalhada do que caracteriza o estado interno de um modelo como esse, poderemos refinar a definição de 
maneira a obter um metamodelo mais aplicável a cenários específicos e que fornceça orientação de como minimizar o número de estados que necessitam ser analizados para se concluir sobre a segurança de se executar uma dada requisição. As seções seguintes se aplicam a esta exploração, levando ao metamodelo definitivo para o problema tratado.

\subsubsection{O cenário de interesse}

Para caracterizar o estado interno do WfS, é interessante explicitar as entidades relacionadas ao processo de autorização no cenário de interesse bem como a informação referente a cada uma delas que é relevante para a tomada de decisão do sistema relativa ao processo de autorização.

Em sistemas de serviços online, a partir de uma visão bastante genérica pode-se dizer que os usuários operam no contexto especificado por meio de um identificador de conta, requisitando ações ao sistema por meio de uma sessão.

Utilizando-se apenas desse conceito, pode-se especializar a definição anterior, dividindo os estados anteriores em estados referentes às contas, estados referentes aos usuários e estados referentes às sessões. Os estados referentes a cada conta podem ser divididos entre estados da conta com relação a cada possível tarefa. Com isso, além de múltiplos conjuntos de estados, tem-se também múltiplas funções de atualização destes. Embora a alteração aumente a complexidade do metamodelo, torna-se mais fácil modelar políticas de sistemas, por ser mais simples reconhecer quais entidades necessitam de alterações de estado frente a cada ação requisitada e refletir tais necessidades nas funções específicas de atualização. 0 principal ganho, contudo, está na possibilidade de tratar o espaço de estados do modelo de maneira segmentada para a realização de sua análise: como existe a distin- 
ção entre estados de tarefas diferentes em cada conta, pode-se identificar, pela avaliação das funções de atualização correspondentes, grupos de requisições que não acarretam a mudança no estado de alguma tarefa específica, de forma que esses grupos possam ser excluídos da análise daquela tarefa. 0 mesmo ocorre para as demais entidades cujos estados são mantidos separadamente: contas, usuários e sessões. Como é natural no comportamento de muitos sistemas que as tarefas disponíveis sejam parcial ou totalmente independentes em seus escopos, a disponibilidade de tais segmentações deverá ser frequente. As possibilidades e condições para particionamento da análise serão discutidas em detalhe no capítulo 4.

Para caracterização dos estados de cada entidade, utilizar-se-á conjuntos de parâmetros do tipo chave-valor, análogos ao definido para requisições. No caso dos estados de usuários, o modelo será ligeiramente mais simples, consistindo apenas de valores que podem ser compreendidos como níveis de autorização dos mesmos para cada tarefa, com interpretação equivalente à utilizada no modelo de Bell-LaPadula (BELL; LAPADULA, 1973). Tratando-o dessa maneira, o modelador poderá valer-se de técnicas tipicamente empregadas em modelos de segurança multinível para a discriminação das tarefas executáveis por cada usuário, classe de usuários ou em situações específicas.

A estrutura do metamodelo proposta difere de diversos modelos de políticas de segurança presentes na literatura (ATLURI; HUANG, 1996a; BASIN; DOSER; LODDERSTEDT, 2003; RAKKAY; BOUCHENEB, 2009; HUANG; KIRCHNER, 2011; XU et al., 2012) por contemplar uma ampla gama de tarefas possíveis e recursos compartilhados limitados. No presente contexto, a conta representa o único repositório de recursos compartilhados entre os sujeitos da política. Isto se mostrará pouco limitante, uma vez que um número ilimitado de parâmetros podem ser modelados como recursos dentro de cada conta. 


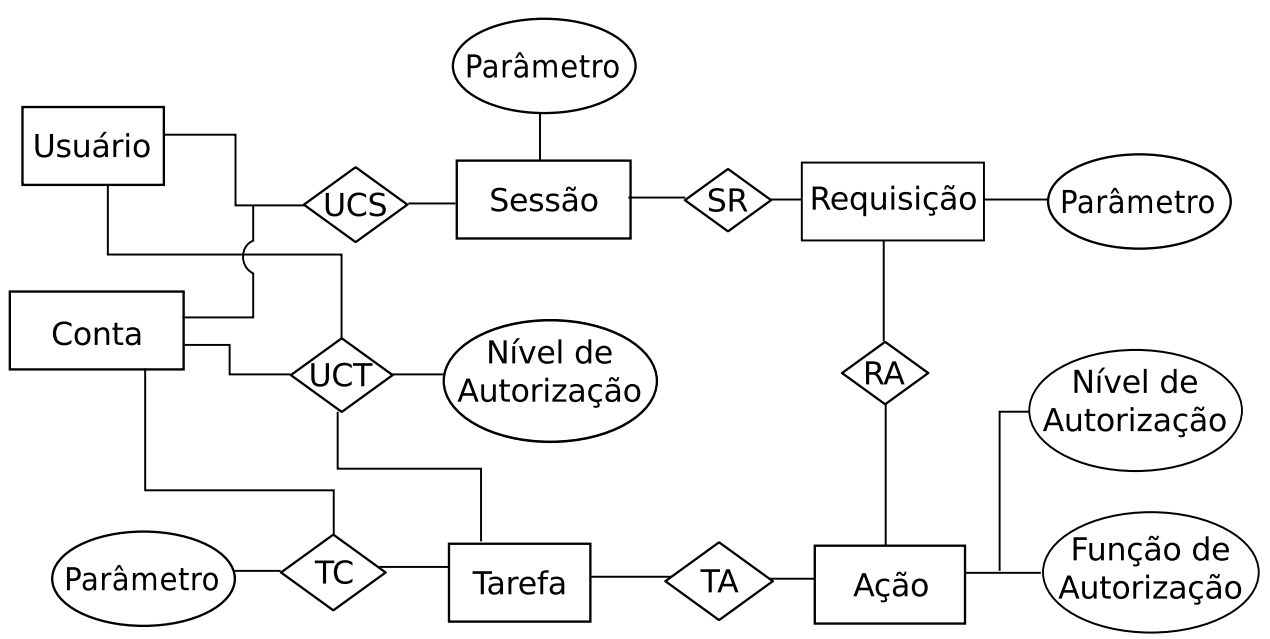

Figura 8: Diagrama entidade-relacionamento para o metamodelo

\subsection{Definição formal do metamodelo}

A figura 8 apresenta o metamodelo na forma de um modelo entidade-relacionamento (CHEN, 1976). Um usuário, acessando uma conta, inicia uma sessão. Por meio dessa sessão, as requisições são emitidas. Toda conta pode possuir um conjunto de dados relativos a cada ação que pode ser realizada, representados pelo atributo "P arâmetro" ligado ao relacionamento "TC" do diagrama. Também há atributos similares específicos para cada sessão e cada requisição. A toda tripla (usuário, conta, tarefa) é atribuído um determinado nível de autorização, e cada ação possível é associada com um nível mínimo de autorização necessário para sua execução. Além disso, a toda ação também é atribuída uma função de restrição que contém a sua própria lógica de autorização em termos das entidades requisitantes e seus parâmetros. As definições referentes a uma política de segurança modelada sobre esse metamodelo devem, portanto, ser concretizadas pela definição de valores aos atributos ilustrados - parâmetros, níveis de autorização e funções de restrição. Tomando sua interpretação matemática da maneira explicada por Chen (1976), a definição formal do metamodelo é como segue. 


\section{Definição 3.2.}

- Sejam Usuário, Conta, Sessão, Requisição, Ação e Tarefa conjuntos de entidades;

- Seja UCS $\subseteq$ Usuário $\times$ Conta $\times$ Sessão uma relação atribuindo uma sessão a um usuário e conta;

- Seja UCT $\subseteq$ Usuário $\times$ Conta $\times$ Tarefa uma relação atribuindo uma tarefa a um usuário e conta;

- Seja SR $\subseteq$ Sessão × Requisição uma relação atribuindo uma requisição a uma sessão;

- Seja $R A \subseteq$ Requisição $\times$ Ação uma relação atribuindo uma ação a uma requisição;

- Seja TA $\subseteq$ Tarefa $\times$ Ação uma relação atribuindo uma ação a uma tarefa;

- Seja TC $\subseteq$ Tarefa×Conta uma relação atribuindo uma tarefa a uma conta;

- Sejam Chave, Valor, Autorização, Inteiro e String conjuntos de valores, com:

- Chave $\subseteq$ String;

- Autorização $\subseteq$ Inteiro; e

- Valor $\subseteq$ Inteiro $\cup$ String $\cup 2^{\text {Inteiro }} \cup 2^{\text {String }}$;

- Seja Parâmetro $\subseteq$ Chave $\times$ Valor uma relação atribuindo um valor a uma chave;

- Seja $P_{S}:$ Sessão $\rightarrow 2^{\text {Parâmetro }}$ uma função que representa o atributo Parâmetro de uma sessão ao mapear uma Sessão em um conjunto de Parâmetro (função a ser definida pelo modelador que utilizar-se do metamodelo); 
- Analogamente, sejam:

- $P_{R}:$ Requisição $\rightarrow 2^{\text {Parâmetro }}$ uma função que representa os parâmetros de requisição; e

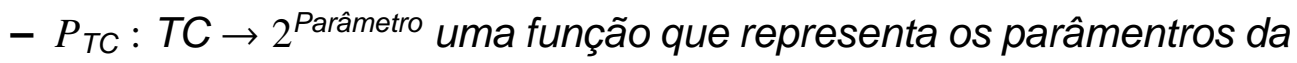
relação tarefa-conta;

- Por fim, sejam:

- $A u t_{A}:$ Ação $\rightarrow$ Autorização; e

- Aut $_{\text {UCT }}:$ UCT $\rightarrow$ Autorização

funções representando os atributos Nível de Autorização.

As funções Aut $_{A}$ e Autuct atribuem valores a cada ação e cada tripla da relação entre usuário, conta e tarefa, sendo que os valores atribuídos às ações representam um critério de classificação que deve ser atingido pelo requisitante representado pela tripla (usuário, conta, tarefa) para que este tenha permissão de executá-la, de acordo com o descrito pelas definições a seguir:

Definição 3.3. Seja $\geq_{\text {Aut }} \subseteq$ Autorização $\times$ Autorização uma ordem parcial sobre o conjunto Autorização, de maneira que $a, b \in$ Autorização, se $a \geq_{\text {Aut }} b$ diz-se que a tem nível de autorização maior ou igual a b;

Assim, Se a fosse o nível de autorização de uma tripla (usuário, conta, tarefa) requisitando uma ação de nível de autorização $b$, então a tripla teria nível de autorização suficiente para a execução da ação. Utilizando as funções definidas anteriormente, formaliza-se tal afirmação da seguinte maneira:

Definição 3.4. Seja $\psi(r):$ Requisição $\rightarrow$ \{verdadeiro, falso $\}$ um predicado auxiliar tal que:

$\psi(r):=\left\{\operatorname{Aut}_{\mathrm{UCT}}(u c t) \geq_{\text {Aut }} \operatorname{Aut}_{A}(a) \mid \exists a \in A c ̧ a ̃ o: R A(r, a) \wedge \exists s \in\right.$ Sessão : 
$\operatorname{SR}(s, r) \wedge \exists u \in$ Usuário, $c \in$ Conta : UCS $(u, c, s) \wedge \exists t \in$ Tarefa : $\operatorname{TA}(t, a) \wedge \exists u c t=(u, c, t): \operatorname{UCT}(u c t)\}$

então a requisição $r$ atende o critério de classificação necessário para a ação solicitada.

Além disso, para que uma requisição seja autorizada, ela deve satisfazer os critérios específicos que representam as regras vinculadas ao negócio, dados por funções de restrição específicas para cada ação. Formalizamos então o processo de autorização de uma requisição como segue:

\section{Definição 3.5 .}

- Seja $S_{A}$ : Ação $\rightarrow\left(2^{\text {Parâmetro }} \times 2^{\text {Parâmetro }} \times 2^{\text {Parâmetro }} \times\right.$ Usuário $\times$ Conta $\rightarrow$ \{verdadeiro, falso\}) uma função de ordem superior que mapeia uma Ação em uma função de restrição de valor booleano; e

- Seja $\phi(r):$ Requisição $\rightarrow$ \{verdadeiro, falso $\}$ um predicado tal que:

$$
\begin{aligned}
& \phi(r):=\left\{S_{A}(a)\left(P_{R}(r), P_{T C}(\tau), P_{S}(s), u, c\right) \wedge \psi(r) \mid\right. \\
& \exists a \in A c ̧ a ̃ o: R A(r, a) \wedge \exists s \in \text { Sessão }: \operatorname{SR}(s, r) \wedge \exists u \in \text { Usuário, } c \in \text { Conta : } \\
& \operatorname{UCS}(u, c, s) \wedge \exists t \in \text { Tarefa }: \operatorname{TA}(t, a) \wedge \exists \tau=(t, c): \operatorname{TC}(\tau)\}
\end{aligned}
$$

Então, diz-se que uma requisição $r$ está autorizada se, e somente se, ela satisfaz o predicado $\phi(r)$.

O predicado $\psi(r)$ visto é o estágio da autorização que implementa controle de acesso multinível ao verificar se um determinado usuário trabalhando com uma determinada conta possui autorização suficiente para realizar a ação desejada no contexto daquela tarefa específica. As funções de autorização $f_{A}$, definidas para cada ação existente no modelo por meio da função de ordem superior $S_{A}$, caracterizam o local onde podem ser inseridas quaisquer instruções 


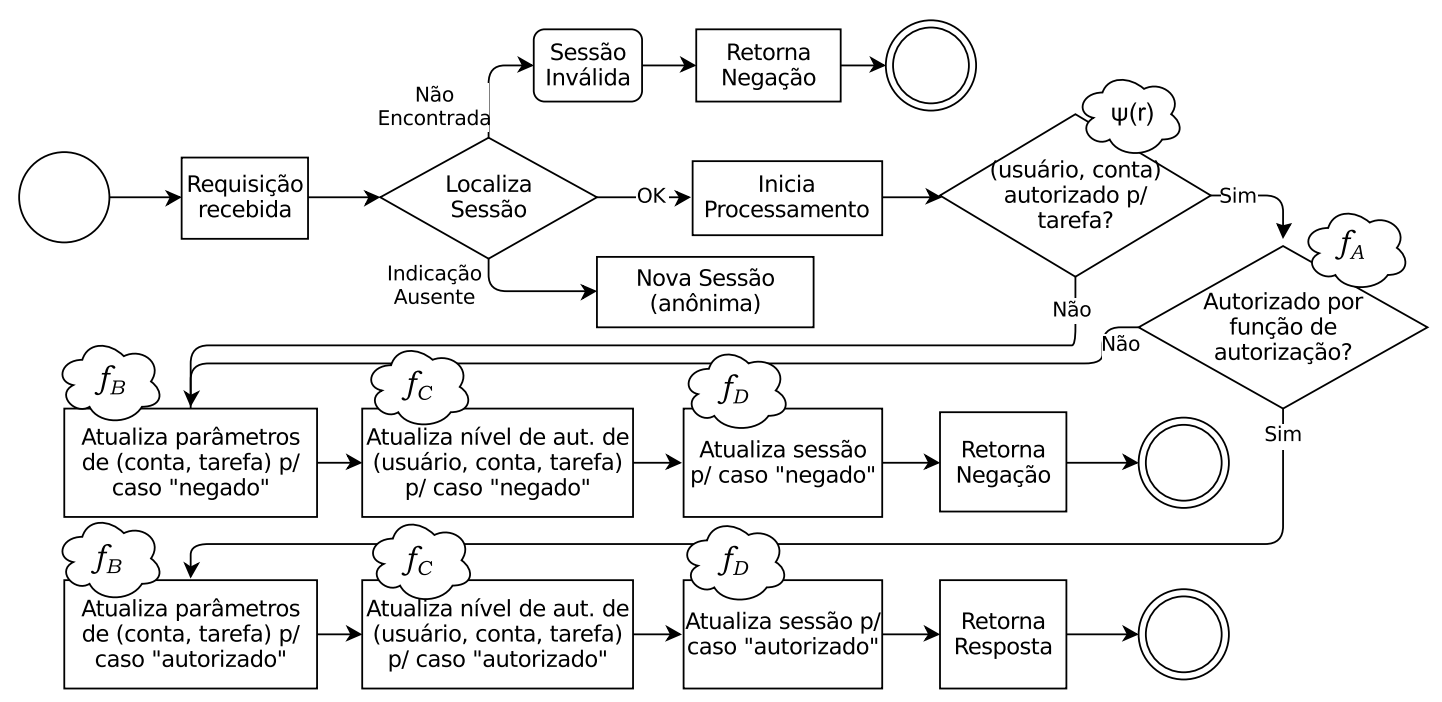

Figura 9: Estágios do processamento de uma requisição

contendo lógica de negócio pertencentes a uma regra de segurança. Numa visão estrita, $f_{A}$ também é capaz de incluir a funcionalidade que $\psi(r)$ provê, mas possuir um mecanismo distinto para o controle de acesso multinível simplifica a modelagem, dado seu uso frequente.

Além do estágio de autorização, um estágio de atualização é desejado, como representado no fluxograma da figura 9. Ao incluir atualizações aos atributos do modelo, permite-se que decisões a respeito da autorização de requisições subsequentes difiram das anteriores, efetivamente tornando o modelo dinâmico e aproximando-o do modelo de Mealy genérico visto inicialmente. Há três atualizações contempladas pelo metamodelo: atualização dos parâmetros dos pares (conta, tarefa); atualização dos níveis de autorização das triplas (usuário, conta, tarefa) e atualização da sessão como um todo (entidades, relacionamentos e parâmetros).

Cada requisição segue um processo que se inicia com a determinação de sua sessão correspondente, que também permitirá a associação da mesma ao usuário e conta respectivos. Então decide-se, com base nos critérios já explicados, se a mesma deverá ou não ser autorizada. De acordo com a deci- 
são tomada, as funções de atualização alteram os parâmetros das entidades, efetivamente levando o sistema ao seu próximo estado.

Adotando um símbolo $\Delta$ sobrescrito como notação para valores durante 0 processamento de uma requisição $r$ e $\Delta+1$ para seus valores atualizados durante o processamento da requisição que sucede $r$, as regras de atualização são formalmente definidas como segue:

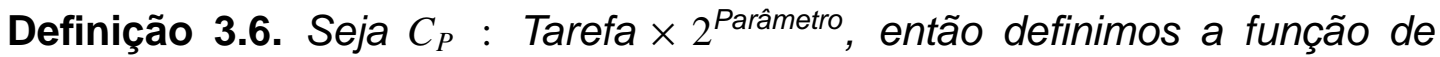
atualização dos parâmetros de contas $f_{B}$ :

$f_{B}: 2^{\text {Parâmetro }} \times 2^{C_{P}} \times 2^{\text {Parâmetro }} \times$ Usuário $\times$ Conta $\times$ Tarefa $\rightarrow 2^{\text {Parâmetro }}$

e então, para a conta $c$ processada em $\Delta$ e $\forall t \in$ Tarefa:

$P_{T C}^{\Delta+1}(t, c)=f_{B}\left(P_{R}(r), \bigcup_{\tau \in \text { Tarefa }}\left(\tau, P_{T C}^{\Delta}(\tau, c)\right), P_{S}^{\Delta}(s), u, c, t\right)$

onde $r$ é a requisição processada em $\Delta, s \in \operatorname{Sessão~:~} \operatorname{SR}(s, r)$ e $u \in$ Usuário : UCS $(u, c, s)$.

Para qualquer outra conta $c^{\prime} \in$ Conta, $\forall t, P_{T C}^{\Delta+1}\left(t, C^{\prime}\right)=P_{T C}^{\Delta}\left(t, C^{\prime}\right)$.

Isso significa que apenas parâmetros relativos à conta que emitiu a requisição podem ser atualizados, contudo, parâmetros de tarefas diferentes daquela processada também podem sofrer mudanças, permitindo alguma dependência entre tarefas no projeto da política de segurança.

Para a atualização do nível de autorização dos pares (usuário, conta), definimos:

Definição 3.7. Seja $U C_{A}$ : Tarefa $\times$ Autorização, então definimos a função de 
atualização de níveis de autorização $f_{C}$ :

$f_{C}: 2^{\text {Parâmetro }} \times 2^{\text {Parâmetro }} \times 2^{\text {Parâmetro }} \times 2^{U C_{A}} \times$ Usuário $\times$

Conta $\times$ Tarefa $\rightarrow$ Autorização

e então, para entidades relacionadas à requisição processada nos mesmos termos que na definição anterios, $\forall t \in$ Tarefa:

$A u t_{U C T}^{\Delta+1}(u, c, t)=f_{C}\left(P_{R}(r), P_{T C}^{\Delta}(t, c), P_{S}^{\Delta}(s), \bigcup_{\tau \in \text { Tarefa }}\left(\tau, A u t_{U C T}^{\Delta}(u, c, \tau)\right), u, c, t\right)$

Para quaisquer outros $c^{\prime} \in$ Conta, $u^{\prime} \in$ Usuário, $\forall t$

$\operatorname{Aut}_{U C T}^{\Lambda+1}\left(u^{\prime}, c^{\prime}, t\right)=A u t_{U C T}^{\Delta}\left(u^{\prime}, c^{\prime}, t\right)$.

Portanto, analogamente a $f_{B}$, uma política de segurança pode alterar os níveis de autorização para qualquer tarefa, mas apenas para o par (usuário, conta) que emitiu a requisição. Finalmente, para a atualização dos elementos relacionados à sessão:

Definição 3.8. Definimos a função de atualização de sessão $f_{D}$ :

$f_{D}: 2^{\text {Parâmetro }} \times 2^{\text {Parâmetro }} \times 2^{\text {Parâmetro }} \times$ Usuário $\times$ Conta $\times$

Sessão $\rightarrow 2^{\text {Sessão }} \times 2^{S R} \times 2^{\text {Parâmetro }}$

e então, para entidades relacionadas à requisição processada,

$\left(\operatorname{Sessão}{ }^{\Delta+1}, S R^{\Delta+1}, P_{S}^{\Delta+1}\right)=f_{D}\left(P_{R}(r), P_{T C}^{\Delta}(t, c), P_{S}^{\Delta}(s), u, c, s\right)$

A partir de todas as definições apresentadas, pode-se definir um modelo segundo o paradigma determinado pelo metamodelo: 
Definição 3.9. Um modelo de sistema de serviços online, nos moldes do metamodelo desenvolvido é uma 13-upla $\mathcal{M}=$ (Tarefa, Ação, Conta, Usuário, TA, Aut ${ }_{A}, P_{T C}^{0}$, Aut $_{U C T}^{0}, P_{S}^{0}, S_{A}, S_{B}, S_{C}, S_{D}$ ), tal que:

- Tarefa, Ação, Conta, Usuário e TA são as definições das entidades vistas para a situação modelada;

- $A u t_{A}:$ Ação $\rightarrow$ Autorização é a função que associa um nível de autorização para cada ação, com Autorização $\subseteq \mathbb{Z}$;

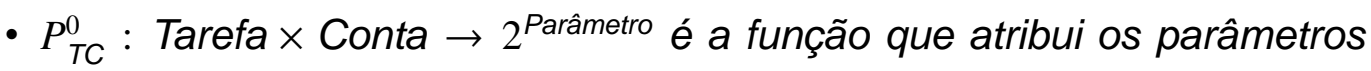
iniciais de cada tarefa para cada conta;

- $A u t_{U C T}^{0}:$ Usuário $\times$ Conta $\times$ Tarefa $\rightarrow$ Autorização é a função que atribui os níveis de autorização iniciais de cada usuário para cada tarefa em cada conta;

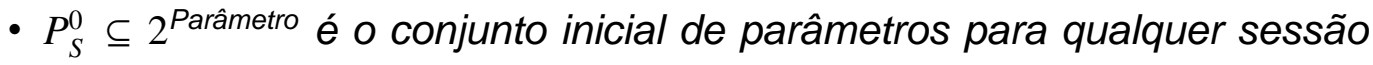
aberta na execução do modelo;

- $S_{A}:$ Ação $\rightarrow F_{A}$ uma função de ordem superior que mapeia cada ação em uma função de autorização $f_{A} \in F_{A}$, ou seja, seleciona a função adequada para a ação a autorizar;

- $S_{B}:$ Ação $\times\{$ autorizada, negada $\} \rightarrow F_{B}$ uma função de ordem superior que atribui para cada ação em caso de requisição autorizada ou negada, uma função de atualização de parâmetros de conta $f_{B} \in F_{B}$;

- $S_{C}:$ Ação $\times\{$ autorizada, negada $\} \rightarrow F_{C}$ uma função de ordem superior que atribui para cada ação em caso de requisição autorizada ou negada, uma função de atualização de níveis de autorização $f_{C} \in F_{C}$; 
- $S_{D}:$ Ação $\times\{$ autorizada, negada $\} \rightarrow F_{D}$ uma função de ordem superior que atribui para cada ação em caso de requisição autorizada ou negada, uma função de atualização de parâmetros de sessão $f_{D} \in F_{D}$;

sendo que Parâmetro é o conjunto de quaisquer pares chave-valor como descritos anteriormente (o mesmo, portanto, para qualquer modelo).

Além do modelo acima, puramente estático, para cada workflow possível observa-se uma configuração dinâmica, que também pode ser definida formalmente:

Definição 3.10. Uma configuração ou caso de um modelo de sistema de serviços online $\mathcal{M}$, é uma 6-upla $C=$ (Sessão, Requisição, $R A, S R, \cup C S, P_{R}$ ), tal que:

- Sessão, Requisição, RA, SR, UCS são as definições das entidades vistas para a situação modelada;

- $P_{R}:$ Requisição $\rightarrow 2^{\text {Parâmetro }}$ é a função que atribui um conjunto de parâmetros a cada requisição;

sendo que Parâmetro é o conjunto de quaisquer pares chave-valor como descritos anteriormente (o mesmo, portanto, para qualquer configuração de modelo).

A partir de uma dada configuração dinâmica, o modelo executa qualquer requisição definida. A ordem de execução de requisições é livre e não há limite para o número de passos de execução, portanto, uma mesma requisição pode ser executada múltiplas vezes. A cada passo de execução, como descrito no fluxograma da figura 9, a requisição é dada como autorizada ou negada pela avaliação do nível de autorização e pela execução da função $f_{A}$ apropriada 
e, em função disso, os parâmetros são atualizados pelas funções $f_{B}$, $f_{C}$ e $f_{D}$, evoluindo de seus valores iniciais dados na definição estática do modelo.

Com relação à definição 3.1 (pág. 44), o metamodelo especificado subdivide os estados do modelo em estados da conta, do usuário e da sessão, e com isso também divide suas funções de atualização. Esta separação beneficiará a verificação de modelos, como será discutido no capítulo 4 .

\subsubsection{Implementação do metamodelo}

A tradução do metamodelo conceitual concebido em um modelo de CPN é bastante direta.

A figura 10 (pág. 58) mostra a rede que implementa o metamodelo. Essencialmente, as entidades são representadas por lugares, seus estados pelas cores das marcas, as transições estão relacionadas aos passos do workflow e as funções de autorização e de transição de estado são modeladas pelas funções dos arcos de saída das transições.

A transição central nomeada "execution" lida com todo o processamento visto no fluxograma da figura 9. As requisições de entrada são extraídas de uma fila implementada no lugar chamado "server queue" e respostas são enviadas a outra fila no lugar "server output". Identificadores de sessão são gerados no lugar "new session pool" e o número de identificação é incrementado apenas em caso de processamento de sessão nova. A transição menor, tachada como "session invalid" é disparada apenas em caso de um identificador recebido não ser encontrado no conjunto de sessões abertas, localizado no lugar chamado "open sessions". As marcas armazenadas no lugar "open sessions" incluem quatro informações: a identificação da sessão, o usuário associado a ela, a conta associada a ela e os parâmetros da sessão. Os lugares 
restantes, "account data" e "user account clearances" contêm os parâmetros ligados a cada conta para cada tarefa e os níveis de autorização para triplas (usuário, conta, tarefa), respectivamente. A função de guarda para a transição de execução garante que a sessão selecionada corresponde àquela referenciada pelos parâmetros com chave igual a "sess" na requisição, quando presente. A região de código para a mesma transição distingue novas sessões de sessões obtidas no lugar "open sessions" e executa a função de autorização determinando a decisão para a requisição em processamento. A função de autorização é responsável por ambos os estágios definidos no fluxograma o primeiro, $\psi(r)$, referenciando o nível de autorização requerido para a ação e o segundo referenciando a função de autorização para a ação. Finalmente, os arcos de saída cuidam da atualização de cada entidade pela chamada de uma função de execução que referencia todas as funções adequadas definidas na política, utilizando o resultado da função de autorização para determinar se é o caso de invocar funções referentes à negação ou autorização da execução. O arco de saída levando à fila de saída chama uma função que monta a mensagem de resposta, também para negação ou autorização, da maneira que for necessário.

\subsection{Exemplo de utilização do metamodelo}

Como mecanismo tanto para a demonstração do método proposto como para validação da sua aplicabilidade em um contexto real, propõe-se um caso de exemplo consistindo de um ambiente de Internet Banking. Dois serviços típicos de uma aplicação como essa são discutidos de maneira a explicitar algumas características e assim justificar a modelagem correspondente e revelar o poder de representação do metamodelo.

Primeiramente definem-se os tipos de requisição necessários segundo a 


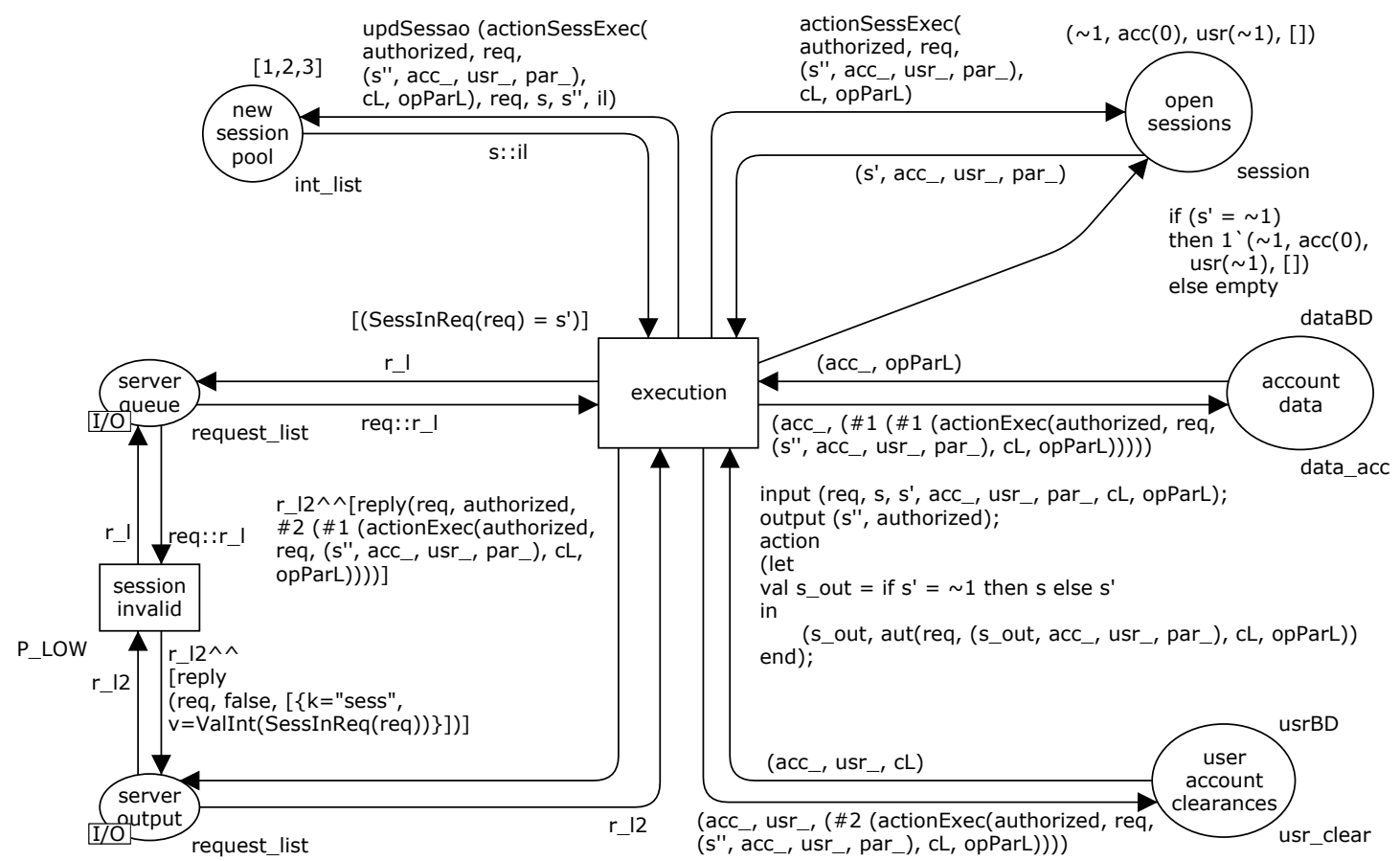

Figura 10: A CPN que implementa o metamodelo

visão de comunicação dos workflows dos serviços. Em seguida, um possível conjunto de regras constituintes de uma política de segurança para esse sistema é apresentado e sua modelagem discutida.

As requisições são representadas na CPN do metamodelo como marcas possuindo uma cor chamada "request". A cor "request" consiste de uma tripla que identifica um nome de origem, a ação requerida e uma lista de parâmetros. A estrutura das requisições para cada ação definida no exemplo será mostrada conforme as ações necessárias são reveladas.

\subsubsection{Login}

Antes de detalhar os serviços previstos no sistema, cabe a discussão a respeito da identificação e autenticação dos usuários, que dará origem a alguns tipos de requisições do workflow. Identificaremos esse processo como uma tarefa autônoma chamada "login". 
Apesar de não estar diretamente relacionado à funcionalidade do sistema, o processo de login é indispensável a todos os serviços para garantir a correta e unívoca associação das requisições recebidas pelo servidor ao cliente em questão. O que é possível e de fato ocorre nas implementações existentes é o estabelecimento de uma sessão duradoura para que a execução deste procedimento seja reaproveitada para uma sequência de operações.

\subsubsection{Troca de chaves}

Para a preservação da confidencialidade de cliente e instituição bancária nos dados trafegados, é necessária uma etapa prévia de troca de chaves criptográficas. Pressupõe-se aqui a aderência ao protocolo TLS (DIERKS; ALLEN, 1999), como é o padrão de facto em operações dessa natureza na Internet. Como a execução dessa etapa é padronizada, anterior a toda a comunicação e não sofre reflexos da política de segurança por não representar transferência de informação sobre o negócio, as mensagens necessárias para sua efetivação são excluídas da modelagem. Isto é consistente com o raciocínio de que tal operação atua em camadas inferiores à aplicação no modelo OSI de referência (ZIMMERMANN, 1980).

\subsubsection{Início de sessão / identificação do cliente}

Neste ponto, para que o servidor esteja informado da identidade de seu interlocutor, o cliente deve informar os dados que o identificam frente ao provedor de serviço. No cenário do exemplo, esses poderiam ser os seus números de agência e conta. É por meio desta identificação que o WfS poderá verificar credenciais e, posteriormente, obter e atualizar dados. J á a partir deste ponto fica definida a sessão do cliente, que deve ser adequadamente identificada, e um contexto apropriado deve ser preparado logicamente no servidor para 
o gerenciamento dos dados que deverão persistir entre requisições. Embora essa tarefa também corresponda a uma atividade de uma camada inferior do modelo OSI, como as regras de segurança poderão incluir afirmações que envolvam a sessão, é relevante à modelagem controlar seu estado.

Consolida-se este estágio no modelo pela inclusão de uma ação identificada como "idtf" à tarefa de login. A requisição desta ação deverá incluir um parâmetro para identificação do usuário e outro para identificação da conta preterida para operações. Um exemplo disto seria:

$$
\text { (“idtf”, }[\{\mathrm{k}=\text { "usr", v=usr }(\theta)\},\{\mathrm{k}=\text { "acc”, v=acc(1) }\}] \text { ). }
$$

Ou seja, requisita-se a execução da ação "idtf" pelo usuário usr( (Q) em uma conta acc(1).

\subsubsection{Autenticação do cliente}

Como forma de atestar a identidade reivindicada pela requisição anterior, o cliente envia uma senha pessoal como parâmetro, completando a tarefa de login. Seria possível estipular o envio desse parâmetro na requisição anterior e, assim, cumprir com a tarefa de autenticação em apenas uma etapa de comunicação. Optou-se pela separação das requisições a fim de emular uma situação mais complexa, na qual um método de autenticação dinâmico tal como a aplicação de um protocolo do tipo desafio-resposta forçaria a existência dessa etapa adicional, efetivamente criando um estado intermediário no qual a sessão do cliente existe mas não está autenticada. Isso nos permite explorar algumas situações de possíveis vulnerabilidades e melhor testar 0 poder da modelagem.

À ação que representa o estágio de autenticação, dá-se o nome de "auth". Como neste ponto uma sessão já foi estabelecida, um parâmetro adicional é 
incluso na requisição para identificá-la, a exemplo do mecanismo tipicamente utilizado para controle de sessões sobre HTTP (COURTS et al., 2000). Um exemplo para uma senha igual a "12345" sobre a sessão 2 tem o seguinte formato:

$$
\text { (“auth", [\{k="sess",v=2\}, \{k="pass”, v=“12345” }\}] \text { ) . }
$$

\subsubsection{Serviço de saldo}

O primeiro serviço escolhido para o exemplo é o pedido de saldo de conta bancária. É vantajoso modelar este serviço por alguns motivos: ele caracteriza uma tarefa de workflow mínima, pois pode ser modelado com apenas uma ação e sem parâmetros, o que é interessante para demonstração da mínima complexidade necessária no processo; ele também é um exemplo de tarefa exclusivamente de consulta, o que implica que conceitualmente, o mesmo não requer alteração de estado do WfS e, salvo por eventuais restrições da política de segurança, poderia ser invocado repetidamente numa sequência de trabalho válida. Portanto, deverá caracterizar a existência de ciclos no espaço de estados do modelo.

Ambas a tarefa e a ação correspondentes ao saldo, recebem o nome de "balance" no modelo. 0 formato para uma requisição da sessão 2 é, portanto:

$$
\text { ("balance", [\{k="sess",v=2\}]). }
$$

\subsubsection{Serviço de transferência entre contas}

Ao contrário do serviço de saldo, a modelagem do serviço de transferência entre contas oferece um exemplo no qual diferentes parâmetros e etapas são verificados na execução da tarefa. 


\subsubsection{Seleção do serviço}

Optou-se pela inclusão de uma etapa inicial que pode ser interpretada como um pedido de status ou da lista de opções do serviço. Tipicamente, no uso de uma API web, as opções e parâmetros para execução já são previamente conhecidos, portanto a omissão dessa requisição ainda constituiria um workflow válido. Apenas a fim de ampliar o exercício da modelagem, 0 sistema de exemplo exigirá que a execução de transferências seja iniciada com uma requisição deste tipo, cuja ação nomearemos "eft_ini" e seguirá a estrutura dada por:

$$
\text { ("eft_ini”, [\{k=“sess”,v=2\}]). }
$$

\subsubsection{Especificação de parâmetros}

A função deste estágio é colher os parâmetros para execução do serviço. No sistema real, diversas informações adicionais podem ser transmitidas ao cliente, a exemplo de limites disponíveis para transferência, nome do creditado, identificação da agência do creditado e assim por diante. A maioria delas constitui serviços funcionalmente independentes e de baixa granularidade e criticidade. Em uma camada de apresentação web dinâmica, poder-se-ia lançar mão de requisições assíncronas coordenadas por scripts (como em AJ AX) para permitir a obtenção desses dados. Portanto, na modelagem do workflow da tarefa, nos interessa apenas o envio dos dados necessários para a caracterização da transação e que precisam ser considerados para a tomada de decisão quanto à sua autorização. No caso da transferência, eles são a conta de crédito e o valor. A ação a requisitar recebe o nome de "eft_forms" e a requisição de transferência para a conta 3 no valor de 100,00 toma a seguinte forma: 


$$
\begin{aligned}
& \text { ("eft_forms”, }[\{\mathrm{k}=\text { "sess", } \mathrm{v}=2\}, \\
& \{\mathrm{k}=\text { ="dest”, } \mathrm{v}=\operatorname{acc}(3)\},\{\mathrm{k}=\text { "value”, } \mathrm{v}=“ 10000 "\}])
\end{aligned}
$$

\subsubsection{Confirmação}

Esta etapa modela a efetivação de uma transação preparada pelas etapas anteriores do workflow da tarefa. A separação entre preparo e efetivação permite que diferentes papeis de usuários sejam caracterizados: um deles poderia ter autorização para o fluxo da tarefa apenas até a preparação da transação, enquanto outro, de maior responsabilidade, poderia executá-la por completo ou simplesmente efetivar uma transação preparada previamente. Com isso, exemplifica-se a modelagem de outras características relevantes para sistemas de serviços online: a possibilidade de existência de múltiplos casos de uso para uma mesma tarefa e o controle de acesso multinível baseado em papeis. Para justificar os parâmetros definidos, é necesssário que se compreenda um aspecto da autenticação do usuário. O serviço de identificação ou autenticação de entidade em segurança da informação é compreendido como uma técnica que assegura uma das partes envolvidas tanto da identidade da sua contraparte quanto do estado ativo desta última no instante em que a evidência para tanto foi criada ou adquirida (MENEZES; OORSCHOT; VANSTONE, 1997). Isto implica um "envelhecimento" das evidências da autenticação, ou seja, com o passar do tempo, a confiança na identidade atestada cai gradativamente, gerando a necessidade de um limite - temporal ou vinculado a outra métrica de sobreutilização - para a validade do login, a partir do qual requer-se uma renovação para que o cliente possa continuar a usufruir dos serviços. Neste caso, como consequência de uma regra de segurança que será vista adiante, adota-se a confirmação de uma transação financeira como um ponto de controle no qual uma nova prova de identidade é exigida. $\mathrm{Na}$ 
modelagem, isso é representado pela inclusão de um parâmetro para informação da senha nas requisições da ação de confirmação de transferência. Uma medida como essa seria capaz de frustrar uma transferência fraudulenta iniciada graças a um ataque de sequestro de sessão, por exemplo. Um segundo parâmetro ainda é necessário para permitir a associação da requisição com a transferência preparada anteriormente. Adota-se um número de sequência a ser informado na resposta da requisição "eft_forms" sob o nome de "tid" (em referência a identificador de transferência). Em suma, tem-se a estrutura de requisição abaixo:

$$
\begin{aligned}
& \text { ("eft_conf", [\{k="sess", v=2\}, }\{\mathrm{k}=\text { ="tid", v=1\}, } \\
& \{\mathrm{k}=\text { "pass",v="12345" }\}] \text { ) . }
\end{aligned}
$$

Finalmente, uma ação para encerramento da sessão também é incluída, com a sintaxe:

$$
\text { ("logout", }[\{\mathrm{k}=\text { "sess", } \mathrm{v}=2\}] \text { ). }
$$

Na prática, existem muitas outras funcionalidades em um sistema bancário como o do exemplo, mas para efeito deste trabalho, os serviços que foram especificados são suficientes para que seja possível ilustrar o processo de modelagem e verificação.

\subsubsection{Política}

A política de segurança de um sistema, como visto, tem por função especificar os serviços de segurança desejados, particionando seus estados entre autorizados e não autorizados. Dentro de um contexto de operação bem definido, os princípios abstratos da política tomam a forma de regras de formulação precisa sobre o comportamento do sistema, identificando na ótica do 
mesmo os estados autorizados e, portanto, seguros segundo sua especificação.

Um possível conjunto de regras de uma política de segurança para o sistema de exemplo é dado a seguir:

1. Para um login ser bem sucedido, o usuário requisitante não deve ter completado login anteriormente, a não ser que tenha também completado um logout entre cada um deles. Consequentemente, em qualquer estado do sistema não deve existir mais que uma sessão ativa por usuário.

2. O erro em fornecer a senha correta para o login em três ocasiões consecutivas bloqueia o acesso a sistema.

3. Apenas usuários com login ativo podem acessar as funcionalidades do sistema, a saber:

(a) a operação de saldo da conta;

(b) a operação de transferência de fundos.

4. Apenas o usuário "mestre" pode completar transferências; o usuário "auxiliar" pode apenas formatá-las para efetivação posterior.

5. A autenticação deve ser reforçada para a efetivação de uma transferência de fundos.

6. A quantia a transferir para uma conta não registrada somada ao montante total já transferido para contas não registradas não deve exceder 0 limite diário de $\$ 500$.

7. A quantia a transferir para uma conta registrada somada ao montante total já transferido não deve exceder o limite diário de \$1500. 
Tabela 1: Resumo da política modelada

\begin{tabular}{|c|c|c|c|c|c|c|}
\hline \multirow{2}{*}{ Ação } & \multirow{2}{*}{ Tarefa } & \multirow{2}{*}{$\begin{array}{l}\text { Nível de } \\
\text { Autorização }\end{array}$} & \multicolumn{4}{|c|}{ Funções } \\
\cline { 4 - 7 } & & Aut. & \multicolumn{2}{|c|}{ Atualização } \\
\cline { 4 - 7 } & & $f_{A}$ & $f_{B}$ & $f_{C}$ & $f_{D}$ \\
\hline idtf & login & 0 & $\mathrm{X}$ & & & $\mathrm{X}$ \\
auth & login & 0 & $\mathrm{X}$ & $\mathrm{X}$ & $\mathrm{X}$ & $\mathrm{X}$ \\
balance & balance & 1 & $\mathrm{X}$ & & & \\
eft_ini & eft & 1 & $\mathrm{X}$ & & & $\mathrm{X}$ \\
eft_forms & eft & 1 & $\mathrm{X}$ & $\mathrm{X}$ & & $\mathrm{X}$ \\
eft_conf & eft & 2 & $\mathrm{X}$ & $\mathrm{X}$ & & $\mathrm{X}$ \\
eft_ogout & logout & 0 & & $\mathrm{X}$ & & $\mathrm{X}$ \\
\hline
\end{tabular}

A especificação da política por meio da simples listagem de regras em linguagem natural dá margem a problemas, como será visto no momento da discussão do processo de análise. No entanto basta que se enxergue estas regras como requisitos mínimos para o sistema ou um subconjunto de sua especificação, uma vez que o propósito maior da introdução deste exemplo é mostrar que os enunciados de regras propostos podem ser representados com a abstração do metamodelo.

\subsubsection{Modelagem}

Formalmente, modelar a política do exemplo significa determinar o valor da 13-upla $\mathcal{M}$ explicitada na definição 3.9 (pág. 55) assim como as configurações dinâmicas necessárias para exercitar todos os usos do modelo, ou seja, a 6-upla $C$ da definição 3.10 .

A tabela 1 resume a maioria das definições para a política de exemplo. Cada linha indica uma das ações definidas. A coluna "Tarefa" associa a ação à tarefa corespondente. A coluna "Nível de Autorização" indica o nível de autorização necessário para que o par (usuário, conta) possa realizar a ação requerida pela requisição (i. e.: Aut $_{A}$ ). Para a coluna da função de autorização, $f_{A}$, células vazias indicam que a autorização é sempre concedida, enquanto 
células marcadas com um " $X$ " indicam a necessidade da definição de uma função para a ação de sua linha. Nas colunas referentes às funções de atualização, células marcadas com um " $X$ " indicam que a avaliação da função indicada é necessária ao menos para um dos possíveis resultados da ação autorizada ou negada. Uma célula vazia indica que, para aquela ação, uma função identidade é usada, implicando permanência no mesmo estado para a entidade afetada.

Pode-se notar da tabela que, por exemplo, a ação "idtf" requer uma função de autorização $\left(f_{A}\right)$ e uma função de atualização de sessão $\left(f_{D}\right)$, mas não requer uma função de atualização de parâmetros de conta $\left(f_{B}\right)$ ou uma função de atualização de níveis de autorização de usuário $\left(f_{C}\right)$. A função de autorização $\left(f_{A}\right)$ deverá verificar se os parâmetros necessários foram informados corretamente e se não há sessão em andamento para o mesmo usuário na mesma conta, de acordo com a regra (1). A função de atualização de sessão é necessária para associar a sessão aberta à conta e usuário informados, com a adição de um parâmetro indicando que a sessão ainda não foi autenticada.

Um exemplo do cabeçalho da função de autorização $f_{A}$ para a ação "eft_conf" é dado abaixo como na sua implementação, em ML:

fun eft_conf_fA (m:request, s:session, q:params)

Os argumentos da função são consistentes com a definição para funções de autorização: o valor m contém os parâmetros da requisição, q, os parâmetros para o par (conta, tarefa) e s é uma tripla contendo usuário, conta e parâmetros da sessão. A íntegra da função encontra-se no apêndice A.

Além dos dados contidos na tabela, resta especificar para o exemplo 0 conjunto de usuários e contas, os valores iniciais dos parâmetros das entidades $\left(P_{\mathrm{TC}}^{0}\right.$, Aut $t_{\mathrm{UCT}}^{0}$ e $\left.P_{S}^{0}\right)$ e as configurações dinâmicas relativas às requisições 
previstas, que chamamos "casos" do modelo $(C)$. Deixamos a discussão das configurações dinâmicas para o capítulo 4, que trata da análise do modelo, onde elas poderão ser melhor justificadas, voltando-nos, então, aos valores iniciais.

Convencionou-se para este modelo, que o usuário usr ( $(\theta)$ assumirá o papel de "mestre" para todas as contas e todos os demais assumirão papeis de "auxiliar". Como os usuários não possuem qualquer definição de estado desatrelada da conta, os usuários usr( $(\theta)$ de cada conta podem ser vistos como entidades distintas. Pelo mesmo motivo, o metamodelo impossibilita o vazamento de informação entre contas. Dada essa convenção, os valores iniciais de níveis de autorização serão iguais a 2 para todas as tarefas para o usuário usr $(\theta)$ e iguais a 1 também para todas as tarefas para os demais usuários. Com esta combinação de valores para os usuários e ações, fica caracterizado que apenas o usuário "mestre" será capaz de completar transferências, como especificado nas regras da política. Previu-se a existência de três contas distintas na modelagem.

Os únicos parâmetros iniciais das contas para a tarefa de login devem ser as senhas de cada usuário existente para aquela conta e a quantidade de tentativas de login fracassadas. Para a tarefa de transferência, são necessários parâmetros especificando os limites restantes para transferência para contas registradas e sem registro, bem como quais são as contas registradas para cada conta definida. Como as funções de autorização têm como argumento apenas os parâmetros da conta que são relativos à tarefa da ação preterida, a ação de confirmação de transferência não pode utilizar o parâmetro de senha do login para sua autenticação, sendo necessária a inclusão de um novo parâmetro de senha para cada usuário autorizado a efetivar transações. 0 serviço de saldo não requer quaisquer parâmetros iniciais, assim como as sessões. 
É possível e mais prático e robusto para a modelagem codificar os estados iniciais de cada parâmetro em cada entidade como sendo a ausência do parâmetro com a chave desejada. Assim, caberá às funções que os utilizam ter ciência do valor padrão para cada parâmetro. 0 único detalhe a atentar caso se empregue tal técnica é que passa a ser obrigatório representar o valor inicial consistentemente como a ausência do parâmetro, do contrário as duas situações (ausência do parâmetro e presença do parâmetro com o valor padrão) serão identificadas como sendo estados distintos, quando na realidade representam a mesma situação.

Para que a descrição da modelagem do exemplo fique completa, basta especificar as definições de cada função indicada na tabela 1 e suas correspondentes para casos de requisições negadas. Estas definições foram incluídas no modelo gerado mas, por razões de simplificação do texto, são omitidas nesta seção. $O$ código correspondente encontra-se no apêndice $A$. Contudo entende-se que o exemplo fornecido é suficiente para a compreensão da estrutura e do processo de modelagem, portanto passamos à discussão dos procedimentos de análise de políticas de segurança com o auxílio do metamodelo. 


\section{ANÁLISE DE POLÍTICAS DE SEGURANÇA PARA SISTEMAS DE GRANDE PORTE}

\subsection{Objetivos da análise}

Como discutido na seção 2.4, para um contexto específico, uma política de segurança é constituída por uma série de diretivas formuladas para atender a princípios genéricos e independentes de implementação a respeito dos requisitos ligados aos serviços de segurança que se deseja fornecer.

De um ponto de vista lógico, é necessário garantir que a representação dessas diretivas seja:

- completa, ou seja, todas as situações possíveis do sistema têm sua arbitragem prevista;

- não redundante, isto é, para qualquer situação passível de arbitragem, existe uma única regra que a rege;

- consistente, ou seja, não existem duas regras tais que, para alguma situação, a primeira autoriza a ação pretendida e a segunda a nega.

Além dessa validação lógica, é essencial colher evidências da equivalência semântica entre as diferentes representações da política de segurança, ou seja, verificar que o modelo do sistema ou a implementação do próprio reflete o conjunto de regras enunciado. 
Dentro do contexto de interesse, pode-se notar que políticas de segurança definidas de acordo com o metamodelo descrito serão inerentemente não redundantes, uma vez que apenas uma única função rege a autorização de cada ação especificada para comunicação. Serão também consistentes por conta da mesma característica, pois a arbitragem de cada ação por uma única função implica uma decisão determinada para cada condição existente. Finalmente, as políticas serão também completas, pois a lógica de autorização está definida para todas as possíveis interações com o sistema.

Contudo não fica evidente pela observação das definições de um modelo construído como proposto se o mesmo é equivalente ao enunciado da política de segurança que orienta sua construção. Portanto, para demonstrar a aplicabilidade do metamodelo, é preciso identificar técnicas adequadas para analisar políticas de segurança que permitam garantir a sua equivalência frente a sua especificação de alto nível.

Uma propriedade adicional que pode ser desejada em definições de políticas de segurança é sua aplicabilidade total ${ }^{1}$, isto é, que as condições para aplicação de todas as regras definidas verifiquem-se para algum modo de operação do sistema. Entende-se com isso que uma política totalmente aplicável é aquela na qual não há regras cujos efeitos nunca chegam a ser exercitados por impossibilidade de satisfação de seus requisitos, seja por características do sistema ou por aplicação de outras regras. Um exemplo intuitivo é um conjunto de regras que contenha afirmações como " $X$ não deve ocorrer" em conjunto com "se $X$ ocorrer, então $Z$ ".

Como a estrutura do metamodelo não restringe o teor das funções de autorização, tais situações poderiam ser modeladas. Não procura-se identificar

\footnotetext{
${ }^{1}$ embora tal propriedade também possa ser vista como um tipo distinto de consistência (RIBEIRO et al., 2000), prefere-se separar os conceitos, já que a aplicabilidade total não é um requisito para a correta avaliação lógica da política.
} 
e impedir tais casos na análise, primeiramente, porque definições desse tipo nunca acarretarão na alcançabilidade de estados inseguros e portanto não configuram falhas de segurança e, além disso, porque pode ser do interesse do projetista da política representar requisitos abrangentes de maneira clara ainda que resultem em situações inalcançáveis, de maneira que, em caso de alteração futura da política, tal requisito permaneça garantidamente preservado.

O processo de análise discutido adiante procura cumprir dois propósitos: detalhar as atividades necessárias para a validação de uma política de segurança modelada segundo as abstrações do metamodelo e demonstrar, com 0 auxílio do exemplo utilizado no capítulo anterior, que uma análise como tal é factível sobre a estrutura do metamodelo, confirmando sua aplicabilidade em sistemas de workflow com regras associadas ao negócio.

\subsection{Metodologia da análise}

Ao definir modelos de políticas de segurança representáveis por redes de Petri coloridas, obteve-se a capacidade de analisar seus grafos de alcançabilidade, ou espaços de estados. Por consequência, qualquer estado interno que um modelo possa assumir estará representado nesse grafo e poderá ser identificado como um estado autorizado ou não autorizado. Esse paradigma de análise já foi explorado para diversos cenários (ATLURI; HUANG, 1996a; RAKKAY; BOUCHENEB, 2009; UEDA, 2012).

Para ilustrar tal paradigma, um raciocínio de análise sobre o exemplo da figura 6 (pág. 33) será de grande valia. Calculando o espaço de estados daquele modelo obtém-se 32 estados. É possível validar que a restrição descrita para o sistema modelado é atendida observando-se os estados nos quais 
existam marcas nos lugares $n$ e allowed. Para cada um deles, de acordo com os valores das marcas em $n$ e $O$, determina-se se o estado é autorizado ou não-autorizado segundo a definição do sistema. Daí, compreender-se-á o estado como seguro se a determinação for compatível com o valor da marca em allowed, e inseguro caso contrário. A tabela 2 lista os casos possíveis no modelo quando a marca em $n$ é $(A, q=1)$.

Tabela 2: Estados do exemplo do cap. 2 e suas classificações, para $(A, q=1)$ em $n$

\begin{tabular}{|c|c|c|}
\hline Lugar $O$ & Soma de $q$ em $O$ & Classificação \\
\hline\{\} & 0 & Autorizado \\
$\{(A, q=1)\}$ & 1 & Autorizado \\
$\{(A, q=2)\}$ & 2 & Não autorizado \\
$\{(A, q=1),(A, q=1)\}$ & 2 & Não autorizado \\
$\{(A, q=1),(B)\}$ & 0 & Autorizado \\
$\{(A, q=2),(B)\}$ & 0 & Autorizado \\
$\{(B),(A, q=1)\}$ & 1 & Autorizado \\
$\{(B),(A, q=2)\}$ & 2 & Não autorizado \\
\hline
\end{tabular}

Perceba-se, da tabela, que para um mesmo valor da marca em $n$ há mútiplos valores da marca em $O$ para os quais a classificação é a mesma. Sabe-se, do enunciado do sistema, que isto ocorre porque a classificação depende, mais especificamente, da soma dos parâmetros $q$ das operações $A$ ocorridas após a última execução de $B$. Portanto, se o modelo for modificado para que $O$ passe a armazenar apenas o valor dessa soma, a quantidade de estados existentes deverá diminuir em relação à versão anterior. De fato, o número de estados nesse caso passa a 12, que são visíveis na figura 11 .

Com a modificação do modelo, a quantidade de informação disponível em cada estado foi reduzida: onde antes era sabida a sequência específica de operações executadas e, com isso, as parcelas constituintes da soma dos parâmetros $q$, agora sabe-se apenas o resultado da soma. É justamente este fato que exige uma modificação no paradigma de análise: se uma vulnerabilidade for inserida no modelo por conta do processamento da informação, a 


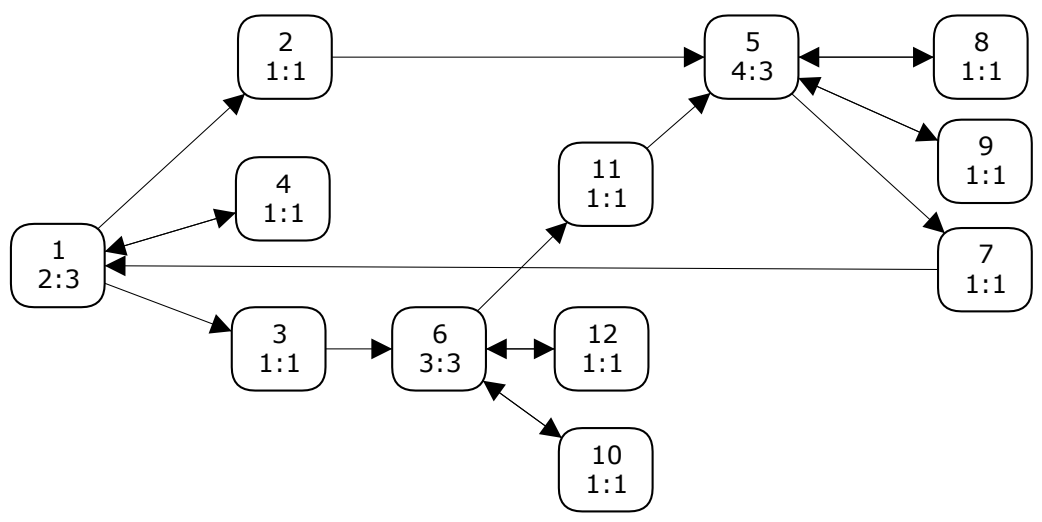

Figura 11: Espaço de estados do modelo do cap. 2 (fig. 6) otimizado

mesma não poderá ser reconhecida pela avaliação de um estado isolado, pois o estado contém apenas a informação já processada.

Como exemplo de vulnerabilidade inserida pelo processamento da informação, imaginemos que a função que processa a entrada e atualiza o lugar $O$, incremente 0 valor da marca em uma unidade a cada operação $A$ autorizada, ignorando o valor do parâmetro $q$. Se a avaliação de segurança observar os estados da rede individualmente, julgará que todos os estados alcançáveis são seguros, pois há coerência entre o valor em $O$, que deveria representar a soma dos parâmetros $q$, e a classificação dada pelo modelo. Porém, tendo ciência da informação descartada - das parcelas da soma - sabe-se que há classificações irregulares. A tabela 3 mostra as distorções existentes.

Tabela 3: Casos do exemplo do cap. 2 após inserção de vulnerabilidade, para $(A, q=1)$ em $n$

\begin{tabular}{|c|c|c|c|}
\hline Últimas operações & Valor em $O$ & Classificação & Avaliação \\
\hline\{\} & 0 & Autorizado & Seguro \\
$\{(A, q=1)\}$ & 1 & Autorizado & Seguro \\
$\{(A, q=2)\}$ & 1 & Autorizado & Inseguro \\
$\{(A, q=1),(A, q=1)\}$ & 2 & Não autorizado & Seguro \\
$\{(A, q=1),(B)\}$ & 0 & Autorizado & Seguro \\
$\{(A, q=2),(B)\}$ & 0 & Autorizado & Seguro \\
$\{(B),(A, q=1)\}$ & 1 & Autorizado & Seguro \\
$\{(B),(A, q=2)\}$ & 1 & Autorizado & Inseguro \\
\hline
\end{tabular}

A fim de justificar a solução encontrada para o problema, mais uma obser- 
vação sobre a natureza dos modelos é necessária. Para um modelo abrangente segundo a definição 3.1 (pág. 44), a decisão entre autorizar e negar cada requisição é função dos parâmetros da própria requisição e do estado interno do sistema. Ora, se no instante de chegada da k-ésima requisição $r_{k}, 0$ estado do sistema é dado por $s_{k-1}$, então a decisão tomada será $\omega\left(s_{k-1}, r_{k}\right)$ e 0 sistema passará ao estado $s_{k}=\delta\left(s_{k-1}, r_{k}\right)$. Pode-se deduzir, então, que para a requisição seguinte $r_{k+1}$, a decisão tomada será $\omega\left(s_{k}, r_{k+1}\right)=\omega\left(\delta\left(s_{k-1}, r_{k}\right), r_{k+1}\right)$. Desse ponto, é notável que pela possibilidade de aplicação recursiva da função $\delta(\cdot)$, a decisão sobre a k-ésima requisição pode ser descrita em função das $k$ requisições recebidas sem que se referencie qualquer estado interno do sistema além do estado inicial $s_{0}$.

Tal propriedade indica que é possível recuperar, no momento da análise, qualquer informação descartada como forma de reduzir o espaço de estados do modelo. Em uma modelagem na forma de rede de Petri, as entradas do sistema são representadas por marcas presentes em algum subconjunto dos lugares da rede. Logo, para um determinado estado que se deseja analisar, a sequência de entradas à qual o sistema foi submetido para chegar àquele estado pode ser caracterizada pelas marcas presentes nesses lugares no estado de interesse e em todos os seus antecessores por todos os caminhos possíveis a partir da marcação inicial da rede.

No exemplo abordado, as entradas submetidas ao sistema são exatamente representadas pelas marcas presentes no lugar $n$, portanto, a forma de reaver as parcelas da soma e detectar a vulnerabilidade descrita é navegar pelo espaço de estados no sentido contrário, partindo do estado em análise em direção ao estado inicial. Se a restrição puder ser satisfeita por todos esses caminhos, o estado estará demonstrado como seguro.

Relacionando esta metodologia de análise com o tipo de modelo definido 
neste trabalho, observa-se que a estrutura proposta no metamodelo, em si, não impõe uma representação dos estados e, portanto, não garante que 0 número de estados de um modelo seja mínimo para a correta modelagem de uma política. Porém, em vista do argumento exposto, pressupõe-se que 0 modelador buscará tal minimização e consequentemente deverá valer-se do método de verificação por caminhos, como fez-se para o modelo do sistema financeiro, que voltará a ser discutido na seção seguinte.

Portanto, aqui a metodologia de análise é proposta com algumas particularidades: inicialmente as regras de segurança devem ser enunciadas de maneira a exprimir informações a respeito do caminho que as caracteriza dentro do espaço de estados, ou seja, as sequências de operações autorizadas e não-autorizadas dentre os possíveis workflows. Em seguida, deve-se planejar a verificação da presença de estados não autorizados pela construção de predicados expressos em função desses caminhos sobre o espaço de estados. A análise é projetada de maneira particionada graças a características do metamodelo que serão evidenciadas nas seções seguintes e enfim executada revelando se há ou não observância às regras de segurança avaliadas pelo modelo.

\subsection{Formulação precisa de regras de segurança}

Antes que se possa construir predicados para avaliação do espaço de estados da rede de Petri do modelo em análise, é preciso certificar-se de que a formulação das regras de segurança pode ser expressa de acordo com 0 paradigma de sistema que o modelo adota.

Como discutido, pressupondo conhecimento das regras, é possível determinar a saída desejada do sistema apenas pela observação das sucessivas 
entradas que o mesmo recebe. Portanto, podemos definir uma formulação para as regras de segurança que seja independente das informações processadas em cada estado do modelo e que possa ser validada pelo reconhecimento das sequências de requisições autorizadas e não autorizadas e do estado inicial do modelo.

Ao final, o que se quer dessa formulação é que ela consiga: eliminar ambiguidades inerentes ao enunciado de regras em linguagem natural, ter um escopo bem delimitado para cada regra e preservar a equivalência semântica com as regras em linguagem natural da maneira mais cognitiva possível.

A formulação definitiva das regras de segurança será atingida pela definição dos predicados para consulta ao espaço de estados da CPN do modelo. Entretanto, um passo intermediário é estabelecido com o uso de uma notação especial a fim de obter uma indicação mais clara das dependências sequenciais das requisições na lógica das regras.

A expressão abaixo representa a regra (1) da política de exemplo utilizada no capítulo 3 utilizando tal notação (com o significado de cada símbolo dado na sequência):

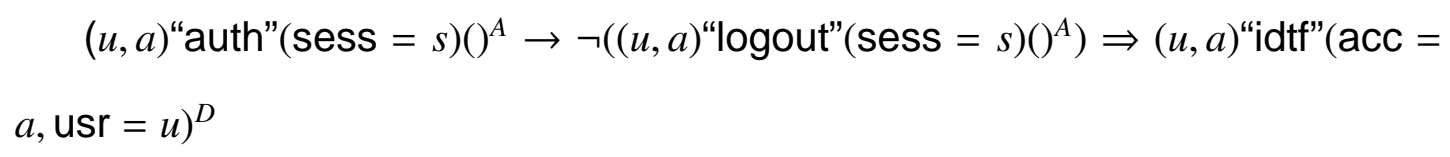

$\alpha \Rightarrow R^{\beta}$ significa que se as condições $\alpha$ forem respeitadas, a decisão $\beta$ deve ser aplicada à requisição $R . R^{D}$ indica a negação do pedido de $R \cdot R^{A}$ indica a autorização do pedido de $R$. O operador $Q \rightarrow R$ indica que $R$ foi processada depois de $Q$ (não necessariamente imediatamente depois). 0 operador $\neg R$ indica que $R$ não foi processada. 
O primeiro par de parênteses após o nome de cada ação envolve os parâmetros da requisição e o segundo, os parâmetros da resposta (logo, não há um segundo par de parênteses para a requisição em análise). Portanto, lê-se a regra como: "Requisições do usuário u para a ação idtf na conta a devem ser negadas caso tenha ocorrido um processamento prévio autorizado de uma ação auth para o mesmo usuário e conta em uma sessão s que não tenha sido seguido por uma requisição autorizada para a ação logout, também na sessão s.".

Não se pretende formalizar completamente a especificação de tal notação neste trabalho. Ela é empregada apenas como um apoio para caracterizar os condicionais que indicam a sequencialização das requisições na lógica expressa nos predicados sobre o espaço de estados do modelo. Isto objetiva facilitar a assimilação pelo leitor, mesmo porque a expressividade da notação é limitada a regras mais simples. Para regras geradoras de linguagens mais complexas, outros tipos de representação são necessários, como será notável por algumas modificações empregadas nos demais exemplos. Uma formalização suficientemente expressiva para uma classe definida de regras é fruto do interesse de trabalhos futuros, como será discutido adiante.

Portanto, para as demais regras do exemplo:

2) A regra indica que qualquer ação deve ser negada ao usuário $u$ na conta $a$ caso três tentativas de autenticação tenham sido negadas anteriormente, sem que tenha havido tentativas autorizadas entre elas para os mesmos usuário e conta. A ação vazia (“_") representa qualquer ação existente no sistema. Assim:

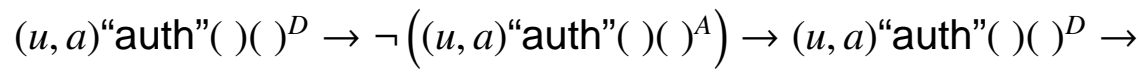

$$
\begin{aligned}
& \left.\neg\left((u, a) \text { "auth" }()()^{A}\right) \rightarrow(u, a) \text { "auth"( }\right)()^{D} \Rightarrow(u, a)^{\prime \prime}{ }_{-} \text {"( ) }{ }^{D}
\end{aligned}
$$


3a) A regra diz que um pedido de saldo será negado caso não tenha existido requisição de autenticação de login autorizada para os mesmos usuário, conta e sessão. Logo:

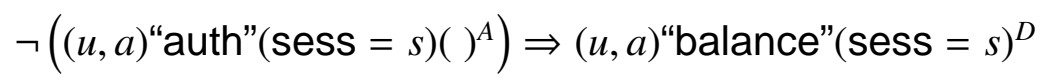

3b) A formação da regra é análoga à anterior, para a ação inicial do fluxo de transferência:

$\neg\left((u, a)\right.$ "auth" $($ sess $\left.=s)()^{A}\right) \Rightarrow(u, a)^{\text {"eft_ini" }}$ _sess $\left.=s\right)^{D}$

4) A regra impede a ação de efetivação de transferência caso o usuário requisitante tenha o papel de auxiliar:

$(u, a)$ "eft_conf"( $)^{D}, u=$ "auxiliar"

5) A regra impede a ação de efetivação de transferência caso a senha fornecida para o usuário não coincida com o seu registro nos parâmetros da conta para transferências:

$(u, a)$ "eft_conf" $(\text { pass }=p)^{D}$,

$p \neq p_{\text {real }}:\left(\right.$ chave_senha $\left.(u), p_{\text {real }}\right) \in P_{\mathrm{TC}}(\mathrm{EFT}, a)$

6) A regra impede a ação de efetivação da transferência $t_{k}$ pelo usuário $u$ na conta $b$ caso a conta de crédito $a_{k}$ não pertença ao conjunto de contas que constitui o parâmetro "registradas" da tarefa de transferências da conta $b$ e a soma dos valores de transferências aprovadas anteriormente para o mesmo usuário e conta supere o valor de 500. Como é necessário representar uma quantidade indefinida de requisições prévias de transferências, denota-se a repetição com o uso dos símbolos $[\ldots]^{i}$ :

$\left[(u, b) \text { "eft_forms" }(v a l=v, \text { dest }=a)(i d t=t)^{A} \rightarrow(u, b) \text { "eft_conf" }(i d t=t)^{A}\right]^{i} \rightarrow$ $(u, b)$ "eft_forms" $\left(v a l=v_{k}\right.$, dest $\left.=a_{k}\right)\left(i d t=t_{k}\right)^{A}$ 
$\Rightarrow(u, b)$ "eft_conf" $\left(i d t=t_{k}\right)^{D}$,

$a_{k} \notin R_{b} \wedge v_{k}+\sum_{i}\left(v_{i} \mid a_{i} \notin R_{b}\right)>500:$ ("registradas", $\left.R_{b}\right) \in P_{\mathrm{TC}}(\mathrm{EFT}, b)$

7) A regra é similar à anterior e impede a ação de efetivação da transferência $t_{k}$ pelo usuário $u$ na conta $b$ caso a conta de crédito $a_{k}$ pertença ao conjunto de contas que constitui o parâmetro "registradas" da tarefa de transferências da conta $b$ e a soma dos valores de transferências aprovadas anteriormente para o mesmo usuário e conta supere o valor de 1500:

$\left[(u, b) \text { "eft_forms" }(v a l=v, \text { dest }=a)(i d t=t)^{A} \rightarrow(u, b) \text { "eft_conf" }(i d t=t)^{A}\right]^{i} \rightarrow$ $(u, b)$ "eft_forms" $\left(v a l=v_{k}\right.$, dest $\left.=a_{k}\right)\left(i d t=t_{k}\right)^{A}$

$\Rightarrow(u, b)$ "eft_conf" $\left(i d t=t_{k}\right)^{D}$,

$a_{k} \in R_{b} \wedge v_{k}+\sum_{i} v_{i}>1500:$ ("registradas", $\left.R_{b}\right) \in P_{\mathrm{TC}}(\mathrm{EFT}, b)$

Verifica-se no exemplo, conforme argumentado anteriormente, que toda a lógica das regras pode ser expressa em função das requisições anteriores e parâmetros iniciais do modelo.

A representação mais correta para as duas últimas regras deveria evidenciar o fato de que a ordem de ocorrência de todas as requisições prévias é livre, exceto pela necessidade de que cada efetivação de transferência susceda a sua preparação correspondente. Tal fato poderia ser expresso pela representação da regra na forma de uma gramática, mas isto vai contra 0 propósito da definição desta notação que é prover clareza para as definições das regras em função das sequências de requisições que as caracterizam. 0 comportamento correto será exposto pela definição em forma de predicado.

Para analisar completamente o cenário concebido, além dessas 8 regras, cada restrição de sequência de workflow deve gerar uma regra adicional, afirmando, por exemplo, que a aprovação de uma transferência (ação "eft_conf") 
deve sempre seguir sua definição (ação "eft_forms").

\subsection{Consultas sobre o espaço de estados da CPN}

Dado um conjunto de condições iniciais, a CPN resultante de um modelo pode ser processada para gerar o grafo de todo os estados possíveis que ela pode assumir. Já que o número desses estados pode ser grande demais para permitir uma análise manual, a ferramenta CPN Tools permite ao modelador automatizar a busca por estados com propriedades específicas por meio da execução de consultas que descrevem essas propriedades e filtram o espaço de estados.

Transportando o conceito de entradas e saídas do sistema visto na seção 3.1 (pág. 43) a uma CPN, tem-se o modelo da figura 12. Os tipos de requisição são armazenados em um único lugar e selecionados, um a um, para envio ao modelo do WfS, que está separado deste por uma modelagem hierárquica. O retorno inclui a informação da decisão do sistema - autorização ou rejeição do pedido - e pode ou não desencadear o envio de uma nova requisição, de acordo com critérios de parada. Essa estrutura garante que 0 espaço de estados resultante da análise da CPN contenha todas as possíveis sequências de requisições até a satisfação do critério de parada ou até que a estabilização dos estados internos do modelo faça com que sequências mais longas de requisições representem ciclos no espaço de estados da rede.

Da maneira como definiu-se a forma de uma requisição, o número de parâmetros que podem estar presentes em cada uma é ilimitado. Além disso, também não há restrições do metamodelo quanto ao valor atribuído a cada parâmetro. Sendo assim, da mesma maneira como ocorre num sistema real, não é possível enumerar todos os tipos de requisição possíveis para um dado 


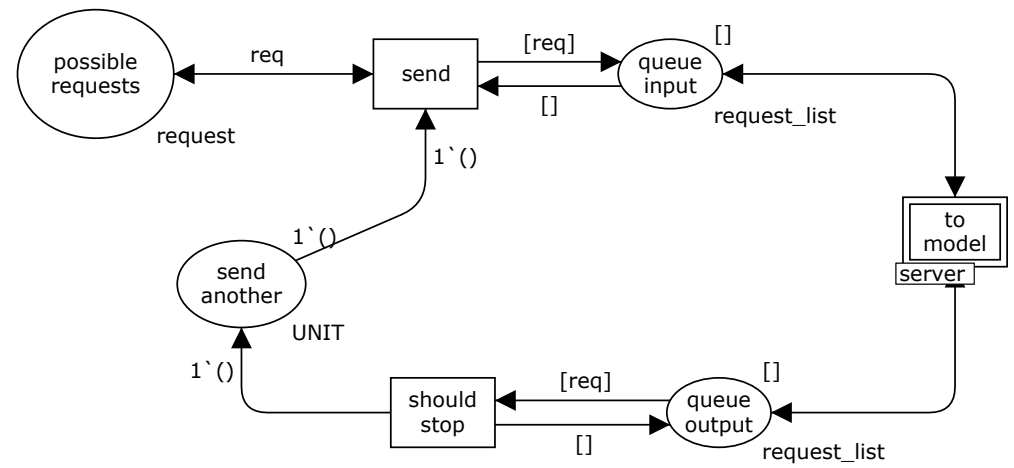

Figura 12: CPN representando o modelo de comunicação com o WfS

modelo de sistema. Sabe-se, contudo, que para que se possa exercitar todos os estados internos do modelo que podem influenciar a tomada de decisões de segurança, isso não é necessário.

Tal fato é ilustrável pela discussão dos tipos de requisição de formatação de transferência necessários para que se verifique a observância à regra (6) do exemplo de política (pág. 65). Como a regra especifica um limite de $\$ 500$ na soma dos montantes transferidos por todas as operações da conta, ao avaliar uma transferência de valor $v$ sendo que o total já transferido pela conta é dado por $V$, as seguintes situações serão possíveis:

$$
\begin{aligned}
& \cdot v>500 \\
& \cdot v=500 \\
& \cdot v+V>500, v<500 \\
& \cdot v+V=500, v<500 \\
& \cdot v+V<500
\end{aligned}
$$

Ou seja, os estados relevantes para a avaliação do comportamento do modelo são aqueles que caracterizam as condições de contorno especificadas pelas 
regras. Nesse caso, incluindo-se os valores de $\$ 200, \$ 250, \$ 500$ e $\$ 600$ nos tipos de requisição definidos, consegue-se reproduzir todos os casos acima.

Outras restrições à livre execução da CPN podem ser necessárias para garantir que o número de estados resultante da análise do modelo seja finito ou suficientemente pequeno para uma análise factível. Tais restrições dependem da lógica empregada nas definições de regras e, logo, devem ser únicas para cada modelo. Limitações esperadas devem incluir o número de sessões simultâneas permitidas e critérios de parada como um número limite de requisições negadas ou de sessões finalizadas. Assim como na restrição dos tipos de requisição disponíveis, é essencial que o modelador se certifique de que as limitações aplicadas não previnem a identificação de falhas de segurança.

Voltemo-nos novamente às regras de segurança especificadas no exemplo. Note-se que cada uma delas postula uma condição suficiente porém não necessária para a decisão sobre a ação que arbitra. Consequentemente, se uma regra afirma que uma requisição $R$ deve ser negada quando satisfizer as condições $\alpha$, para testar essa regra, deve-se buscar estados nos quais $\mathrm{R}$ satisfaz as condições $\alpha$, e ainda assim tenha sido autorizada. Como a análise de espaço de estados é projetada para cobrir todas as situações possíveis, se nenhum estado como tal puder ser encontrado, então a regra foi atendida.

Na ferramenta CPN Tools, a função PredAllNodes permite que se filtre 0 espaço de estados gerado de acordo com algum predicado, normalmente afirmando propriedades de uma marcação. Além disso, combinando as funções InArcs e SourceNodes, pode-se obter uma lista dos estados imediatamente antecessores de qualquer estado de interesse. Aplicando-as recursivamente, é possível gerar a lista ordenada de todos os caminhos acíclicos levando aos estados que satisfazem o segundo membro de qualquer regra. Com o auxílio das funções PredAllSccs e SccToNodes, também é possível determinar todos 
os conjuntos de estados formando ciclos no grafo de espaço de estados. Assim, testar qualquer regra expressa em nossa notação torna-se questão de verificar a presença ou ausência de estados representando as restrições da regra nas listas e para algum ou todos os caminhos que levam a um conjunto de estados.

Para a maioria das regras, contudo, alguma simplificação é possível e desejada para otimizar o desempenho da consulta. O pseudocódigo a seguir mostra a estrutura da consulta para validação da regra (7), que é um bom exemplo de regra complexa, de acordo com a lógica empregada para execução da consulta na ferramenta CPN Tools.

1: confs $\leftarrow$ todo os estados nos quais uma ação "eft_conf" tenha sido autorizada

2: for all estados $s_{1}$ em confs do

3: if $s_{1}$ está contido em um ciclo then

4: $\quad$ adiciona $s_{1}$ a estados_inseguros

5: end if

6: for all estados $s_{2}$ em caminhos acíclicos $\mathrm{p}$ de $s_{1}$ reversamente até 1 do

7: $\quad$ if uma ação "eft_conf" foi autorizada em $s_{2}$ and conta $\left(s_{2}\right)=\operatorname{conta}\left(s_{1}\right)$ and usuário $\left(s_{2}\right)=$ usuário $\left(s_{1}\right)$ then

8: $\quad$ adiciona parâmetro tid de $s_{2}$ à lista t

9: $\quad$ end if

10: if uma ação "eft_forms" foi autorizada em $s_{2}$ and conta $\left(s_{2}\right)=\operatorname{conta}\left(s_{1}\right)$ and usuário $\left(s_{2}\right)=$ usuário $\left(s_{1}\right)$ and parâmetro acc de $s_{2}$ está na lista de contas registradas de conta $\left(s_{1}\right)$ and parâmetro tid de $s_{2}$ está na lista t then

11: $\quad$ limite_consumido $\leftarrow$ limite_consumido + (parâmetro val de $s_{2}$ )

12: remove tid da lista $\mathrm{t}$ 


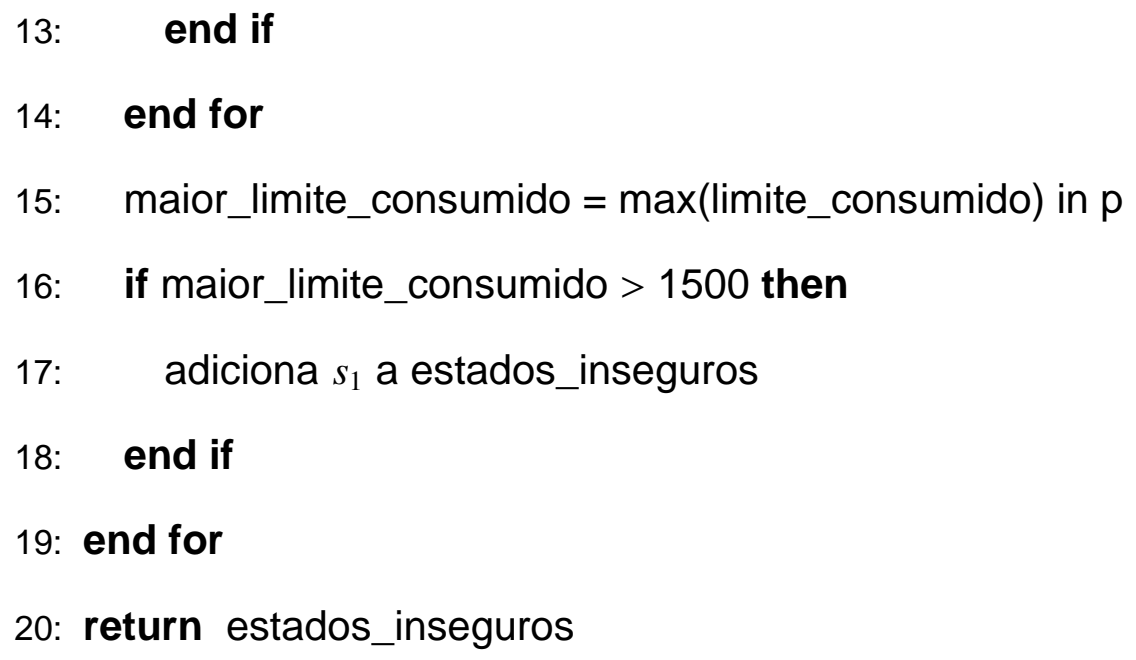

Interpretando o algoritmo, vemos que a consulta baseia-se em efetivações de transferências autorizadas, pois a regra especifica sua negação e estamos buscando os estados que a violam. A primeira verificação atesta que se há efetivações de transferência contidas em caminhos cíclicos, então certamente, como os valores transferidos têm de ser maiores que zero, existem fluxos possíveis de execução que excedem o limite estipulado. Após isso, para cada efetivação autorizada, computa-se os caminhos acíclicos que levam até ela, somando os montantes transferidos ao longo da execução de cada um deles. Se a maior soma exceder o limite, o estado terá violado a regra.

Perceba-se que o algoritmo é bastante custoso para um grafo com muitos estados, porém, se tentássemos fazer com que o modelo preservasse em cada estado a informação relativa ao caminho percorrido, o algoritmo seria mais simples mas o número de estados cresceria imensamente. Se, por outro lado, procurássemos verificar o atendimento da regra por meio de suposições a respeito da representação interna dos estados (e.g.: no caso exemplificado, isto seria equivalente a verificar o valor de um parâmetro da conta que controla o limite ainda disponível), estaríamos sujeitos a erros lógicos decorrentes de discrepâncias entre as suposições utilizadas para a modelagem do comportamento desejado e o comportamento verdadeiro (e.g.: um erro aritmético no 
cálculo do limite disponível para as transferências que ocorreria na modelagem e estaria indetectável pela consulta). Ao exprimir a lógica da consulta em função exclusivamente das requisições emitidas e do estado inicial do modelo, ataca-se o problema por outra dimensão, eliminando qualquer pressuposição de modelagem correta.

Para cada regra da política, foi escrita uma consulta como a demonstrada, a qual seleciona todos os estados inseguros existentes no espaço de estados sob a ótica da regra. Caso algum estado seja retornado, existe vulnerabilidade no modelo e o estado retornado deve ser inspecionado. Caso contrário, o modelo é seguro segundo as sentenças da política modeladas pelas consultas.

A sintaxe e funções auxiliares para navegar o espaço de estados estão todas documentadas em (J ENSEN; CHRISTENSEN; KRISTENSEN, 2006).

\subsection{Partição da análise}

Em muitos sistemas de workflow (ATLURI; HUANG, 1996a; XU et al., 2012; UEDA, 2012), as possíveis sequências de ações que podem ser requisitadas por um usuário são poucas, e podem ser completamente incluídas no modelo. Contudo, há sistemas onde uma maior variedade de casos de uso são viáveis, levando qualquer tentativa de modelar todos os possíveis fluxos de trabalho a gerar um espaço de estados grande demais para análise. Isto é um caso direto do problema da explosão de estados da área de verificação de modelos. Para tais casos, uma estratégia mais minuciosa se faz necessária (GROOTE; KOUTERS; OSAIWERAN, 2012; HUANG; KIRCHNER, 2011). A solução encontrada está fundamentada na partição da análise dos modelos.

É razoável presumir que, para a maioria dos sistemas, serviços distintos frequentemente consistem de workflows independentes e, portanto, tarefas ou 
grupos de tarefas podem ser os elementos centrais de uma divisão da análise. A estruturação do metamodelo, com essa finalidade, separa os domínios de dados que constituem o estado interno de cada tarefa.

Note-se que a decisão a respeito de uma requisição segundo estipulado pelo metamodelo é uma função dos parâmetros de um par (conta, tarefa) e de um nível de autorização da tripla (usuário, conta, tarefa), ao passo que as funções de atualização de estado para esses mesmos parâmetros e para esse nível de autorização são executadas para todas as tarefas. Na prática, isto significa que ao atualizar um estado, uma ação que é parte de uma certa tarefa pode ou não alterar parâmetros para outra tarefa como desejar, mas a decisão sobre a autorização é sempre baseada apenas em parâmetros exclusivos da tarefa que abriga a ação cuja execução é pretendida.

Inspecionando as definições para funções de atualização de estados, pode-se determinar sobre quais tarefas cada ação exerce influência, identificando pares de tarefas para os quais nenhuma de suas ações altera parâmetros ligados à outra. Nessa situação, pode-se dizer que as tarefas são independentes e suas análises podem ser realizadas separadamente, exceto se alguma delas promover alterações de estado na sessão ou, mais sutilmente, se uma ação influenciar uma terceira tarefa que, por sua vez, influencia aquela supostamente independente da primeira. A ressalva a respeito da alteração de parâmetros da sessão é necessária porque, ao contrário do que ocorre para as contas e usuários, os parâmetros da sessão não são separados em domínios de tarefas, justamente para permitir que hajam informações universalmente visíveis no modelo. Por consequência disso, é aconselhável que 0 modelador evite o uso de parâmetros de sessão para que não dificulte desnecessariamente a análise.

A maneira de separar a análise de tarefas é alterar o conjunto de tipos de 
requisição disponíveis para avaliação, excluindo aquelas cujas ações pertencem ao fluxo da tarefa reconhecida como independente do lugar da CPN que as contém, visto na figura 12 .

Outras subdivisões mais simples podem ser obtidas mesmo quando existem dependências entre tarefas, eliminando os tipos de requisições das tarefas dependentes daquela que se deseja analisar que não são necessários ao fluxo que de fato afeta a tarefa de interesse, por exemplo, requisições com parâmetros inválidos que já se demonstrou serem adequadamente rejeitadas.

Avaliações com múltiplos usuários, contas e sessões também serão desnecessárias para muitos casos, posto que a alteração de parâmetros permitida pelo metamodelo é limitada ao escopo da conta e usuário que executam a ação. Isto só será diferente caso a atualização da sessão modifique seu usuário ou conta associada, o que normalmente só faz sentido durante um login.

Como simplificação adicional, a menos que a política de segurança a analisar contenha regras tais como a regra (2) do exemplo, onde consequências de uma requisição negada são especificadas, as funções de atualização de estados para os casos nos quais não ocorre autorização da ação deverão ser inertes e, então, o recebimento de uma resposta de requisição negada pode ser utilizado como condição de parada da execução da CPN, eliminando diversos caminhos cíclicos no grafo do espaço de estados e agilizando a avaliação de predicados.

\subsection{Validação da análise}

Apresentam-se alguns resultados da análise realizada sobre o cenário de exemplo. A partir da definição das consultas para regras e de acordo com as 
observações de minimização de espaço de estados, a análise foi particionada em oito casos. Isto significa que oito valores de $C$ distintos foram modelados, de acordo com a definição formal em 3.10. Para cada caso, um conjunto de tipos de requisição diferente foi disponibilizado para a geração de fluxos. Dentro de cada caso, a análise de espaço de estados garante que todas as sequências destes tipos de requisição são exercitadas. Para cada requisição processada, o modelo indica se a mesma foi ou não autorizada, permitindo a rastreabilidade dos fluxos autorizados e com isso, do reconhecimento das regras atendidas.

O primeiro caso exercitado é de rápida avaliação e contém apenas um tipo de requisição de cada ação necessária para que se complete uma consulta a saldo. Esse teste permite verificações gerais a respeito do controle de autenticação. 0 segundo caso tem o propósito de validar totalmente o serviço de login. Diversas variações incluindo requisições de formatação inválida são incluídas a fim de identificar quaisquer vulnerabilidades ocultas que porventura tenham sido criadas por consequência dos mecanismos de aplicação das regras de segurança. Como durante o procedimento de autenticação a sessão é associada a uma determinada conta e usuário, requisições partindo de diferentes combinações de contas e usuários também são previstas. A dependência do login pelos serviços de saldo e transferência é da mesma natureza, portanto inclui-se apenas algumas variações de pedido de saldo para este caso de validação mais completa, uma vez que esta operação é mais simples e deve reduzir o esforço de análise.

O terceiro caso inclui também a possibilidade de realização de transferências sem muitas variações e exclui as diversas requisições de formato inválido e variações de usuários e contas acessados do caso anterior, pois pelo conhecimento do modelo e pelo mapeamento de dependências explicado an- 
teriormente, sabe-se que quaisquer problemas nas definições de segurança relativas a esses itens teriam sido notáveis na análise do caso anterior.

0 quarto, quinto e sexto casos exploram, separadamente, as possibilidades de uso de mais de uma conta, o perfil mais simples de usuário e a combinação do acesso com os dois perfis definidos completando a validação das regras de transferência e saldo e suas interações com o login. Salvo pela eventualidade da interferência de uma dada conta em outra, a interação entre contas é limitada o suficiente para que não seja necessária a inclusão de experimentos com o acesso a mais de duas contas.

O sétimo e oitavo casos exercitam as diversas combinações de valores de transferência para contas não registradas e registradas para validação das regras de limites.

A tabela 4 resume o conteúdo de cada caso e apresenta alguns dados indicativos do esforço de análise. A listagem completa das variações de requisições cobertas por cada caso pode ser vista no apêndice $B$. No apêndice $C$ podem ser vistas as evidências da coleta de dados referentes à tabela.

Tabela 4: Detalhes das divisões da análise do exemplo

\begin{tabular}{|c|c|c|c|c|}
\hline Caso & $\begin{array}{c}\text { Tipos de } \\
\text { requisição }\end{array}$ & $\begin{array}{c}\text { Regras } \\
\text { avaliadas }\end{array}$ & Estados & $\begin{array}{c}\text { Tempo } \\
\text { cálculo }\end{array}$ \\
\hline mínimas p/ fluxo de saldo & 4 & 1,3 & 268 & $<1 \mathrm{~s}$ \\
variações login e saldo & 12 & $1,2,3$ & 67117 & $173 \mathrm{~s}$ \\
mínimas p/ saldo e transf. & 8 & $2,4,7$ & 5262 & $2 \mathrm{~s}$ \\
saldo e transferência, 2 contas & 15 & $1,4,7$ & 94936 & $221 \mathrm{~s}$ \\
saldo e transf., "auxiliar" & 8 & $2,4,5$ & 453 & $<1 \mathrm{~s}$ \\
transf., "auxiliar" e "mestre" & 18 & $5,6,7$ & 36663 & $49 \mathrm{~s}$ \\
vários valores transf. & 10 & 7 & 62605 & $156 \mathrm{~s}$ \\
vários val. transf. registr. & 9 & 8 & 31818 & $42 \mathrm{~s}$ \\
\hline
\end{tabular}

Algumas restrições foram aplicadas para minimização do espaço de estados em alguns casos. Nos casos 2 e 5 utilizou-se o critério de parada de que após um pedido de "logout", apenas mais uma requisição fosse enviada. Isso 
é suficiente para que possamos verificar que a sessão realmente deixou de estar ativa por meio da regra (1). Nos casos 4, 6, 7 e 8, além da ação de "logout", também a negação de uma ação foi incluída como critério de parada.

0 tempo consumido pela execução das consultas também varia conforme o tamanho do espaço de estados. Para as consultas mais simples, das regras (1), (4) e (5), a execução se completa em poucos segundos. Para as demais, contudo, o tempo de execução é da mesma ordem de grandeza da geração do espaço de estados do caso avaliado. Vale ressaltar que a validação segundo o método proposto é uma tarefa executada numa única ocasião por modelo, o que significa que a espera pelos cálculos é tipicamente tolerável.

Adicionalmente, realizou-se um teste do cálculo do espaço de estados da união entre os tipos de requisição dos oito casos, totalizando 38 tipos, sem a aplicação dos critérios de parada. Após 18005 segundos (aproximadamente cinco horas), 404436 estados haviam sido contabilizados sem completar 0 cálculo do espaço de estados, como pode ser visto também no apêndice $C$. Isso evidencia o problema de explosão de estados teorizado e demonstra 0 ganho obtido pela partição da análise do modelo.

Para ilustrar a maneira com que uma consulta auxilia a detecção de vulnerabilidades no modelo, a figura 13 mostra uma seção do espaço de estados do caso 4 após a substituição da função de avaliação $\left(f_{A}\right)$ da ação de saldo por uma função que a autoriza incondicionalmente. A execução da consulta referente à regra (3a) nesta condição acusou, entre outros, o estado 1023 como inseguro. A sua inspeção revela que, de fato, nele ocorre a autorização de uma operação de saldo sem que tenha havido uma autenticação válida anteriormente em seu workflow. A vulnerabilidade criada se revela de maneira sutil, pois para explorá-la é necessário que uma segunda sessão de mesmo usuário e conta seja iniciada, a fim de que que esta segunda se aproveite da 


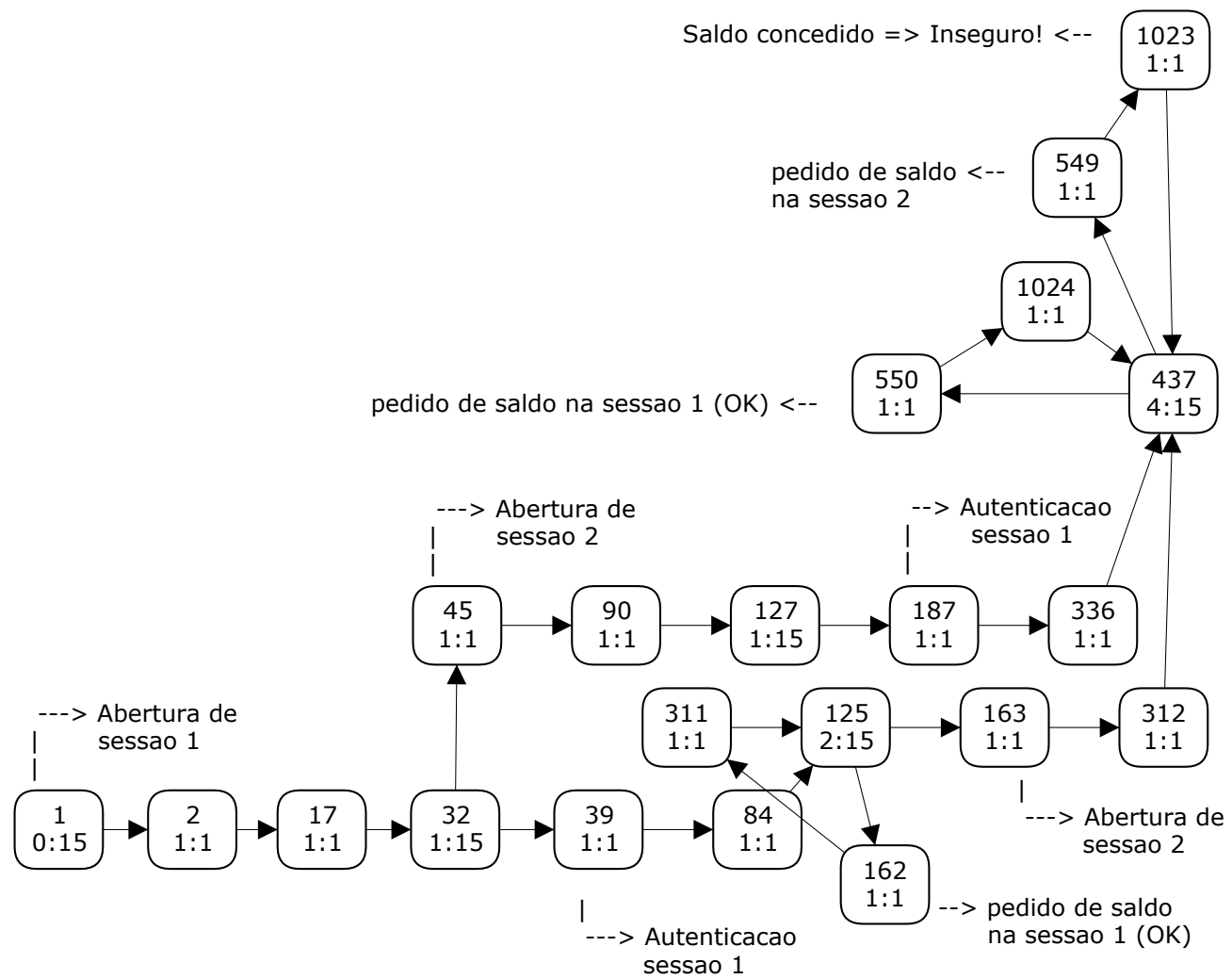

Figura 13: Seção do espaço de estados evidenciando estado inseguro

autenticação da primeira para ser vista como válida. Tal sequência de operações dificilmente seria testada caso não nos valêssemos da análise de espaço de estados. A função que foi substituída para causar a vulnerabilidade foi originalmente escrita após a descoberta deste problema pela consulta da regra (3a).

Em uma versão anterior da modelagem, um erro similar foi detectado: após uma autenticação rejeitada, o usuário conseguia executar as ações dos demais serviços normalmente como se a mesma tivesse sido bem sucedida. O problema havia sido inserido na função de atualização de níveis de autorização de usuário $\left(f_{C}\right)$ do caso de rejeição de ações de autenticação. Isto ocorreu quando foi programado o mecanismo para o bloqueio da conta após três tentativas falhas de autenticação. A lógica programada erroneamente lia-se "caso tenha havido duas tentativas anteriores de autenticação incorretas, remova 
as permissões do usuário. Do contrário, conceda as permissões de acesso", quando, evidentemente, as permissões do caso alternativo deveriam ser mantidas em seu estado anterior. Na versão final, um parâmetro de sessão auxilia a restrição do acesso quando a autenticação ainda não foi completada.

Das situações citadas vê-se que com a constatação do auxílio trazido pelas consultas ao espaço de estados durante a modelagem do exemplo, obteve-se um forte indício da sua valia no processo de especificação de políticas de segurança.

\subsection{Resultados obtidos e avaliação do processo}

Prevenir a explosão de estados envolve fazer presunções inteligentes ou simplificações durante a modelagem (GROOTE; KOUTERS; OSAIWERAN, 2012) e os limites aceitáveis do tamanho e tempo de cálculo do espaço de estados dependem da aplicação.

Os resultados mostrados indicam que o espaço de estados é de maneira geral mais sensível a um aumento no número de contas distintas do que variações de requisições. Esse fato pode ser compreendido como o efeito da necessidade de diversos estados intermediários causados pelas múltiplas ordens com as quais cada requisição pode ser enviada ao modelo quando muitos usuários o excitam simultaneamente. É importante notar que tolerar fluxos maiores para um único usuário é uma característica bastante positiva, já que permite a avaliação do efeito combinado de múltiplas tarefas realizadas em sequência, que é a análise necessária quando subdivisões não são possíveis.

Combinando esse fato, os vários mecanismos discutidos para redução do espaço de estados, a tratabilidade da estrutura geral de consultas baseadas em regras e a análise bem sucedida do caso de exemplo, há boas evidências 
da utilidade dos métodos propostos.

Em suma, tem-se que a especificação da política na forma de predicados é independente dos aspectos da modelagem da CPN sobre o metamodelo que são específicos para cada cenário e possui associação direta às regras do enunciado da política, mas justamente em função dessa associação direta, é uma especificação possivelmente incompleta, redundante e inconsistente. Já a modelagem com base no metamodelo está livre dessas falhas mas não é diretamente associável à especificação. O processo de análise definido garante essa associação validando a modelagem por CPN como representação da política de segurança, consequentemente garantindo a consistência da sua especificação.

Ainda assim, embora o processo possa garantir que o modelo construído respeita a todas as definições dadas pela especificação de alto nível, caso esta não seja completa, haverão situações não previstas pela política original. Como qualquer modelo elaborado em função do metamodelo aqui descrito será completo por construção, as arbitragens para os casos não contemplados pela política também estarão definidas por ele, mas possivelmente de maneira implícita e avessa ao desejo do modelador. o processo de análise como proposto não é capaz de evidenciar tais lacunas na especificação. Essa deficiência deve, para muitos casos, ser sanada na ocasião da modelagem como sugerem Baier e Katoen (2008) por tornar-se evidente ao modelador. A formalização da linguagem de formação de regras para casos específicos também pode simplificar a tarefa de evidenciar regras faltantes, como ocorre nos casos tratados por Xu et al. (2012).

Nesse sentido, a notação adotada para interpretação das regras em função das sequências de requisições é de fácil associação à especificação da política e permite representá-la de maneira adequada à construção de predi- 
cados para consulta ao espaço de estados. Da maneira como exposta, entretanto, a mesma ainda é insuficiente para regras de maior complexidade.

Adicionalmente, o modelo em CPN, agora validado como representação da política de segurança, é uma especificação muito mais útil à implementação da política num sistema real, por ser função de entidades muito próximas das abstrações que deverão ser empregadas para a reprodução do comportamento desejado em um software. 


\section{CONSIDERAÇÕES FINAIS}

O sucesso na modelagem da política de segurança do exemplo indica que atingiu-se uma definição para o metamodelo que satisfaz os requisitos de expressão de regras de autorização com lógica complexa e ligadas a parâmetros do modelo de negócio. A descrição de regras baseada na comunicação com o sistema e sua tradução para predicados do espaço de estados do modelo proveem um método viável de garantir o comportamento apropriado do mesmo e a consistência de um determinado conjunto de regras. 0 problema de explosão de estados foi evitado por meio de uma combinação da expressão das consultas ao espaço de estados em função dos caminhos no grafo de alcançabilidade e orientações para subdivisão da análise com equivalência de resultados garantida.

O método de análise discutido é suficiente para atestar se uma política de segurança modelada é consistente. Contudo, verificar se a mesma é completa e não redundante requer não só a conclusão de que a CPN do modelo representa totalmente a descrição da política como também que ambas são equivalentes. Uma possibilidade existente dentro do arcabouço construído é analisar o espaço de estados de maneira a extrair o conjunto de regras nele implícito, associando-o posteriormente à descrição original da política. Como a definição proposta do metamodelo também suporta essa linha de análise, atingiu-se 0 objetivo de fornecer uma abordagem para modelagem de políticas de segurança rica em lógica de negócio que é adequada para uma análise 
completa.

Acredita-se que as políticas de segurança construídas com a formalização documentada resultam em especificações que representam o comportamento dos sistemas num baixo nível de abstração, simplificando sua implementação em software e trazendo um valor adicional à sua adoção.

\subsection{Revisão de trabalhos relacionados}

Há, atualmente, diversas abordagens para o problema de modelagem e validação formal de políticas de segurança em estudo, com diferentes ramos de aplicabilidade. Para melhor situar as contribuições dadas, são revisados os trabalhos mais relacionados, dando ênfase às diferenças entre eles e o que se apresenta nesta dissertação.

Uma diferença significativa entre nossa abordagem e todas as demais na linha de Atluri e Huang (1996a), é que suas análises (ADAM; ATLURI; HUANG, 1998; ATLURI; HUANG, 2000) são focadas em encontrar um estado com propriedades que caracterizem incidentes de segurança, enquanto a nossa determina uma condição de insegurança pela localização de um caminho de estados. Ao adotar esse conceito, introduzimos um compromisso entre tempo de busca no grafo de espaço de estados do modelo e tamanho do mesmo espaço de estados que, dentro do nosso conhecimento, ainda não havia sido investigado pela literatura nessa área.

A definição de uma "dependência de valor" dada por Adam, Atluri e Huang (1998) se adequa à nossa tradução definitiva de uma regra complexa de negócio. Contudo, modelar como eles propõem requer o conhecimento de todos os possíveis resultados de cálculos durante o projeto do modelo, tornando a tarefa impraticável. Graças ao conceito de marcas coloridas, somos capa- 
zes de diferenciar estados atribuindo o resultado de um cálculo a uma marca, simplificando a modelagem.

A definição de um metamodelo sobre o qual a análise é fundamentada segue o mesmo rumo tomado na definição do SecureUML (BASIN; DOSER; LODDERSTEDT, 2003). No nosso caso, o modelo entidade-relacionamento substitui o uso da UML pelos autores, por ter-se dado maior ênfase ao tratamento da informação, sendo a dinâmica do modelo de responsabilidade da rede de Petri. Embora o metamodelo que eles definem seja, de maneira geral, de maior facilidade de compreensão, ele não é preparado para lidar com fluxos de trabalho e espcificações complexas de lógica de negócios. Além disso, a análise que eles propõem (BASIN et al., 2009) menciona que o suporte ao tratamento de estados do sistema, que poderia incluir a análise de workflows como propomos, necessitaria de reflexões acerca das consequências das fórmulas de suas especificações, e foi deixado para trabalhos futuros.

Mais recentemente, um processo de análise de modelos de RBAC (SANDHU et al., 1996) em fluxos de trabalho utilizando CPN que compartilha muitas características com o nosso foi descrito (RAKKAY; BOUCHENEB, 2009). Assim como os exemplos anteriores, sua formalização também exclui a habilidade de expressar restrições relacionadas a parâmetros de negócio e um tratamento para análise de casos muito complexos tal qual a partição de análise aqui discutida não existe.

Outra proposta (HUANG; KIRCHNER, 2011) na linha de simplificação de análises de políticas de segurança baseia-se em explorar os diferentes graus de dependência e interação entre atividades de um mesmo sistema modelando-as como módulos independentes e aplicando regras de composição. Isso se aproxima dos paradigmas que nortearam a subdivisão da análise como discutido anteriormente. Apesar de ser bastante rica nas possibilidades de 
composição de serviços, a proposta tem por foco avaliar o comportamento de algumas propriedades notáveis de redes de Petri após essas operações de composição entre os módulos, enquanto nosso trabalho interessa-se em fornecer diretivas para a análise de espaço de estados como um todo.

Por fim, Xu et al. (2012) utilizam um abordagem para o projeto de testes que possui semelhanças com a nossa, pois a "geração de mutantes", central em sua avaliação do método, é equivalente à enumeração dos tipos de requisições possíveis que se faz na análise apresentada. Além da omissão no tratamento de regras relacionadas a negócios como nos demais trabalhos, os autores mencionam que, para sistemas maiores, a análise de árvores de alcançabilidade poderia necessitar da divisão do sistema em submódulos independentes, mas não discorrem sobre como tal divisão poderia ser realizada. Ao introduzirmos a noção de restrição de domínios de dados para atualizações de estado, demos um passo maior na direção de fornecer uma orientação para a divisão desses sistemas de maior porte.

Tabela 5: Comparação entre trabalhos relacionados

\begin{tabular}{|c|c|c|c|c|c|}
\hline 10. Autor & $\begin{array}{c}\text { Modelagem de } \\
\text { segurança }\end{array}$ & Análise & $\begin{array}{c}\text { Lógica de } \\
\text { negócio }\end{array}$ & $\begin{array}{c}\text { Suporte a } \\
\text { workflows }\end{array}$ & > Escala \\
\hline Atluri & Sim & Sim & Sim & Sim & Não \\
Basin & Sim & Em parte & Não & Não & Sim \\
Rakkay & Sim & Sim & Não & Sim & Em parte \\
Xu & Em parte & Sim & Não & Sim & Não \\
Ortega & Sim & Sim & Sim & Sim & Sim \\
\hline
\end{tabular}

A tabela 5 resume a contribuição de cada abordagem e suas limitações com relação aos critérios relevantes segundo a definição de problema adotada para o escopo deste trabalho ao final do capítulo 2. Fica evidente que ao combinar a necessidade de expressão de regras de segurança contendo características de lógica de negócio com a necessidade de análise formal, nenhuma solução disponível tinha condições de fazê-lo para sistemas do mundo real. Nesse sentido, este trabalho (última linha da tabela) preenche uma la- 
cuna na literatura.

\subsection{Contribuições}

Identifica-se como principais contribuições:

- A proposta de um metamodelo capaz de representar de maneira precisa, inambígua, completa, não redundante e consistente uma política de seguranca para sistemas de serviços online com regras intimamente ligadas ao negócio;

- O desenvolvimento do conceito de separação de domínios de estados para subdivisão da análise, o que pode ser explorado em diversas outras áreas de aplicação de verificação de modelos;

- A introdução de um conceito de análise de fluxos de trabalho (workflows) que propõe um compromisso entre tempo de busca no grafo de alcançabilidade e o número de estados gerados;

- A demonstração de um exemplo do processo proposto para estabelecimento de equivalência entre o modelo CPN e a representação das regras de segurança baseada em predicados sobre o espaço de estados do modelo.

Materializou-se o sucesso no desenvolvimento dessas contribuições pela publicação de um artigo em periódico internacional da área (ORTEGA; RUGGIERO, 2013). 


\subsection{Trabalhos Futuros}

Os resultados alcançados dão margem à seleção de diversos objetos de pesquisa futura, dos quais ressalta-se:

O aperfeiçoamento mais direto do trabalho envolve a formalização de uma linguagem para descrição de regras de segurança cujas sentenças possam ser automaticamente interpretadas em função do espaço de estados da CPN do modelo. Com isso, o passo seguinte seria identificar, a partir da especificação da CPN, um conjunto mínimo de regras que resume seu comportamento. Assim, as limitações atuais da análise seriam totalmente superadas.

Outra modificação positiva seria a inclusão no metamodelo de um controle de contexto a fim de representar situações globais do sistema ou exteriores a ele nas regras de segurança, como condições do tipo "se for quarta-feira" ou "se estver chovendo". O paradigma de comunicação com o WfS poderia ser aumentado para receber mensagens de atualização de contexto da mesma maneira com que recebe requisições de usuários. O comportamento estocástico da rede de Petri se encarregaria de garantir que tais atualizações de contexto pudessem ocorrer em qualquer instante, emulando a chegada de requisições em qualquer estado possível com respeito a esse contexto.

Mais uma extensão desejável ao metamodelo é um aperfeiçoamento da dinâmica no controle de acesso e na representação de RBAC. A inclusão de um mecanismo para que usuários possam alterar os níveis de permissão de outros facilitaria a exploração de toda uma gama de problemas em RBAC que, na estrutura atual, só podem ser representados pelo compartilhamento de parâmetros de contas, de maneira trabalhosa à modelagem e de complexa expressão matemática.

Como sugestão final, seria de grande valia à aplicabilidade do processo 
como um todo a tradução das redes de Petri de modelos de segurança em código para implantação em um sistema real. Um caminho plausível para essa conversão seria a geração de uma biblioteca de software para consulta sobre as decisões de autorização de um sistema tal qual um oráculo, configurada apenas em função dos elementos reais que equivalem às entidades definidas pelo metamodelo. 0 uso de código gerado automaticamente a partir do modelo sobre o qual comprovou-se as propriedades de interesse a respeito da política minimiza a chance de inclusão de defeitos no processo de tradução, fornecendo melhores garantias de segurança além de um ganho de produtividade pela simplicidade na implementação final do sistema. 


\section{REFERÊNCIAS}

AALST, W. van der. Three good reasons for using a petri-net-based workflow management system. Information and Process Integration in Enterprises, Springer, p. 161-182, 1998.

AALST, W. van der; HEE, K. M. V. Workflow management: models, methods, and systems. [S.I.]: The MIT press, 2004.

ADAM, N.; ATLURI, V.; HUANG, W.-K. Modeling and analysis of workflows using petri nets. Journal of Intelligent Information Systems, Springer, v. 10, n. 2, p. 131-158, 1998.

ATLURI, V.; HUANG, W.-K. An authorization model for workflows. In: BERTINO, E. et al. (Ed.). Computer Security - ESORICS 96. [S.I.]: Springer Berlin / Heidelberg, 1996, (Lecture Notes in Computer Science, v. 1146). p. 44-64.

. An extended petri net model for supporting workflows in a multilevel secure environment. In: Proc. of the IFIP Working Conference on Database Security. [S.I.: s.n.], 1996. p. 199-216.

. A petri net based safety analysis of workflow authorization models. Journal of Computer Security, IOS P ress, v. 8, n. 2/3, p. 209-240, 2000.

BAIER, C.; KATOEN, J .-P. Principles of model checking. [S.I.]: MIT press Cambridge, 2008.

BASIN, D. et al. Automated analysis of security-design models. Information and Software Technology, Elsevier, v. 51, n. 5, p. 815-831, 2009.

BASIN, D.; DOSER, J.; LODDERSTEDT, T. Model driven security for process-oriented systems. In: ACM. Proceedings of the eighth ACM symposium on Access control models and technologies. [S.I.], 2003. p. 100- 109.

BELL, D.; LAPADULA, L. Secure computer systems: Mathematical foundations. [S.I.], 1973.

BIBA, K. Integrity considerations for secure computer systems. [S.I.], 1977.

BISHOP, M. Computer Security: Art and Science. [S.I.]: Addison-Wesley, 2003.

CHEN, P. The entity-relationship model - toward a unified view of data. ACM Transactions on Database Systems (TODS), ACM, v. 1, n. 1, p. 9-36, 1976. 
COURTS, H. R. et al. System and method for maintaining a state for a user session using a web system having a global session server. 2000. Patente US 6076108.

DIERKS, T.; ALLEN, C. RFC 2246: The TLS Protocol Version 1. 1999. Status: PROPOSED STANDARD.

GARFINKEL, S.; SPAFFORD, G.; SCHWARTZ, A. Practical UNIX \& Internet Security. [S.I.]: O'Reilly Media, Inc., 2003.

GROOTE, J .; KOUTERS, T.; OSAIWERAN, A. Specification guidelines to avoid the state space explosion problem. Fundamentals of Software Engineering, Springer, p. 112-127, 2012.

HUANG, H.; KIRCHNER, H. Formal specification and verification of modular security policy based on colored petri nets. Dependable and Secure Computing, IEEE Transactions on, IEEE, v. 8, n. 6, p. 852-865, 2011.

JENSEN, K. Theoretical aspects of coloured petri nets. A Decade of Concurrency, Lecture Notes in Computer Science, Springer-Verlag, v. 803, p. 230-272, 1994.

J ENSEN, K.; CHRISTENSEN, S.; KRISTENSEN, L. Cpn tools state space manual. Department of Computer Science, Univerisity of Aarhus, 2006.

J ENSEN, K.; KRISTENSEN, L. Coloured Petri Nets: Modelling and Validation of Concurrent Systems. [S.I.]: Springer-Verlag Berlin Heidelberg, 2009.

J IANG, Y. et al. Security analysis of mandatory access control model. In: IEEE. Systems, Man and Cybernetics, 2004 IEEE International Conference on. [S.I.], 2004. v. 6, p. 5013-5018.

KNORR, K. Dynamic access control through petri net workflows. In: Proceedings of the 16th Annual Computer Security Applications Conference. Washington, DC, USA: IEEE Computer Society, 2000. (ACSAC '00), p. 159-.

KNORR, K. et al. Multilevel security and information flow in petri net workflows. In: CITESEER. Proceedings of the 11th Conference on Advanced Information Systems Engineering. [S.I.], 2001.

MEALY, G. A method for synthesizing sequential circuits. Bell System Technical Journal, v. 34, n. 5, p. 1045-1079, 1955.

MELL, P.; GRANCE, T. The NIST Definition of Cloud Computing. National Institute of Standards and Technology, 2011.

MENEZES, A.; OORSCHOT, P. V.; VANSTONE, S. Handbook of applied cryptography. [S.I.]: CRC, 1997.

MILNER, R. The definition of standard ML: revised. [S.I.]: The MIT press, 1997. 
MURATA, T. Proceedings of the IEEE, IEEE, v. 77, n. 4, p. 541-580, 1989.

ORTEGA, F.; RUGGIERO, W. Security policies for WFMS with rich business logic - a model suitable for analysis. International Journal of Computer Science and Information Security, v. 11, n. 4, p. 1-9, A pril 2013.

PETRI, C. Kommunikation mit Automaten. Tese (Doutorado) - Institut für instrumentelle Mathematik, Bonn, 1962.

RAKKAY, H.; BOUCHENEB, H. Security analysis of role based access control models using colored petri nets and cpntools. In: GAVRILOVA, M.; TAN, C.; MORENO, E. (Ed.). Transactions on Computational Science IV. [S.I.]: Springer Berlin / Heidelberg, 2009, (Lecture Notes in Computer Science, v. 5430). p. 149- 176.

RATZER, A. et al. Cpn tools for editing, simulating, and analysing coloured petri nets. In: AALST, W. van der; BEST, E. (Ed.). Proceedings of the 24th International Conference on the Application and Theory of Petri Nets. [S.I.: s.n.], 2003. v. 2790.

RIBEIRO, C. et al. Security policy consistency. In: IMPERIAL COLLEGE, LONDON, UK. CL2000 - First Workshop on Rule-Based Constraint Reasoning and Programming. [S.I.], 2000.

RUMBAUGH, J .; J ACOBSON, I.; BOOCH, G. Unified Modeling Language Reference Manual, The. [S.I.]: Pearson Higher Education, 2004.

SANDHU, R. et al. Role-based access control models. Computer, IEEE, v. 29, n. 2, p. 38-47, 1996.

SANDHU, R.; SAMARATI, P. Authentication, access control, and audit. ACM Computing Surveys (CSUR), ACM, v. 28, n. 1, p. 241-243, 1996.

SHANNON, C. E. Programming a computer for playing chess. Philosophical Magazine, v. 41, n. 314, p. 256-275, 1950.

UEDA, E. T. Análise de Políticas de Controle de Acesso Baseado em Papeis com Rede de Petri Colorida. Tese (Doutorado) - Escola Politécnica da Universidade de São Paulo, 2012.

ULLMAN, J . D. Elements of ML programming. [S.I.: S.n.], 1998.

WORKFLOW MANAGE MENT COALITION. Workflow Management Coalition Terminology \& Glossary. 1999. Documento No. WF MC-TC-1011.

$X U, D$. et al. A model- based approach to automated testing of access control policies. In: ACM. Proceedings of the 17th ACM symposium on Access Control Models and Technologies. [S.I.], 2012. p. 209-218.

ZHANG, Z.; HONG, F.; LIAO, J. Modeling chinese wall policy using colored petri nets. In: IEEE. Computer and Information Technology, 2006. CIT'06. The Sixth IEEE International Conference on. [S.I.], 2006. p. 162-162. 
ZHANG, Z.; HONG , F.; XIAO, H. Verification of strict integrity policy via petri nets. In: IEEE. Systems and Networks Communications, 2006. ICSNC'06. International Conference on. [S.I.], 2006. p. 23-23.

ZIMMERMANN, H. Osi reference model-the iso model of architecture for open systems interconnection. Communications, IEEE Transactions on, IEEE, v. 28, n. 4 , p. $425-432,1980$. 


\section{APÊNDICE A - CÓDIGO-FONTE DA MODELAGEM DO EXEMPLO}

\section{A.1 Funções de autorização $\left(f_{A}\right)$}

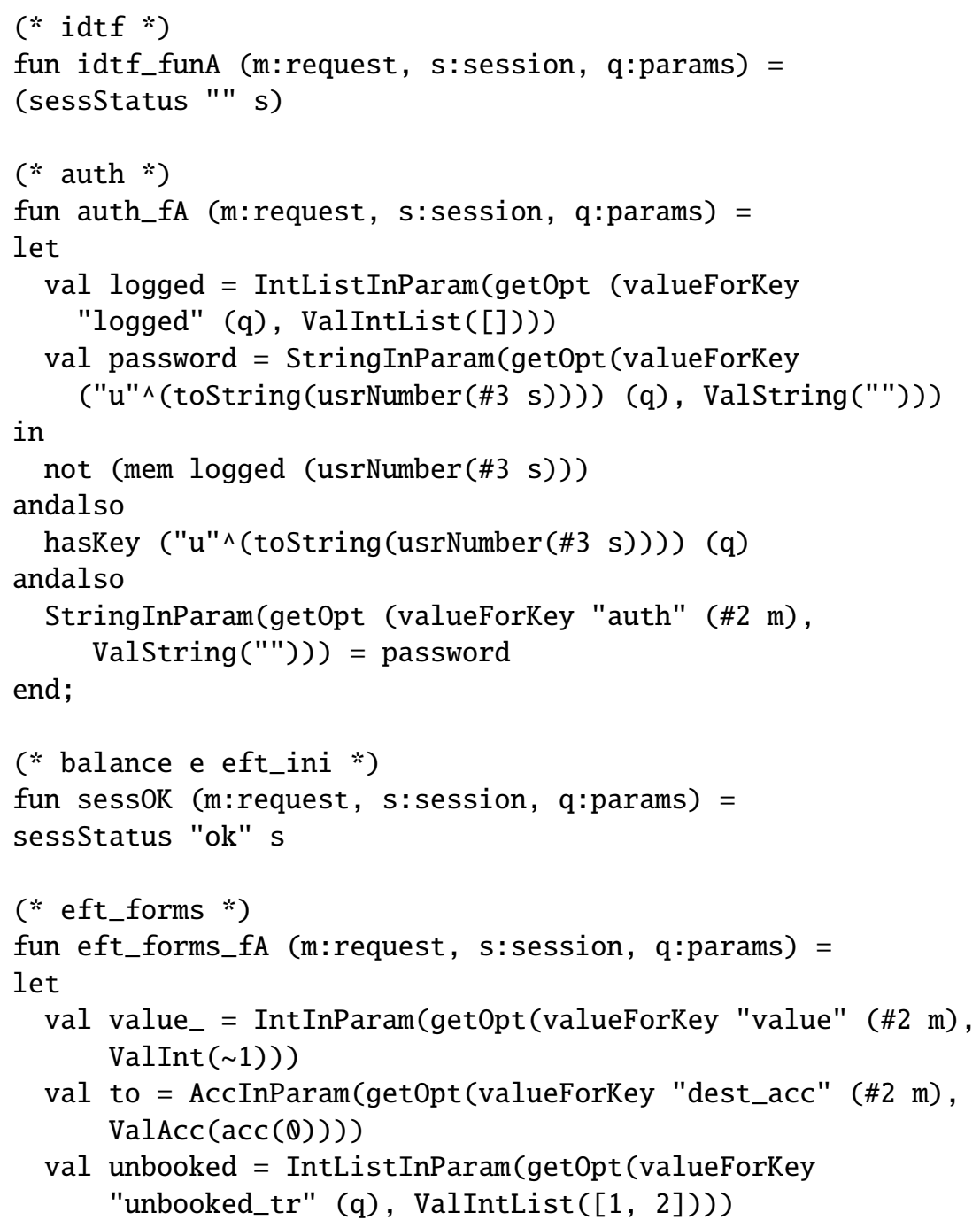




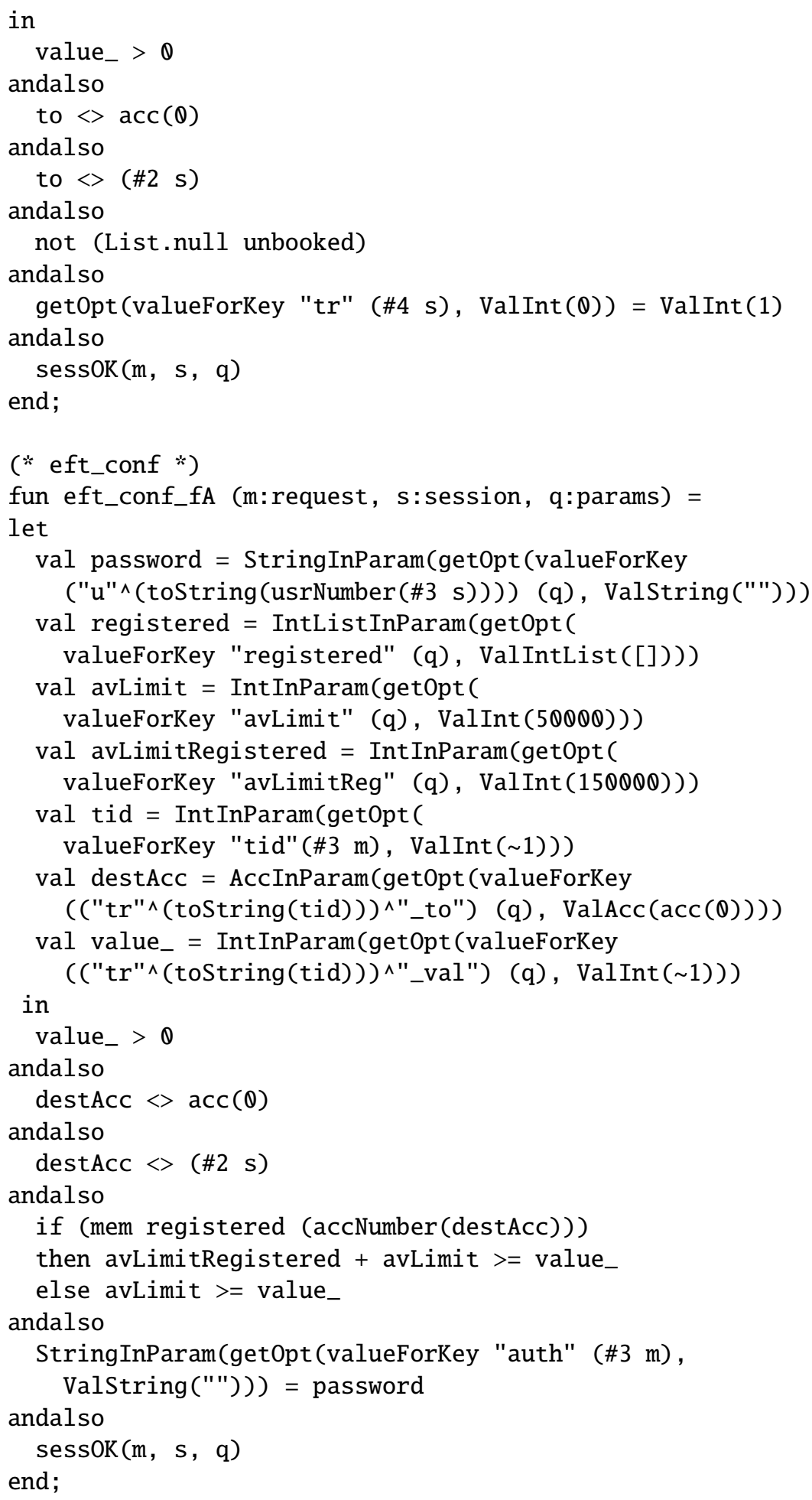

\section{A.2 Funções de atualização de contas $\left(f_{B}\right)$}

(* idtf*)

fun idtf_funB (m:request, s:session, pL:op_params_list) = 


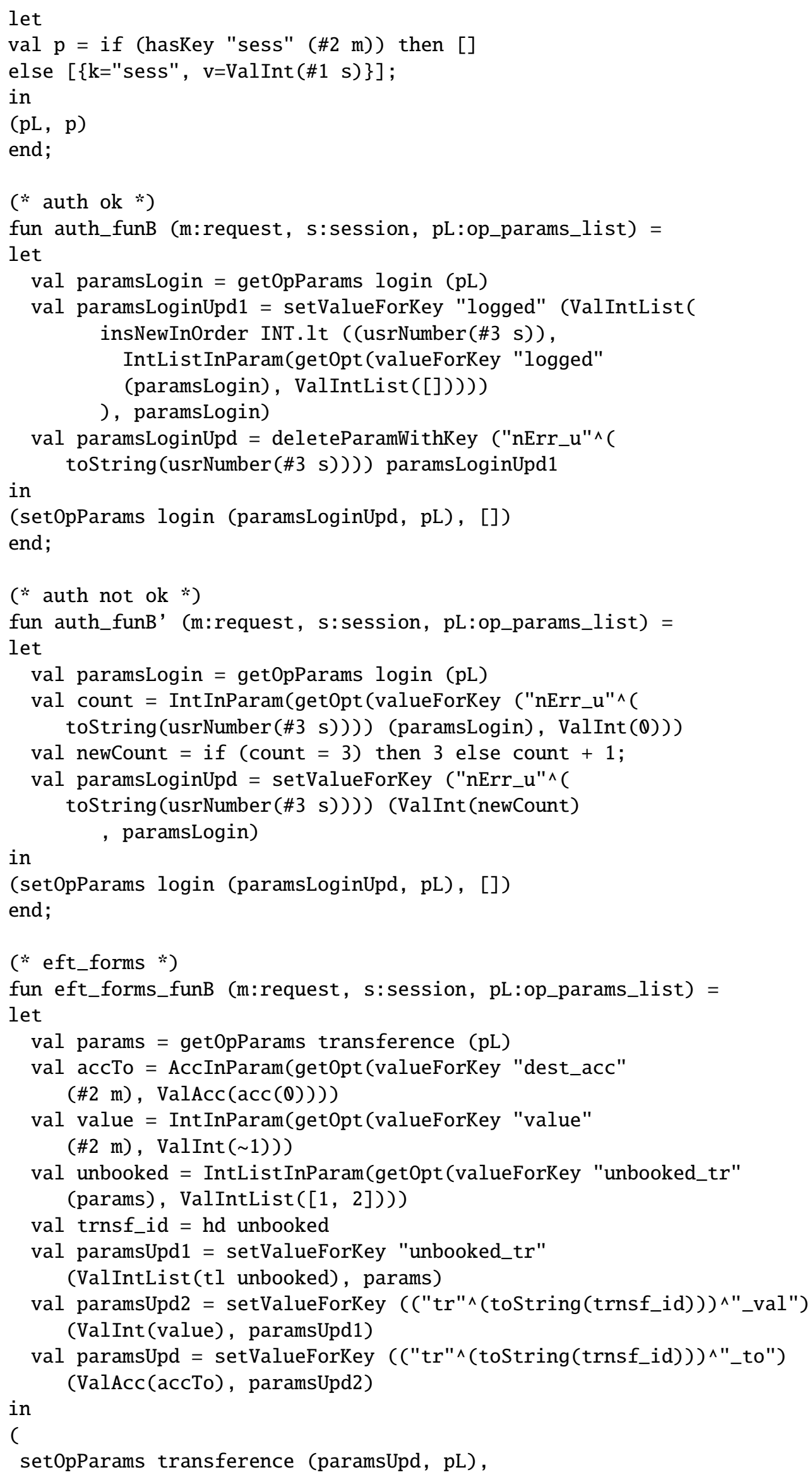




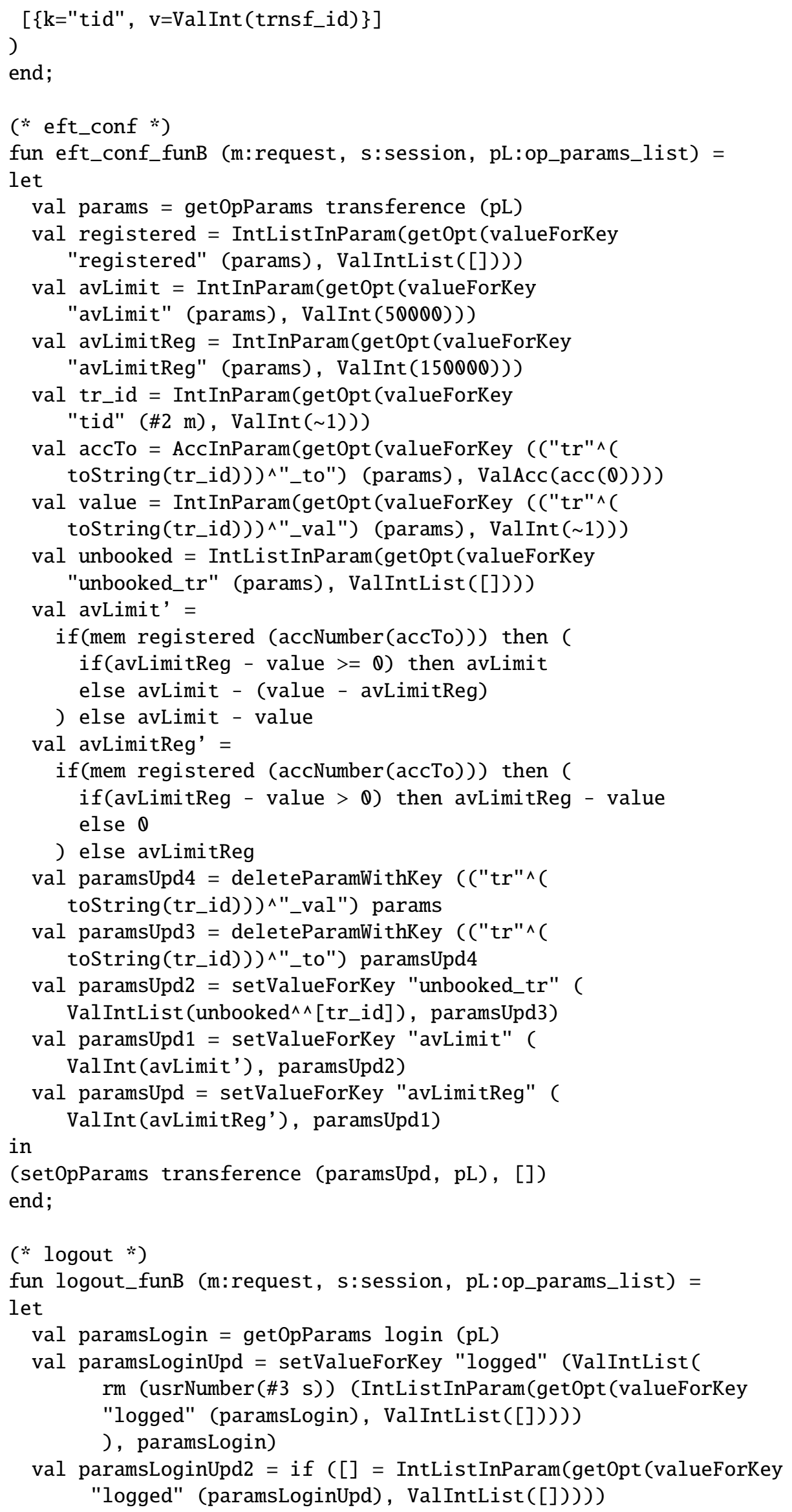




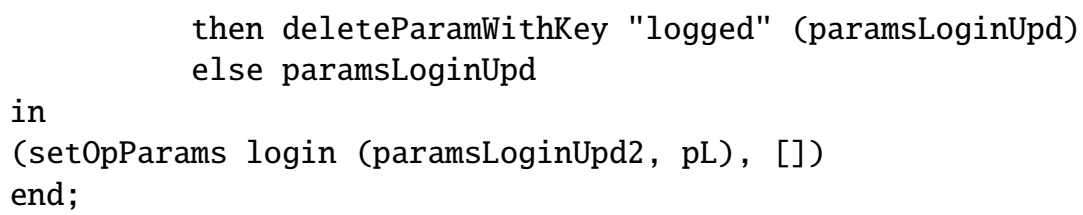

\section{A.3 Funções de atualização de usuários $\left(f_{C}\right)$}

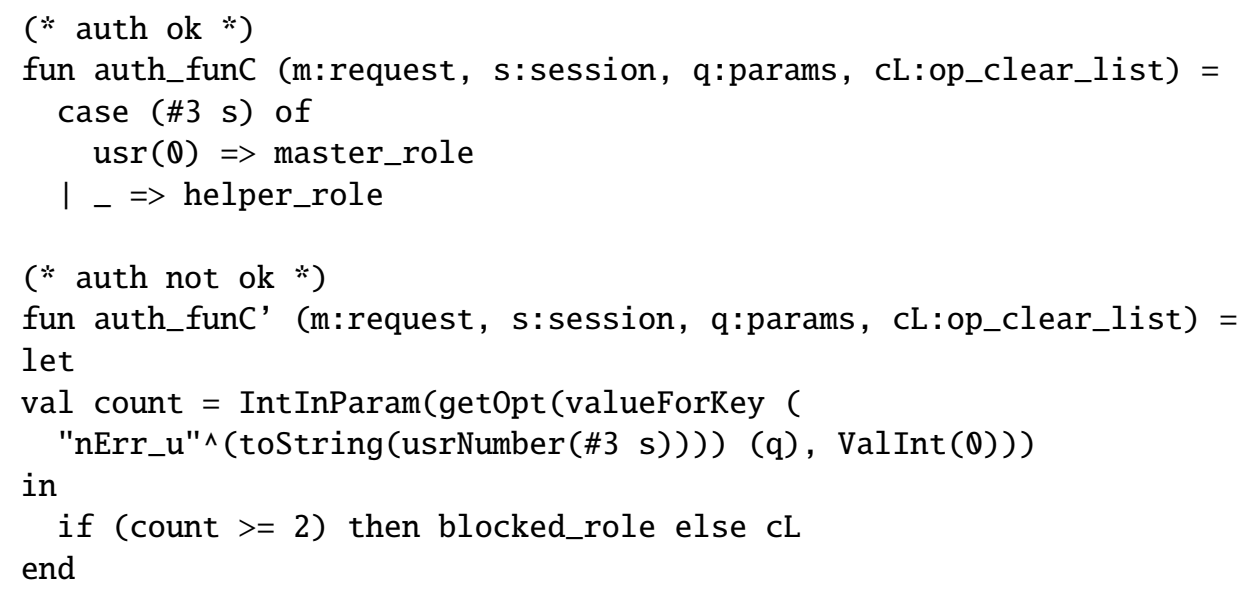

\section{A.4 Funções de atualização de sessões $\left(f_{D}\right)$}

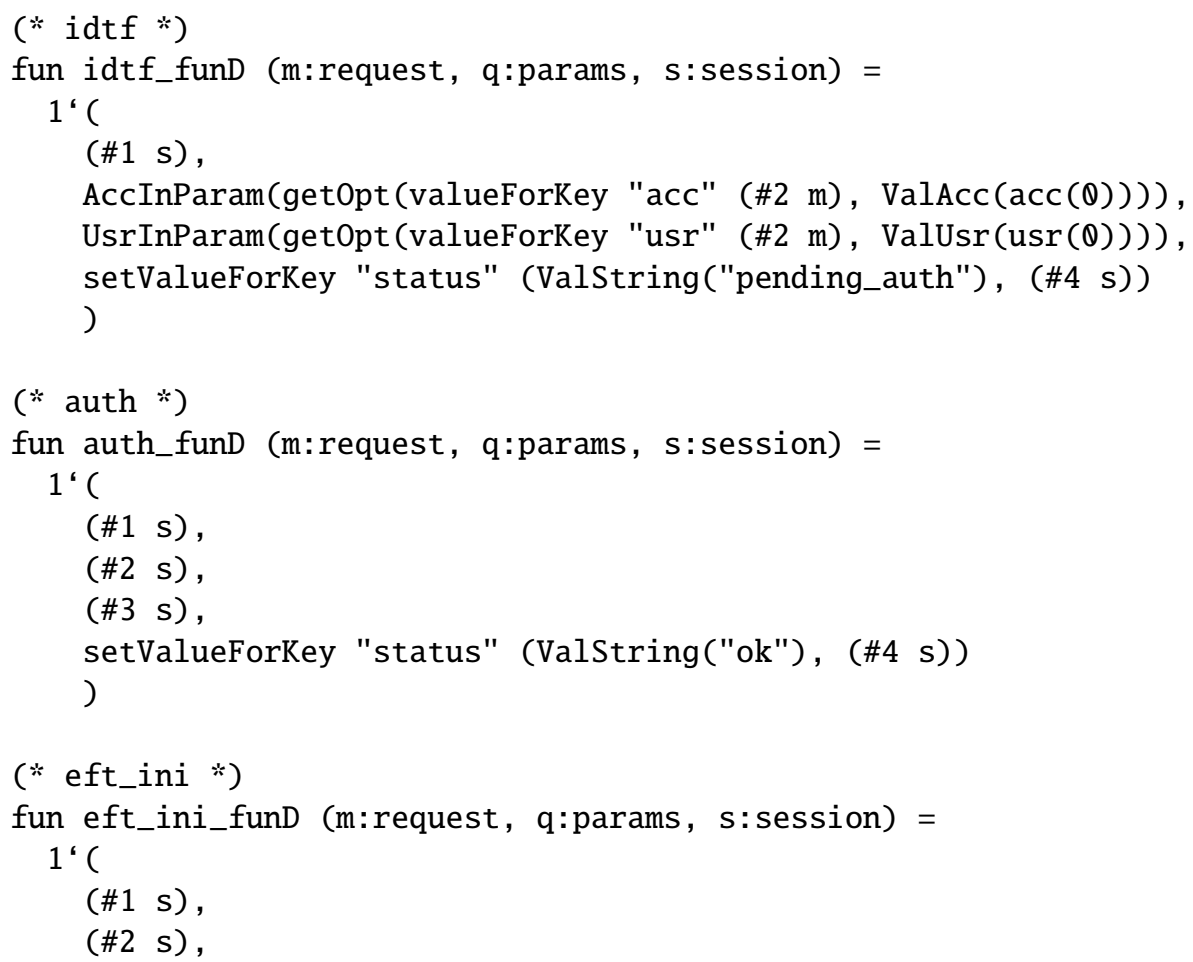




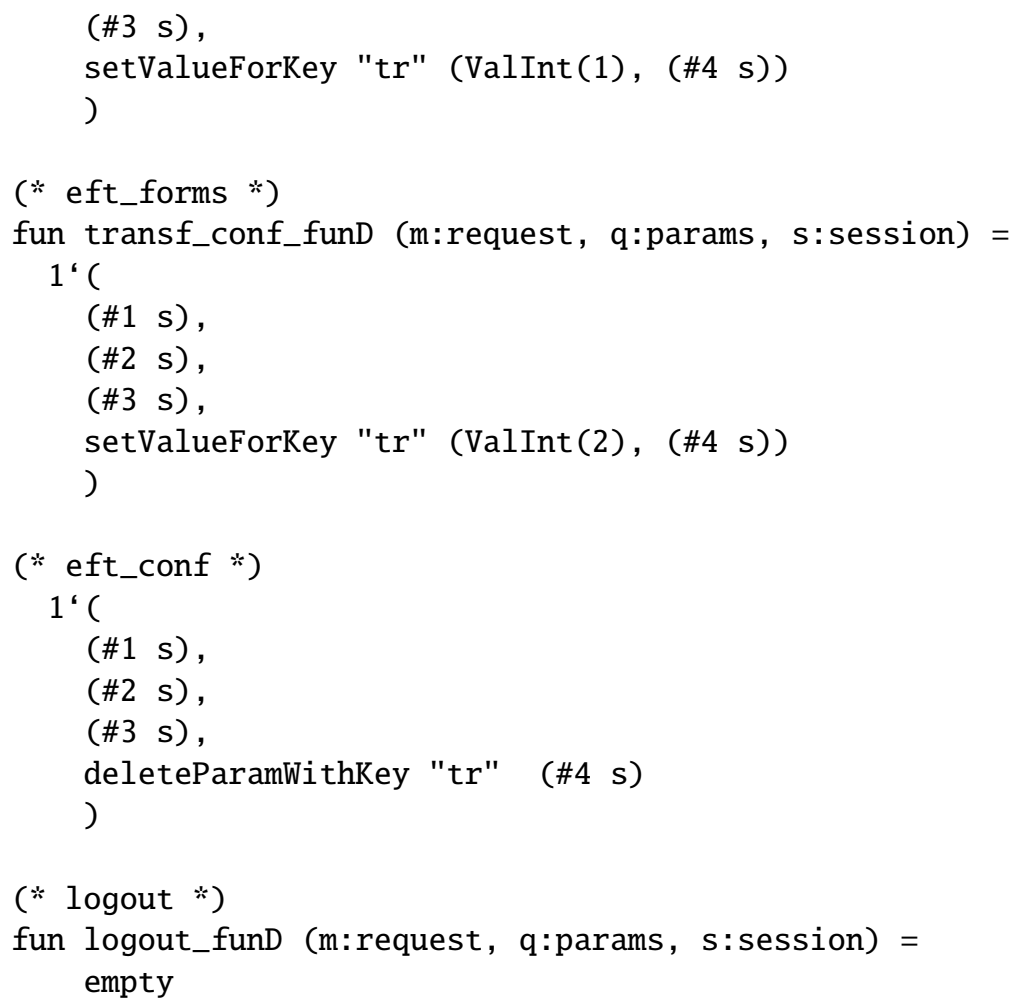

\section{A.5 Definições de estados iniciais}

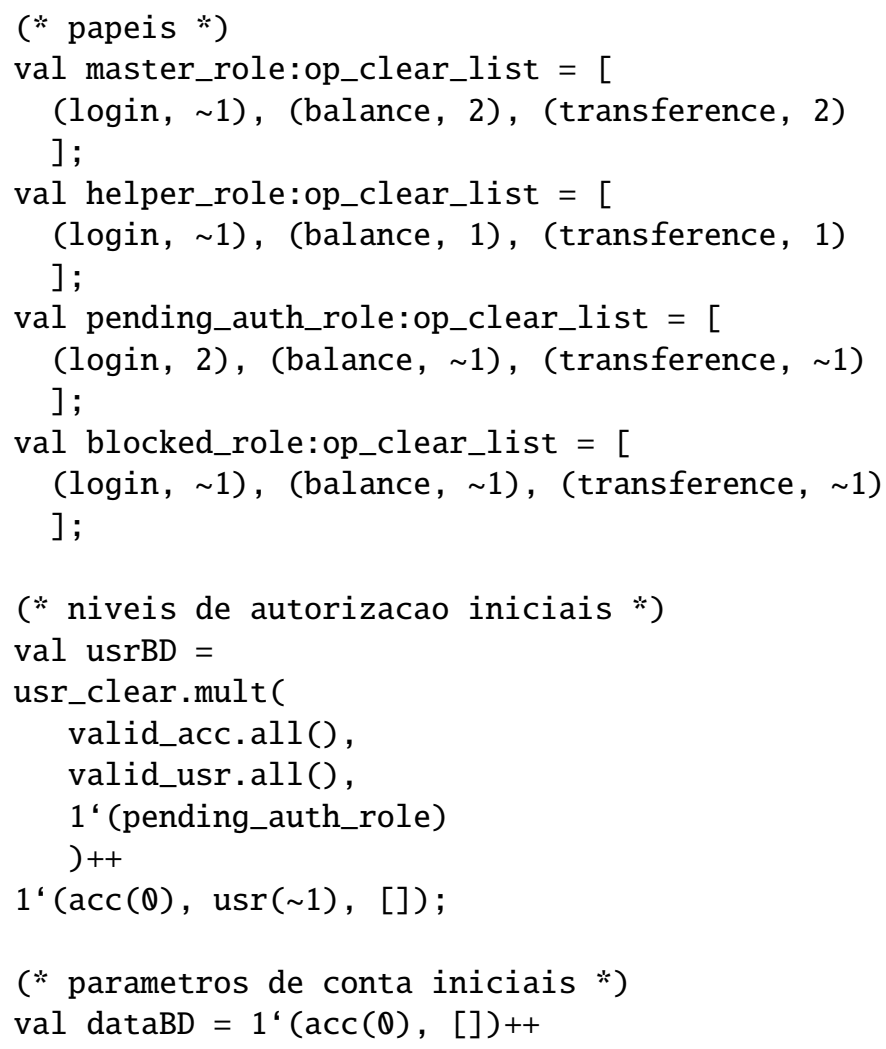




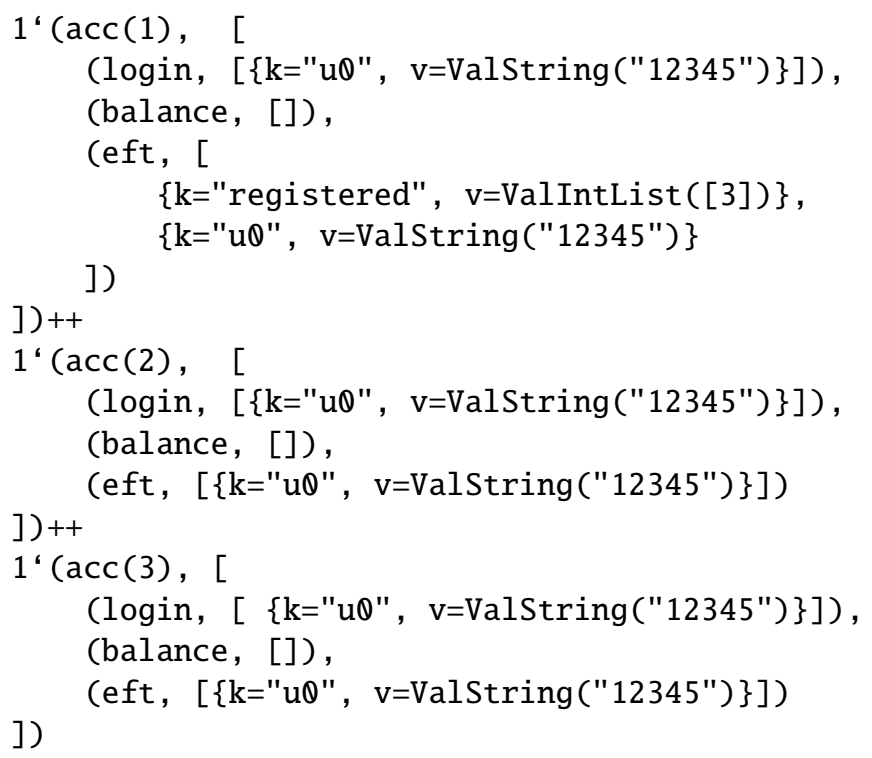




\section{APÊNDICE B - DETALHAMENTO DOS CASOS DE ANÁLISE DO EXEMPLO}

Os códigos a seguir representam os multiconjuntos de requisições utilizados para os casos de análise do exemplo, na ordem com que foram apresentados na tabela 4:

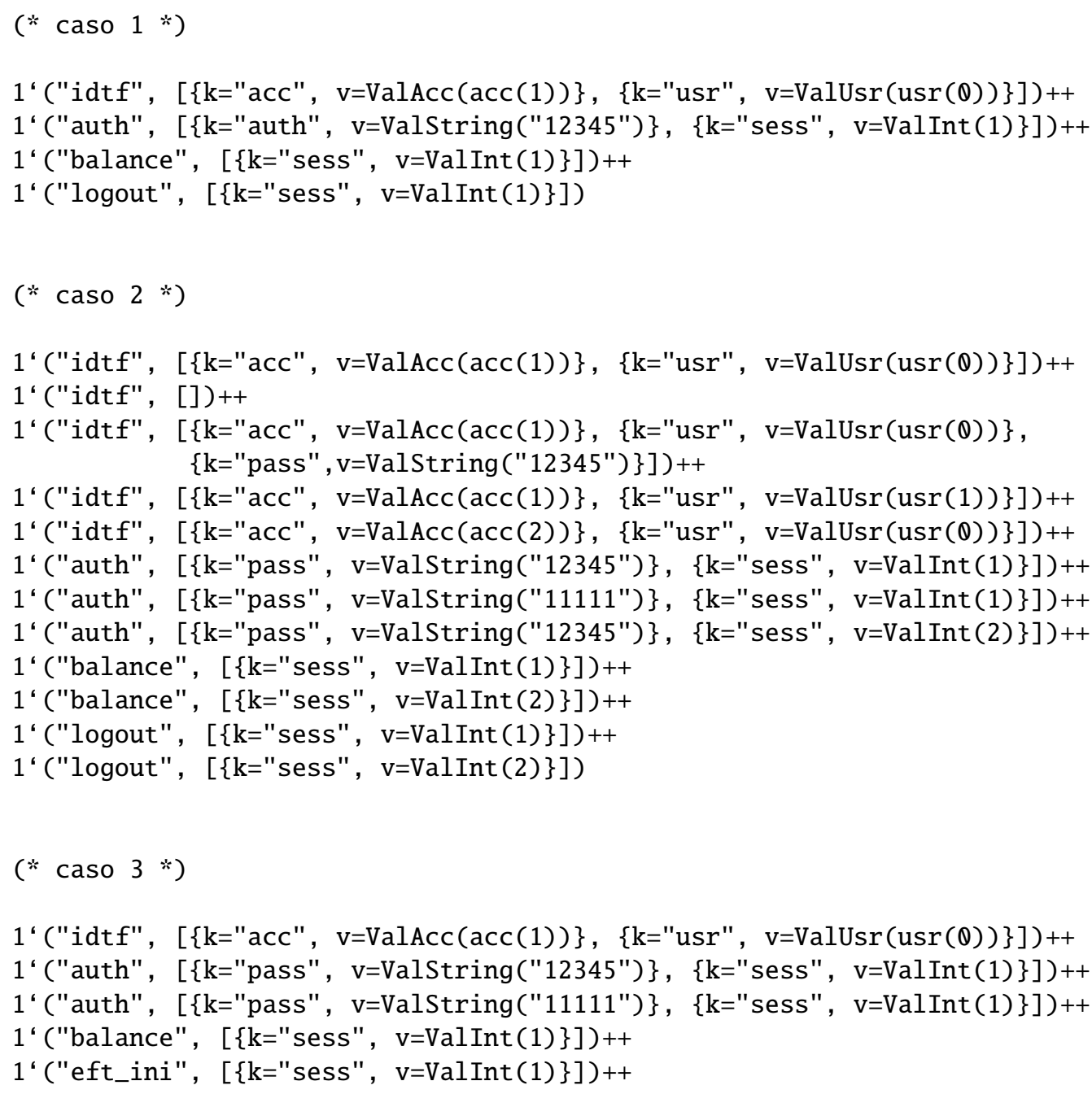




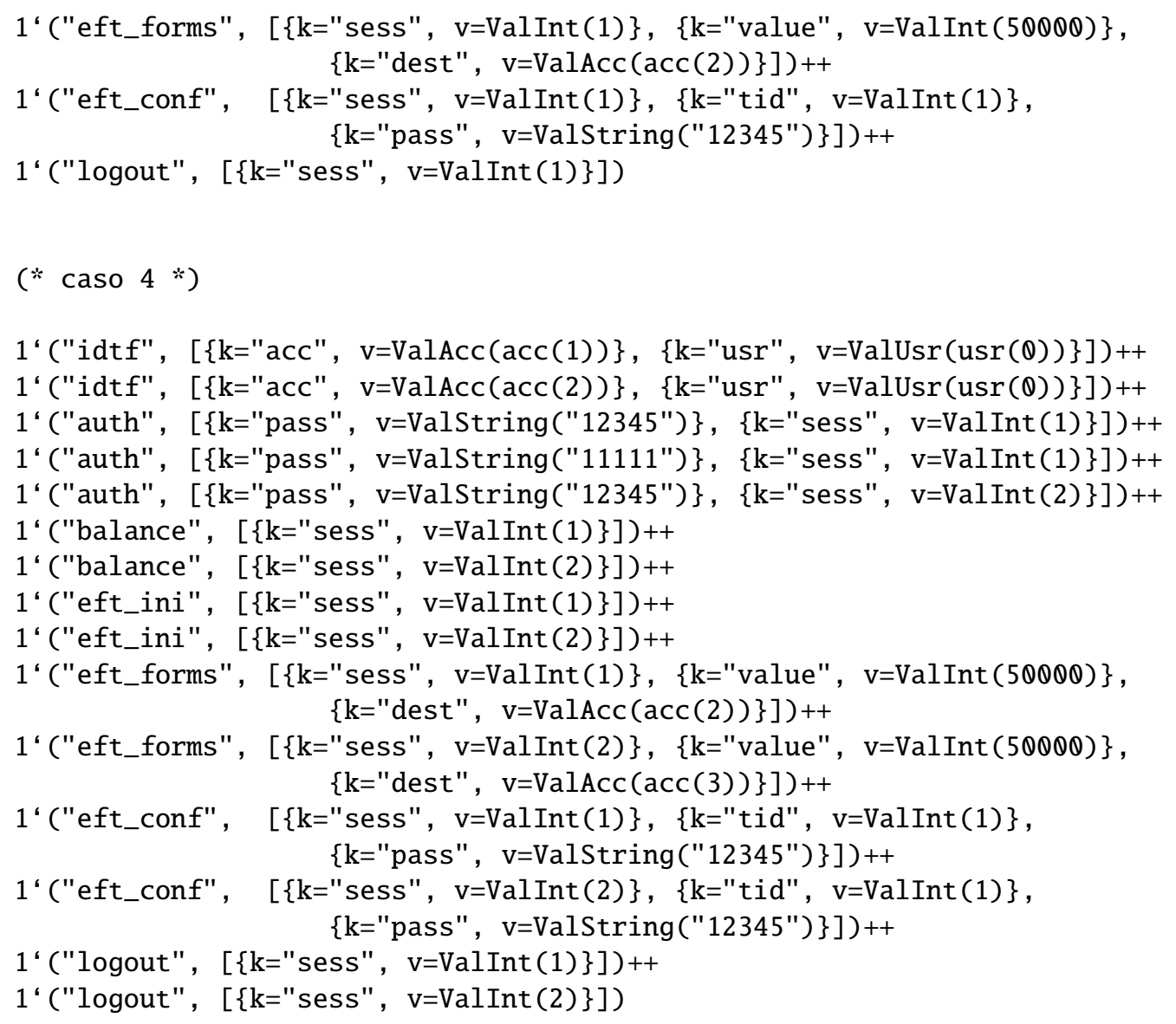

$(* \operatorname{caso} 5 *)$

1'("idtf", [\{k="acc", v=ValAcc(acc(1)) $\},\{\mathrm{k}=" \mathrm{usr} ", \mathrm{v}=\operatorname{ValUsr}(\mathrm{usr}(1))\}])++$ 1 '("auth", [\{k="pass", v=ValString("12345") $\},\{\mathrm{k}=$ "sess", v=Valint(1) $\}])++$ 1 '("auth", [\{k="pass", v=ValString("11111") $\},\{\mathrm{k}="$ sess", v=Valint(1) $\}])++$ 1 '("balance", [\{k="sess", v=Valint(1) $\}])++$ 1 '("eft_ini", [\{k="sess", v=Valint(1) $\}])++$

1 '("eft_forms", [\{k="sess", v=ValInt (1) $\},\{\mathrm{k}=$ "value", v=ValInt $(50000)\}$, $\{\mathrm{k}=$ "dest", $\mathrm{v}=\operatorname{ValAcc}(\operatorname{acc}(2))\}])++$

1 '("eft_conf", $\quad[\{\mathrm{k}=$ "sess", v=ValInt(1) $\},\{\mathrm{k}=$ "tid", $\mathrm{v}=\operatorname{Val} \operatorname{Int}(1)\}$, $\{\mathrm{k}=$ "pass", v=ValString("12345") $\}])++$

1 '("logout", [\{k="sess", v=ValInt (1) $\}]$ )

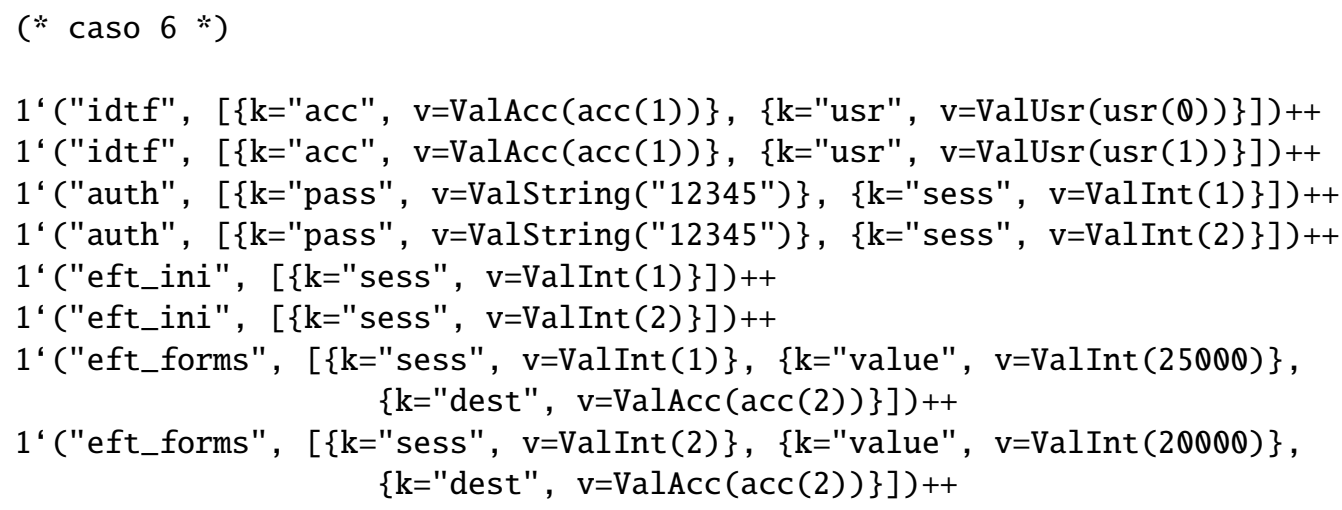


1'("eft_conf", [\{k="sess", v=ValInt (1) \}, $\{\mathrm{k}=" \mathrm{tid} ", \mathrm{v}=\operatorname{Val} \operatorname{Int}(1)\}$, $\{\mathrm{k}=$ "pass", v=ValString ("12345") $\}])++$

1'("eft_conf", [\{k="sess", v=ValInt(1) \}, \{k="tid", v=ValInt(1)\}, $\{\mathrm{k}=$ "pass", $\mathrm{v}=$ ValString ("11111") $\}])++$

1 ("eft_conf", [\{k="sess", v=ValInt(1),$\{k \mathrm{k}=" \mathrm{tid} ", \mathrm{v}=\operatorname{Val} \operatorname{Int}(2)\}$, $\{\mathrm{k}=$ "pass", $\mathrm{v}=$ ValString $(" 12345 ")\}])++$

1'("eft_conf", [\{k="sess", v=ValInt(1) \}, \{k="tid", v=ValInt(2) \}, $\{\mathrm{k}=$ "pass", $\mathrm{v}=$ ValString ("11111") $\}])++$

1'("eft_conf", [\{k="sess", v=ValInt(2)\}, $\{\mathrm{k}=" \mathrm{tid}$ ", v=Valint(1)\}, $\{\mathrm{k}=$ "pass", $\mathrm{v}=$ ValString("12345") $\}])++$

1' ("eft_conf", [\{k="sess", v=ValInt(2)\}, $\{\mathrm{k}=" \mathrm{tid}$ ", v=ValInt(1) $\}$, $\{\mathrm{k}=$ "pass", $\mathrm{v}=$ ValString ("11111") $\}])++$

1'("eft_conf", [\{k="sess", v=ValInt(2)\}, \{k="tid", v=ValInt(2) \}, $\{\mathrm{k}=$ "pass", $\mathrm{v}=$ ValString ("12345") $\}])++$

1'("eft_conf", [\{k="sess", v=ValInt(2)\}, \{k="tid", v=ValInt(2)\}, $\{\mathrm{k}=$ "pass", $\mathrm{v}=$ ValString ("11111") $\}])++$

1 ' ("logout", $[\{\mathrm{k}="$ "sess", $\mathrm{v}=\operatorname{Val} \operatorname{Int}(1)\}])++$

1 '("logout", [\{k="sess", v=ValInt (2) $\}]$ )

$(* \operatorname{caso} 7 *)$

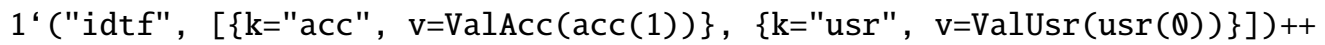
1 '("auth", [\{k="pass", v=ValString ("12345") \}, \{k="sess", v=ValInt(1) $\}])++$ 1 '("eft_ini", [\{k="sess", v=Valint(1) $\}]$ )++

1'("eft_forms", [\{k="sess", v=ValInt (1) \}, \{k="value", v=ValInt (20000)\}, $\{\mathrm{k}="$ dest", $\mathrm{v}=\operatorname{ValAcc}(\operatorname{acc}(2))\}])++$

1'("eft_forms", [\{k="sess", v=ValInt (1) $\},\{\mathrm{k}=$ "value", v=Valint (25000) $\}$, $\{\mathrm{k}=$ "dest", $\mathrm{v}=\operatorname{ValAcc}(\operatorname{acc}(2))\}])++$

1'("eft_forms", [\{k="sess", v=ValInt(1) \}, \{k="value", v=ValInt (50000)\}, $\{\mathrm{k}="$ dest", $\mathrm{v}=\operatorname{ValAcc}(\operatorname{acc}(2))\}])++$

1'("eft_forms", [\{k="sess", v=ValInt(1)\}, \{k="value", v=ValInt $(60000)\}$, $\{\mathrm{k}=$ "dest", $\mathrm{v}=\operatorname{ValAcc}(\operatorname{acc}(2))\}])++$

1'("eft_conf", [\{k="sess", v=ValInt(1)\}, \{k="tid", v=ValInt(1) \}, $\{\mathrm{k}=$ "pass", $\mathrm{v}=$ ValString $(" 12345 ")\}])++$

1'("eft_conf", [\{k="sess", v=ValInt(1)\}, \{k="tid", v=Valint(2)\}, $\{\mathrm{k}=$ "pass", $\mathrm{v}=$ ValString ("12345") $\}])++$

1 '("logout", [\{k="sess", v=ValInt(1) $\}]$ )

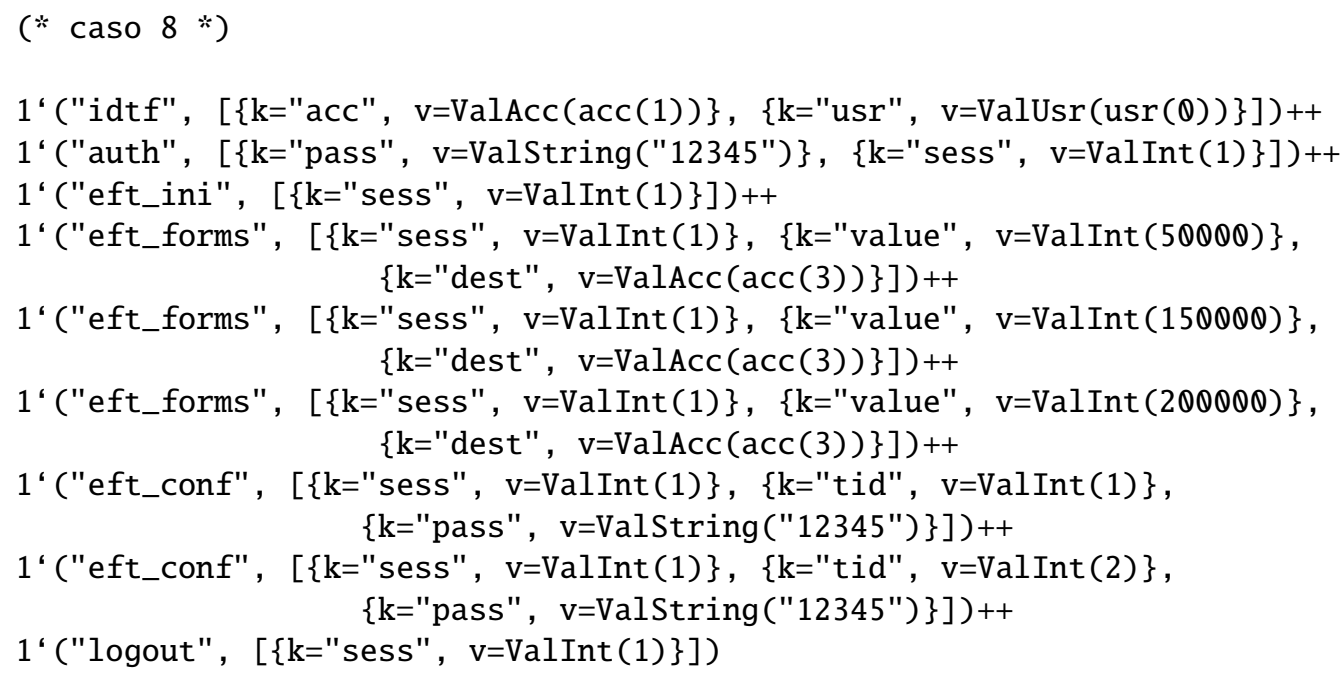




\section{APÊNDICE C - EVIDÊNCIAS DA COLETA DE DADOS PARA OS CASOS DE ANÁLISE}

As figuras a seguir mostram a avaliação no ambiente CPN Tools das consultas que fornecem os dados apresentados na tabela 4 (pág. 90). 0 círculo numerado próximo ao lugar "possible requests" indica a quantidade de marcas presentes no mesmo, que equivale ao número de tipos de requisições possíveis no caso avaliado. O balão ligado à função NoOfNodes() apresenta o número de nós (estados) calculado. 0 balão da função NoOfSecs () fornece o tempo, em segundos, gasto para o cálculo do espaço de estados e o balão restante, da função EntireGraphCalculated() indica se o espaço de estados foi totalmente calculado apresentando o valor "true" em caso positivo e "false" em caso negativo.

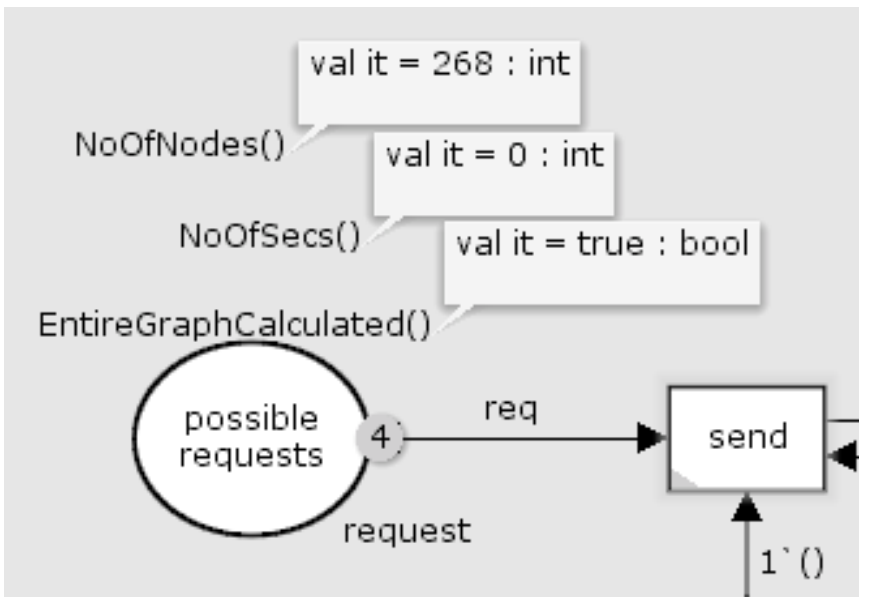

Figura 14: Dados caso 1 


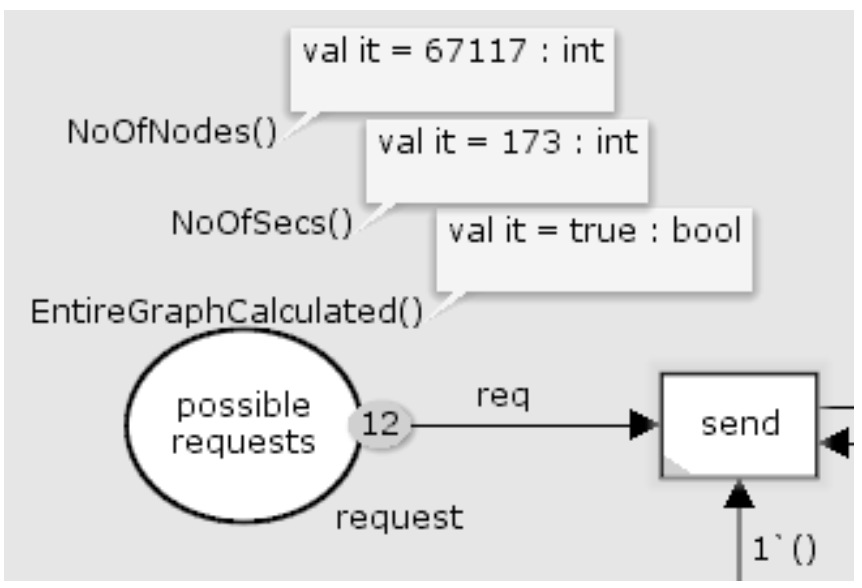

Figura 15: Dados caso 2

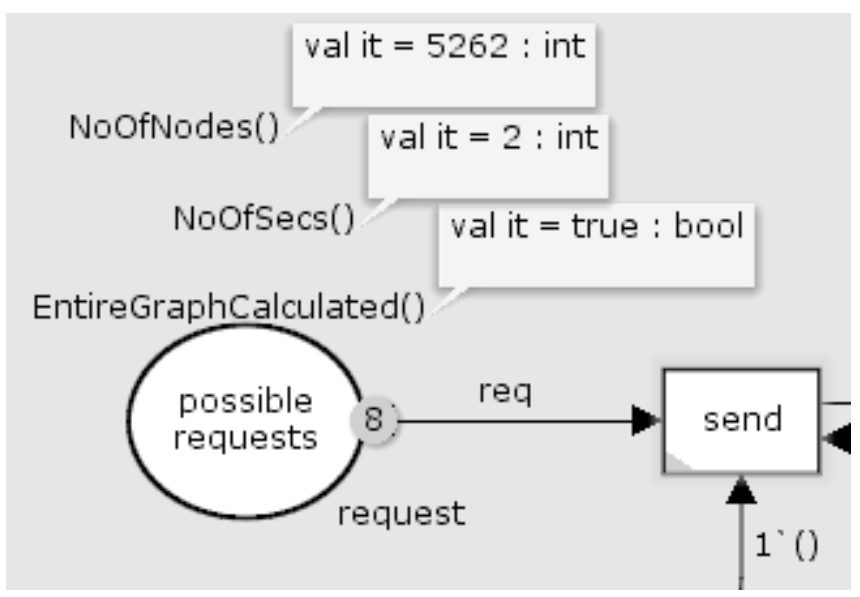

Figura 16: Dados caso 3

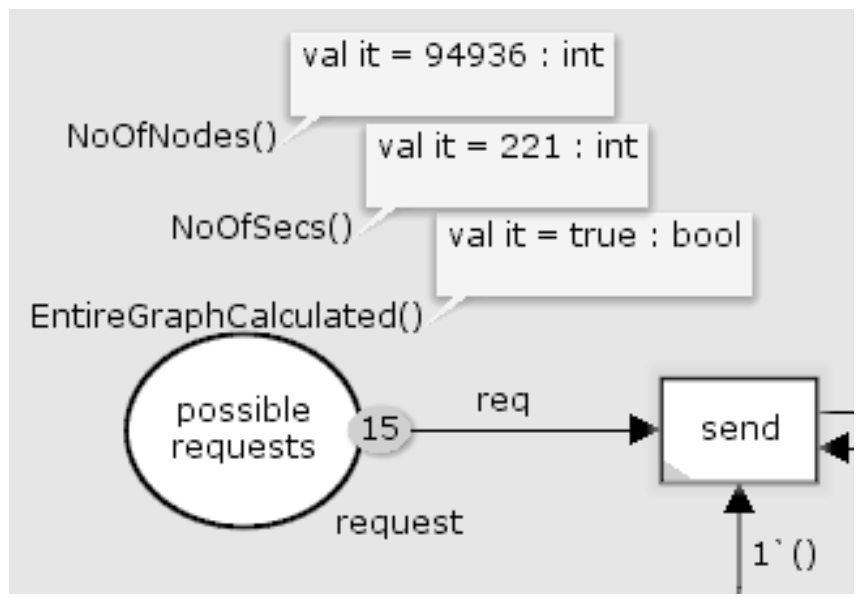

Figura 17: Dados caso 4 


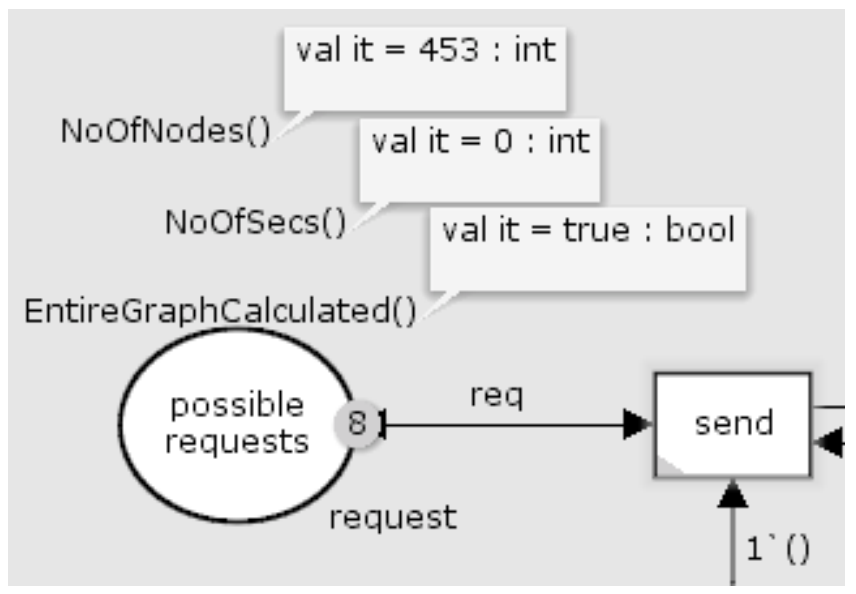

Figura 18: Dados caso 5

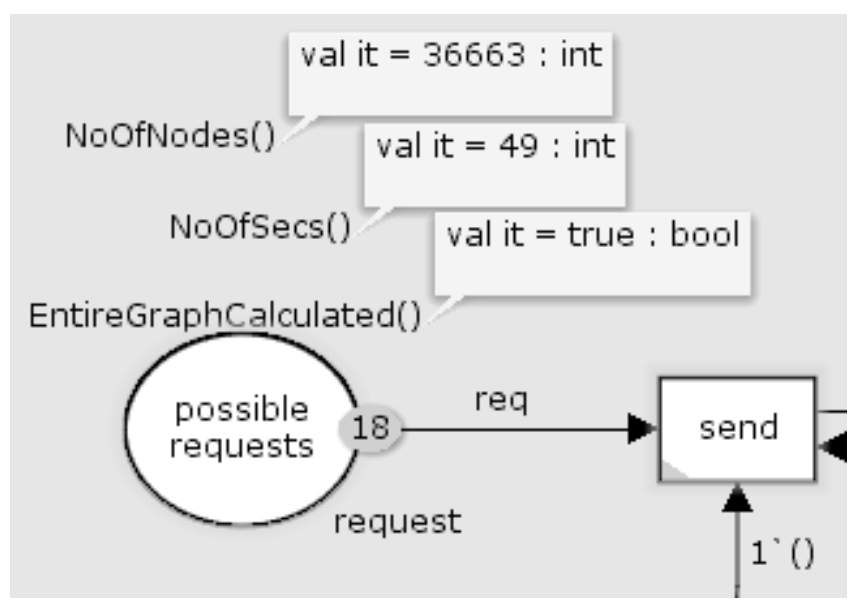

Figura 19: Dados caso 6

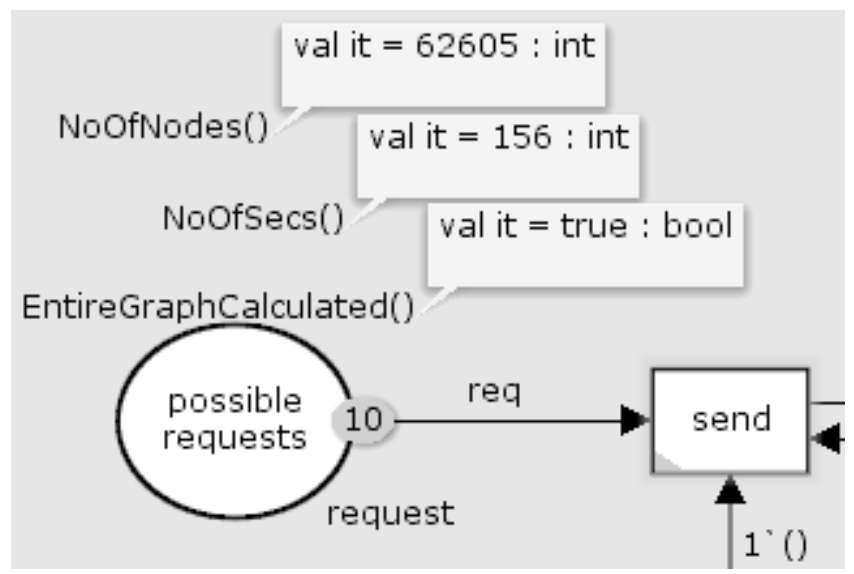

Figura 20: Dados caso 7 


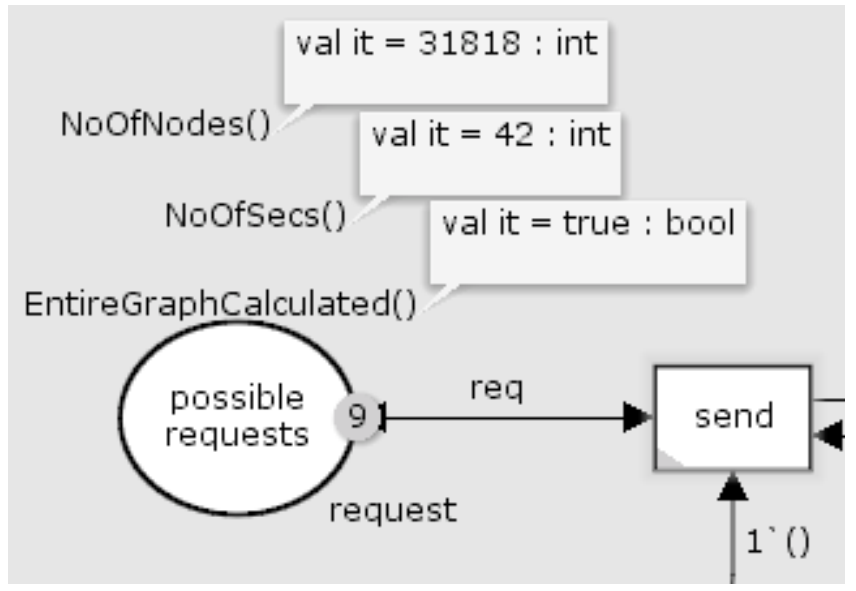

Figura 21: Dados caso 8

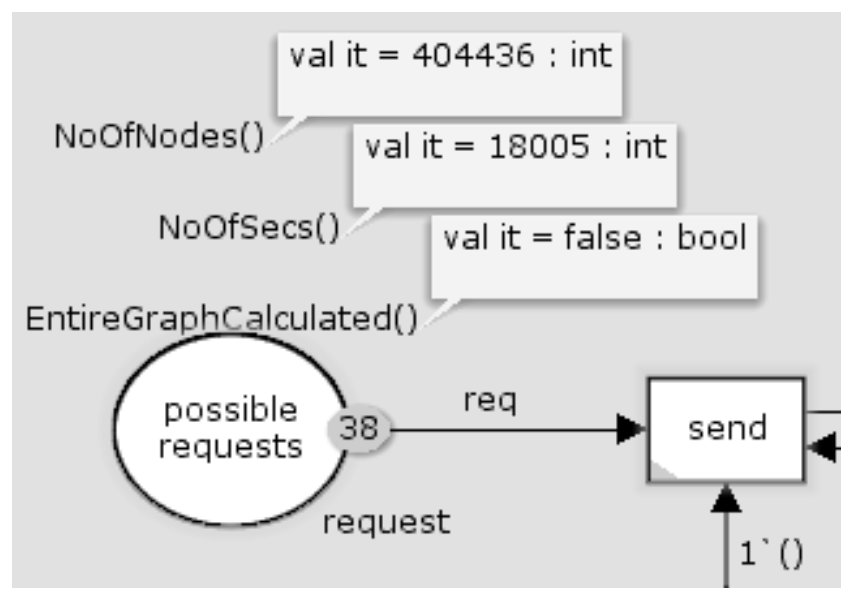

Figura 22: Dados da união de todos os casos 